Aus der Abteilung Humangenetik

(Prof. Dr. med. Dr. h.c. W. Engel)

im Zentrum Hygiene und Humangenetik

der Medizinischen Fakultät der Universität Göttingen

\title{
Zur Funktion des
}

Brunol4-Gens

\section{Inaugural-Dissertation}

zur Erlangung des Doktorgrades

der Medizinischen Fakultät der

Georg-August-Universität zu Göttingen

\author{
vorgelegt von \\ Heike Lucia Ellen \\ aus Norden
}

Göttingen 2011 
Dekan:

I. Berichterstatter:

II. Berichterstatter/in:
Prof. Dr. med. C. Frömmel

Prof. Dr. med. Dr. h.c. W. Engel

Priv.-Doz. Dr. med. Männer

Tag der mündlichen Prüfung: 24. Juli 2012 


\section{Inhaltsverzeichnis}

INHALTSVERZEICHNIS..

ABKÜRZUNGEN ............................................................................................. IV

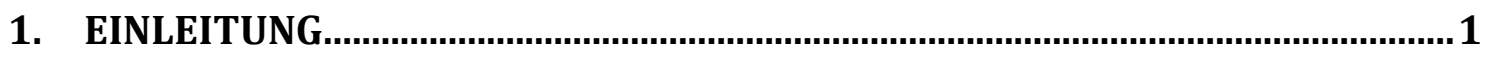

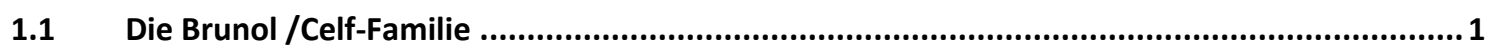

1.2 Übersicht über die Funktionen der Mitglieder der Brunol/Celf-Familie .....................................

1.3 Untersuchungen von für Mitglieder der Brunol-Familie defizienten Tieren ..............................4

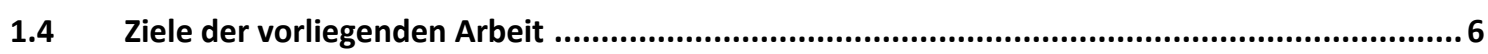

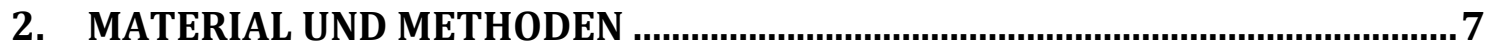

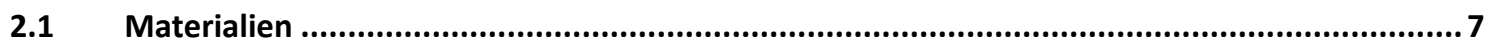

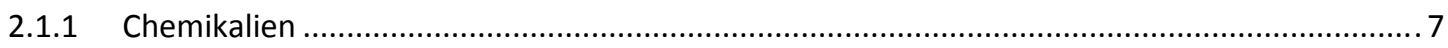

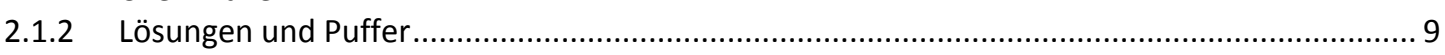

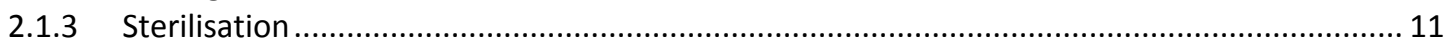

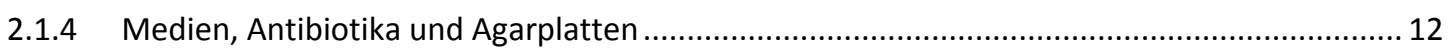

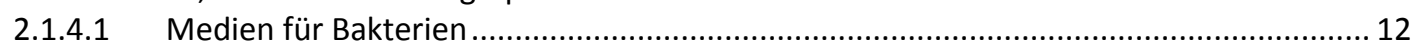

2.1.4.2 Medien für Zellkultur .................................................................................... 12

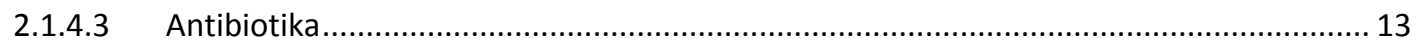

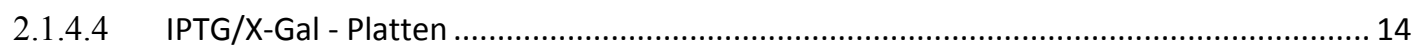

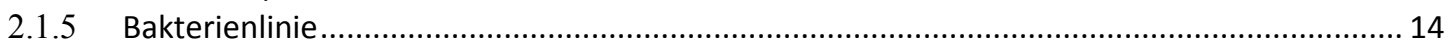

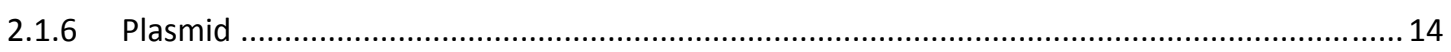

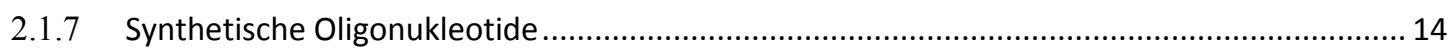

2.1.7.1 Primer für Genotypisierungen ........................................................................... 14

2.1.7.2 Primer zum Herstellen der Sonden für Northern-Blot-Analyse .................................... 14

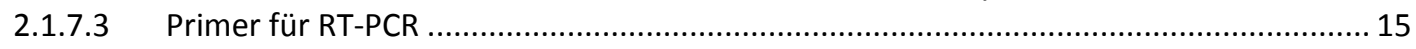

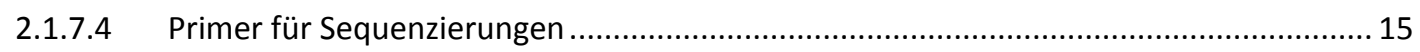

2.1.8 cDNA Proben für die Northern-Blot-Analyse .............................................................. 15

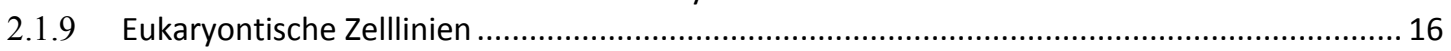

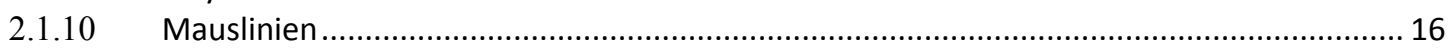

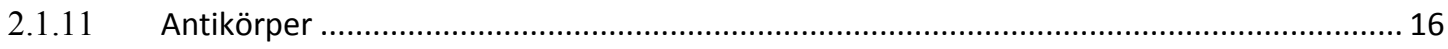

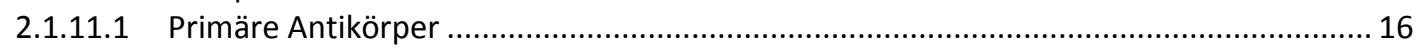

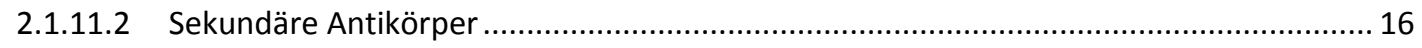

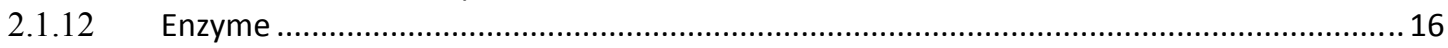

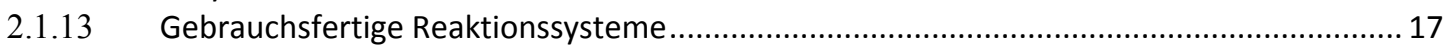

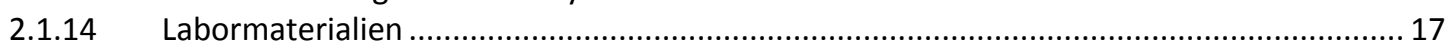

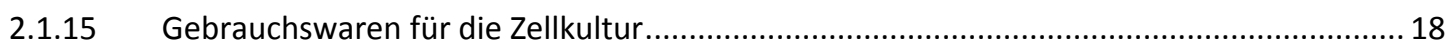

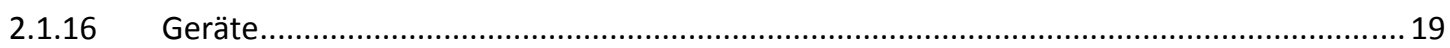

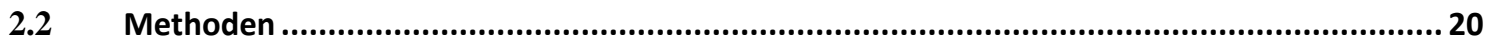

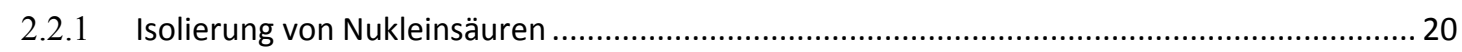

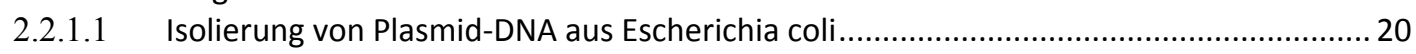

2.2.1.2 Isolierung genomischer DNA aus Geweben ............................................................... 20

2.2.1.2.1 Isolierung genomischer DNA aus Geweben mittels Lysepuffer I ........................... 21 
2.2.1.2.2 Isolierung genomischer DNA mit Viagen DirectPCR-Tail (Peqlab, Erlangen) ............. 21

2.2.1.3 Isolierung genomischer DNA aus ES-Zellen............................................................ 21

2.2.1.4 Isolierung von Gesamt-RNA aus Gewebeproben.................................................. 22

2.2.2 Bestimmung der Konzentration von Nukleinsäuren....................................................... 22

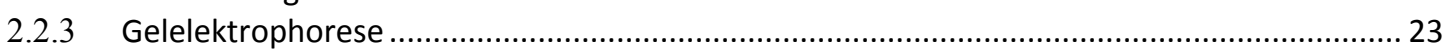

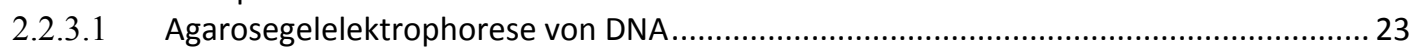

2.2.3.2 Agarosegelelektrophorese von RNA ...................................................................... 23

2.2.4 Isolierung von DNA-Fragmenten nach Auftrennung durch Gelelektrophorese .....................24

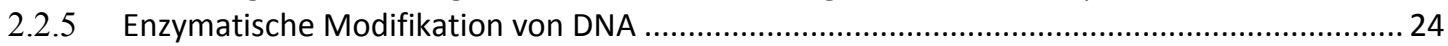

2.2.5.1 Spaltung von DNA mittels Restriktionsendonukleasen................................................. 24

2.2.5.2 Ligation von DNA Produkten in pGEM ${ }^{\circledR}$ T easy- Vektor (TA-Klonierung) ...........................25

2.2.6 Transformation kompetenter E.-coli-Bakterien............................................................. 25

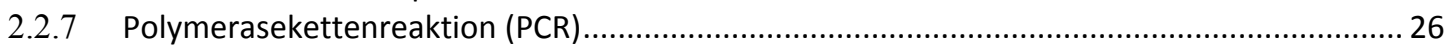

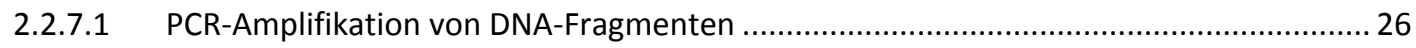

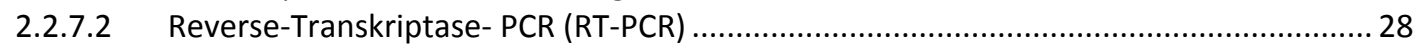

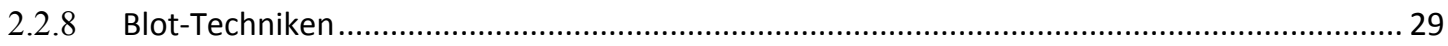

2.2.8.1 Southern-Blot-Technik für den Transfer von DNA auf Nitrozellulose-Filter .................... 29

2.2.8.2 Northern-Blot -Technik für den Transfer von RNA auf Nitrozellulose-Filter....................30

2.2.9 Random-Prime-Methode zur Herstellung ${ }^{32}$ P-markierter DNA ........................................... 30

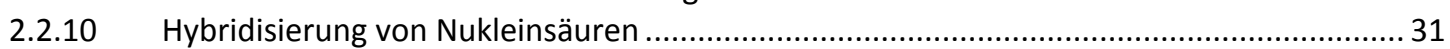

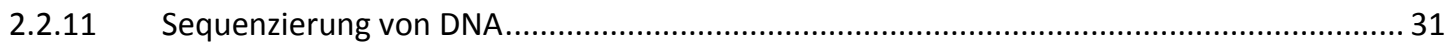

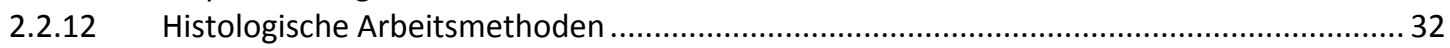

2.2.12.1 Gewebepräparation und Fixierung für die Einbettung in Paraffin................................ 32

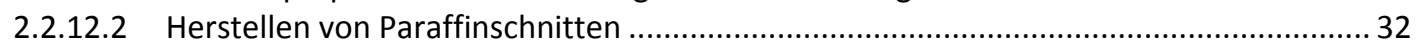

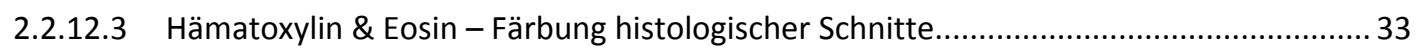

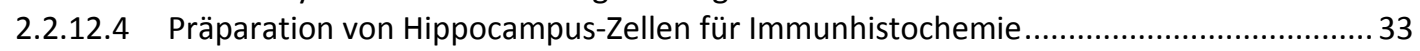

2.2.12.5 Färbung mit DAPI, Munc18-Antikörper und Beta-III-Tubulin-Antikörper ........................ 34

2.2.13 Untersuchung von Spermien - Parametern..................................................................... 35

2.2.13.1 Zählen von Spermien in der Cauda epididymidis .................................................... 35

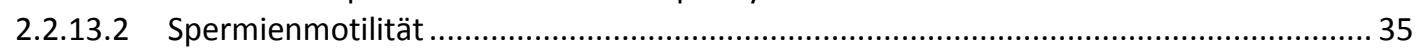

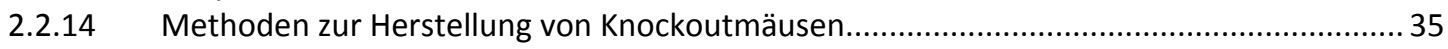

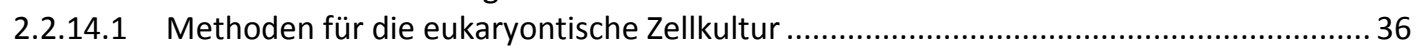

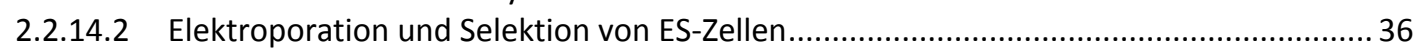

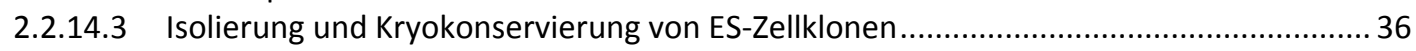

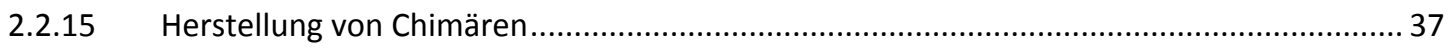

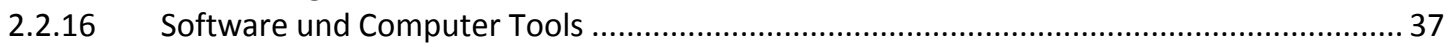

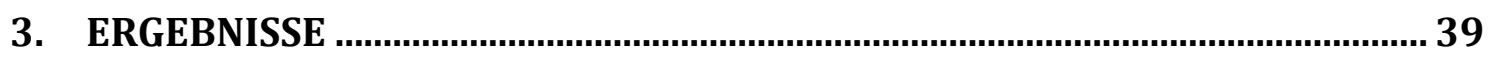

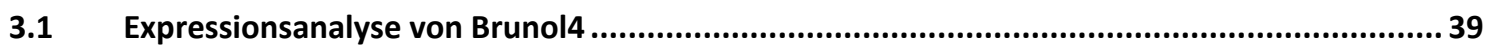

3.2 Herstellung einer Brunol4-defizienten Maus ..............................................................4 41

3.2.1 Elektroporation von ES-Zellen mit dem Targeting-Vektor Brunol4 und Selektion homolog

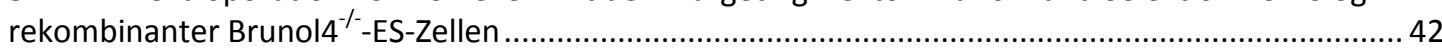

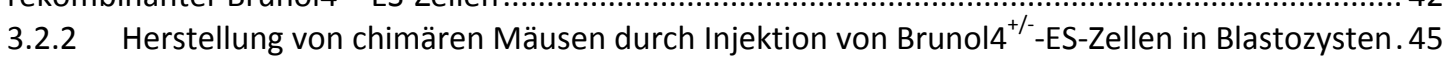

3.2.3 Züchtung und Genotyp-Analysen der Nachkommen in der F1- und F2-Generation ............... 45

3.3 Kontrolle der Inaktivierung des Brunol4-Gens ..............................................................48

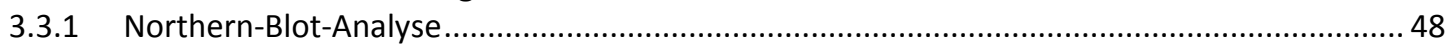

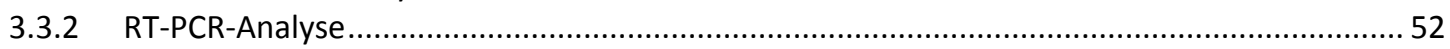

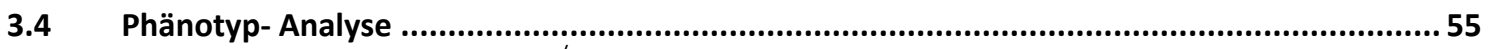

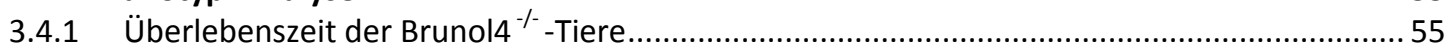

3.4.2 Vergleich der Körpergewichte von Brunol4-defizienten Mäusen und Geschwistertieren ........57

3.4.3 Auftreten von Krampfanfällen bei adulten Brunol $4^{-/-}$-Tieren ...............................................5 59 
3.5 Morphologische Untersuchungen des Gehirns 60

3.5.1 Histologie des Gehirns bei Brunol4-defizienten Mäusen .....................................................6 60

3.5.2 Untersuchungen auf Unterschiede in der Verteilung und Expression von munc-18 und beta-

Tubulin sowie in der Länge der Neuronenfortsätze bei Brunol4 ${ }^{-/-}$-Mäusen

3.6 Generierung und Untersuchung von Brunol1/Brunol4-Doppelt-Knockout-Mäusen................65

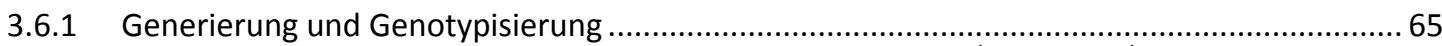

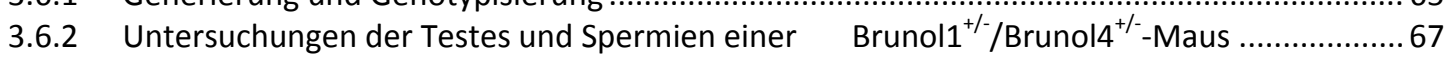

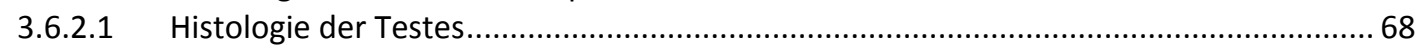

3.6.2.2 Morphologische Untersuchung der Spermien nach DAPI-Färbung ..............................69

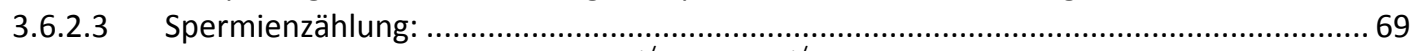

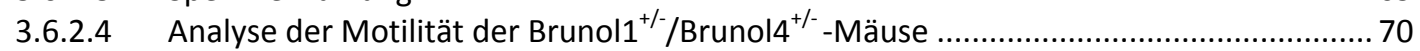

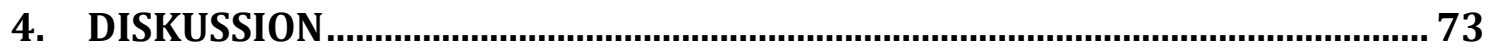

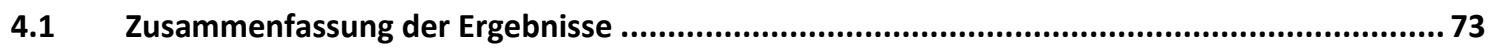

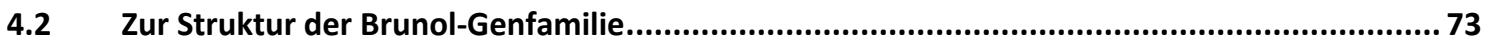

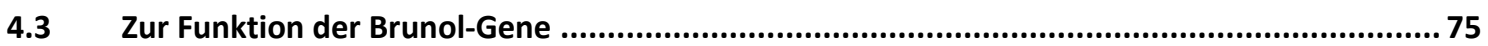

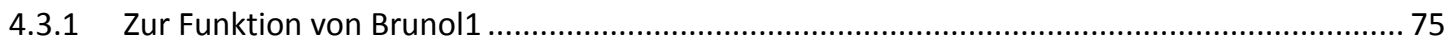

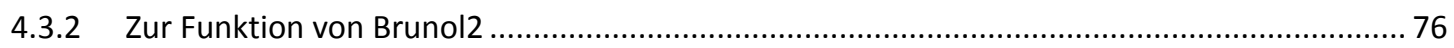

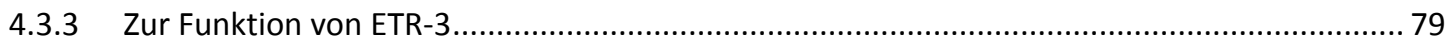

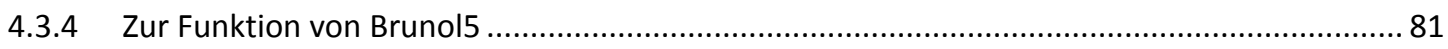

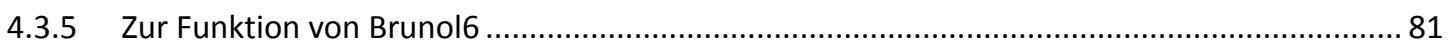

4.4 Zur Funktion von Brunol4 .......................................................................................8 82

4.4.1 Neurologische Auffälligkeiten bei Brunol4-defizienten Tieren ohne morphologisches Korrelat

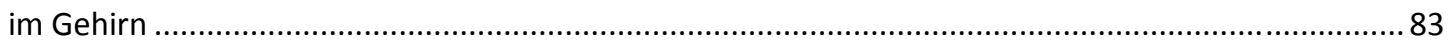

4.4.2 Verkürzte Lebenserwartung von Brunol4-defizienten Tieren ............................................ 88

4.4.3 Signifikante Wachstumsretardierung bei Brunol4-defizienten Tieren ................................. 89

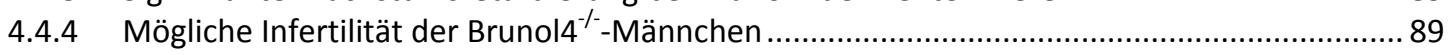

4.5 Zur Expression der Bruno-like-Gene bei der Maus .........................................................99

4.5.1 Weitere Spleißvariante der Brunol4 -mRNA .................................................................. 92

4.6 Hohe Letalität bei Brunol1 ${ }^{/-} /$Brunol4 $^{-/-}$-Doppelt-Knockout-Mäusen ....................................93

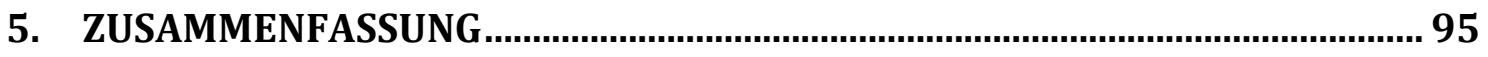

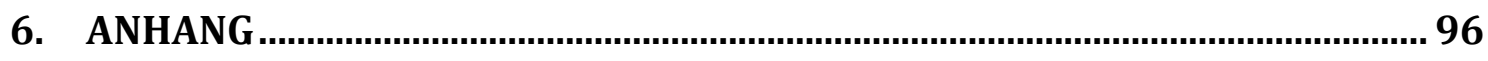

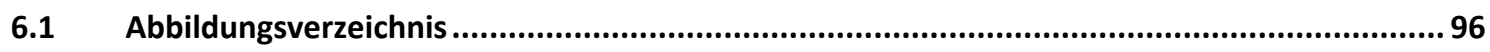

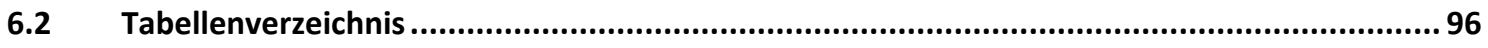

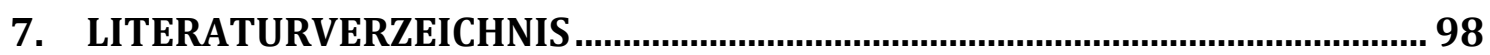




\section{Abkürzungen}

aa

Abb.

ATP

Bp

bzw.

${ }^{\circ} \mathrm{C}$

c-

ca.

cDNA

Chr.

$\mathrm{Ci}$

d

d.h.

Dapi

dCTP

DEPC

$\mathrm{dH}_{2} \mathrm{O}$

DNA

DNase

dpc

E

E.coli

E-Cup

ES-Zelle

et al.

F

F1

F2

FCS

FM

$g$

g amino acids

Abbildung

Adenosintriphosphat

Basenpaare

beziehungsweise

Grad Celsius

Centi- $\left(1 \times 10^{-2}\right)$

circa

complementary DNA

Chromosom

Curie

Tag

das heißt

4',6'-Diamidino-2-Phenylindoldihydrochlorid

Desoxycytidintriphosphat

Diethylpyrocarbonat

Destilliertes $\mathrm{H}_{2} \mathrm{O}$

Desoxyribonukleinsäure

Desoxyribonuklease

dies post coitum

Embryonaltag

Escherichia coli

Eppendorf-Cup

Embryonale Stammzelle

et alii

Farad

Erste Filialgeneration

Zweite Filialgeneration

Fetal Calf Serum

Fluoreszenz-Mikroskop

Gravity of Earth $\left(9,81 \mathrm{~m} / \mathrm{s}^{2}\right)$

Gramm 


\begin{tabular}{|c|c|}
\hline $\begin{array}{l}\text { GFP } \\
\text { Gy }\end{array}$ & $\begin{array}{l}\text { Green fluorescent protein } \\
\text { gray }\end{array}$ \\
\hline $\mathrm{h}$ & Stunde \\
\hline $\mathrm{HE}$ & Hämatoxylin/Eosin \\
\hline HPRT & Hypoxanthin- Phosphoribosyl- Transferase \\
\hline ID & Identifikationsnummer \\
\hline IPTG & Isopropyl- $\beta$-thiogalactopyranosid \\
\hline $\mathrm{k}-$ & kilo- $\left(1 \times 10^{3}\right)$ \\
\hline Kap. & Kapitel \\
\hline 1 & Liter \\
\hline$\mu-$ & Mikro- $\left(1 \times 10^{-6}\right)$ \\
\hline M & Molar (Mol/1) \\
\hline $\mathrm{m}$ & Meter \\
\hline m- & milli- $\left(1 \times 10^{-3}\right)$ \\
\hline $\mathrm{Mb}$ & Megabasen \\
\hline $\min$. & Minute/n \\
\hline mRNA & messenger-Ribonukleinsäure \\
\hline n- & nano- $\left(1 \times 10^{-9}\right)$ \\
\hline Neo & Neomycin \\
\hline o.g. & Oben genannte(n) \\
\hline $\mathrm{Pa}$ & Pascal \\
\hline PBS & „Phosphate Buffered Saline“" \\
\hline PCR & Polymerase-Kettenreaktion \\
\hline $\mathrm{pH}$ & Negativer dekadischer Logarithmus der Protonenkonzentration \\
\hline Prä-mRNA & Präkursor-mRNA \\
\hline RNA & Ribonukleinsäure \\
\hline RNase & Ribonuklease \\
\hline $\mathrm{RT}$ & Raumtemperatur \\
\hline RT-PCR & reverse transkriptase polymerase chain reaction \\
\hline $\mathrm{S}$ & Svedberg \\
\hline s. & siehe \\
\hline SDS & Natriumdodecylsulfat \\
\hline sek. & Sekunde \\
\hline s.o. & siehe oben \\
\hline SS & single strand \\
\hline SSC & Standard Saline Citrat (-Puffer) \\
\hline
\end{tabular}




$\begin{array}{ll}\text { Tab. } & \text { Tabelle } \\ \text { TBE } & \text { Tris-Borat-EDTA (-Puffer) } \\ \text { TE } & \text { Tris-EDTA (-Puffer) } \\ \text { Tris } & \text { Tris-hydroxymethyl-aminomethan } \\ \text { U } & \text { Unit } \\ \text { u.a. } & \text { unter anderem } \\ \text { ü.N. } & \text { über Nacht } \\ \text { UK } & \text { United Kingdom } \\ \text { UTR } & \text { untranslated region } \\ \text { V } & \text { Volt } \\ \text { v.a. } & \text { vor allem } \\ \text { vgl. } & \text { vergleiche } \\ \text { v/v } & \text { Volumen pro Volumen } \\ \text { WT } & \text { Wildtyp } \\ \text { X-Gal } & \text { 5-Brom-4-Chlor-3-Indolyl-3-Galactopyranosid } \\ \text { Symbole für Nukleotide (1-Buchstaben-Code) } \\ \text { A } \quad \text { Adenosin }\end{array}$




\section{Einleitung}

\subsection{Die Brunol /Celf-Familie}

Bei der Brunol-bzw. Celf-Familie handelt es sich um eine Gruppe von sechs RNA bindenden Proteinen. Die Gene wurden in unterschiedlichen Laboratorien kloniert bzw. identifiziert. Daher führten unterschiedliche namensgebende founder-Proteine zu zwei Bezeichnungen für dieselbe Familie. Aufgrund der Ähnlichkeit in der Sequenz mit dem Drosophila-melanogaster-Protein Bruno (Kim-Ha et al. 1995) wird die Familie BrunolFamilie (bruno like) genannt (Good et al. 2000). Der Name Celf-Familie basiert auf den Homologien zu CUG-BP1 (auch Celf1) (Timchenko et al. 1996) und Etr-3 (auch CUGBP2/Celf2) (Hwang et al. 1994) und steht für $\underline{C} U G-B P 1$ and Etr-3 like factors (Ladd et al. 2001; Ladd et al. 2004). Die Proteine werden mit Celf1 bis Celf6 bzw. Brunol1, Brunol2 und Brunol4 bis Brunol6 bezeichnet. In der Maus wird das sechste Mitglied in der Brunol-Familie CUG-BP2 bzw. Etr-3 genannt. Die Nummerierung der Mitglieder dieser Genfamilie ist in den unterschiedlichen Nomenklaturen nicht einander entsprechend. Tabelle 1.1 gibt daher eine Übersicht über die Gene mit den dazugehörigen Bezeichnungen und der chromosomalen Lokalisation bei Maus und Mensch, sowie den Grad der Homologie zwischen den jeweiligen Proteinen der beiden Spezies. Im Folgenden wird für die Mitglieder der Brunol/Celf-Familie die BrunolNomenklatur verwendet.

\begin{tabular}{|l|l|l|l|l|l|l|}
\hline \multicolumn{7}{|l|}{ Mitglieder der Brunol/Celf-Familie } \\
\hline $\begin{array}{l}\text { Mus } \\
\text { musculus }\end{array}$ & $\begin{array}{l}\text { Brunol1 } \\
\text { Celf3 }\end{array}$ & $\begin{array}{l}\text { Brunol2 } \\
\text { Celf1 }\end{array}$ & $\begin{array}{l}\text { CUG-BP2 } \\
\text { Etr-3 } \\
\text { Celf2 }\end{array}$ & $\begin{array}{l}\text { Brunol4 } \\
\text { Celf4 }\end{array}$ & $\begin{array}{l}\text { Brunol5 } \\
\text { Celf5 }\end{array}$ & $\begin{array}{l}\text { Brunol6 } \\
\text { Celf6 }\end{array}$ \\
\hline Lokalisation & Chr. 3 & Chr. 2 & Chr. 2 & Chr. 18 & Chr. 10 & Chr. 9 \\
\hline $\begin{array}{l}\text { Homo } \\
\text { sapiens }\end{array}$ & $\begin{array}{l}\text { Brunol1 } \\
\text { Celf3 }\end{array}$ & $\begin{array}{l}\text { Brunol2 } \\
\text { Celf1 }\end{array}$ & $\begin{array}{l}\text { Brunol3 } \\
\text { Celf2 }\end{array}$ & $\begin{array}{l}\text { Brunol4 } \\
\text { Celf4 }\end{array}$ & $\begin{array}{l}\text { Brunol5 } \\
\text { Celf5 }\end{array}$ & $\begin{array}{l}\text { Brunol6 } \\
\text { Celf6 }\end{array}$ \\
\hline Lokalisation & Chr. 1 & Chr. 11 & Chr. 10 & Chr. 18 & Chr. 19 & Chr. 15 \\
\hline $\begin{array}{l}\text { Protein- } \\
\text { Homologie }\end{array}$ & $97 \%$ & $99 \%$ & $85 \%$ & $96 \%$ & $95 \%$ & $97 \%$ \\
\hline
\end{tabular}

Tab. 1.1: Nomenklatur, Lokalisation und Homologien zwischen den Mitgliedern der Brunol/Celf-Familie bei Maus und Mensch 
Zur Übersicht sind die einzelnen Vertreter der Brunol/Celf-Familie mit den dazugehörigen Namen je nach Nomenklatur dargestellt. Außerdem gibt die Tabelle Auskunft über die chromosomale Lokalisation der Gene sowie über den Grad der Homologien zwischen den Proteinen bei Mensch und Maus.

Die Proteine Brunol1, Brunol2, Etr-3 und Brunol4 - Brunol6 sind sowohl strukturell als auch in der Sequenz miteinander verwandt. Die Primärstruktur der Proteine ist in Abbildung 1.1 dargestellt.

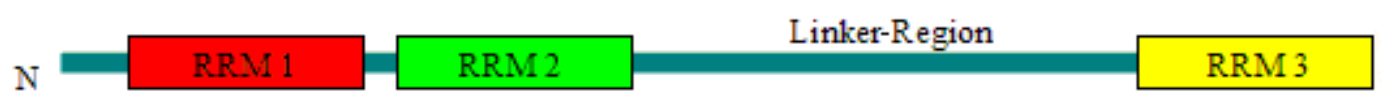

Abb. 1.1: Proteinstruktur der Mitglieder der Bruno-like/Celf- Familie

Am N-terminalen Ende der Proteine befinden sich zwei RRMs (RNA recognition motif). Diese sind durch eine Linker-Region mit einem dritten C-terminalen RRM verbunden (nach Burd und Dreyfuss 1994).

Die Proteine enthalten drei RNA bindende Domänen (RBD oder RRM für $R N A$ recognition motif). Zwei dieser RRMs befinden sich am $\mathrm{N}$-terminalen Ende und sind durch eine Linker-Region mit dem C-terminalen RRM verbunden (Burd und Dreyfuss 1994). Die Aminosäuresequenzen der RRMs sind bei den verschiedenen BrunolMitgliedern sehr ähnlich, die Sequenz der Linker-Region ist jedoch weniger konserviert. Sie wird daher auch divergent region genannt (Ladd et al. 2001). Entsprechend ihrer Sequenz in der Linker-Region lassen sich die Proteine in zwei Untergruppen einteilen, welche jeweils größere Ähnlichkeiten zeigen. Die erste Gruppe enthält Brunol2 und Etr-3, die zweite enthält Brunol1 sowie Brunol4-Brunol6 (Ladd et al. 2001; 2004). Die Analyse der veröffentlichten Daten (Choi et al. 1998; Good et al. 2000; Li D et al. 2001) und Datenbankrecherchen (NCBI) zeigen, dass einige Transkripte der Brunol/Celf-Familie alternativ gespleißt werden. Aktuell werden in der Maus 2 Proteinisoformen für das Brunol2-Gen (NP 059064.2, NP 059064.2), 6 Proteinisoformen für Etr-3 (P 001103698.1 , NP 001103699.1, NP 001103700.1, NP $\underline{001103701.1}$, NP 001103701.1, NP 001103702.1 , NP 001153764.1 , NP 001153765.1 , NP 034290.2) und 6 Isoformen für Brunol4 (P_001139764.1, NP_001139765.1, NP 001139766.1, NP_001139767.1, NP_001167545.1, NP_573458.2 ) beschrieben. 


\section{2 Übersicht über die Funktionen der Mitglieder der Brunol/Celf- Familie}

RNA-Bindungsproteine spielen im Rahmen der posttranskriptionellen Regulation der Genexpression sowohl für die normale Zellfunktion als auch für die Entwicklung eine große Rolle (Antic und Keene 1997). Durch Bindung an bestimmte Sequenzen der RNA sind die Brunol-Proteine am Alternativen Spleißen von Prä-mRNA, der Translationsinitiation und der Stabilisierung von mRNA beteiligt.

Wie im Folgenden geschildert, können Fehlregulationen dieser Mechanismen an der Pathogenese unterschiedlicher Erkrankungen beteiligt sein.

So ist das Alternative Spleißen von Exon 5 des kardialen TroponinT (cTNT) in Mäusen entwicklungsabhängig. Exon 5 ist vor allem in mRNA des embryonalen Herzens vorhanden, während es in mRNA des adulten Herzens meist fehlt (Cooper und Ordahl 1985). Alle sechs Proteine der Brunol-Familie fördern die MSE-abhängige ( $\underline{\text { muscle }}$ specific splicing enhancers) Exon-Inklusion in cTNT-Minigen-Prä-mRNA in Fibroblasten (Ladd et al. 2001; 2004) und Brunol2 und Etr-3 induzieren die Inklusion von Exon 5 des cTNT in Mäusen (Charlet-B et al. 2002a; Ladd et al. 2005a). Entsprechend korreliert der Switch der Spleißvarianten mit einer Herunterregulation von Etr-3 und Brunol2 (Ladd et al. 2005a). Versuche mit einem herzspezifischen dominant-negativen Protein (ein strukturell dem Wildtyp ähnliches Protein, jedoch mit Funktionsverlust), welches das Brunol-vermittelte Spleißen hemmt, führen bei Mäusen zu schwerer Kardiomyopathie (Ladd et al. 2005b). Diese heilt jedoch bei Tieren mit niedrigerer Expression des dominant-negativen Proteins im adulten Stadium spontan. Daraus kann gefolgert werden, dass das Brunol-abhängige alternative Spleißen im Herzen nur in der frühen postnatalen Phase für die Herzfunktion erforderlich ist (Terenzi et al. 2009). Untersuchungen zu Etr-3 und Brunol4 deuten an, dass die zwei Nterminalen RRMs und ein kleiner Teil der Linker-Region ausreichend für die volle MSE-abhängige Spleiß-Aktivität sind (Singh et al. 2004).

Brunol2 und Brunol6 sowie Etr-3 hemmen außerdem das Spleißen des alternativen Exon 11 des humanen Insulinrezeptors (IR) (Savkur et al. 2001; Ladd et al. 2004; Han und Cooper 2005). Des Weiteren unterdrückt Etr-3 die Inklusion von Exon 2 bzw. Exon2 und Exon 3 der Tau Prä-mRNA in T98-Zellen (humanes Glioblastom), und auch Brunol4 trägt möglicherweise zur Inhibition der Inklusion bei (Leroy et al. 2006a). 
Verändertes Alternatives Spleißen dieser durch Brunol-Proteine regulierten RNAs von kardialem Troponin $\mathrm{T}$, dem Insulinrezeptor und Tau wurde bei der Myotonen Dystrophie Typ I (DM1) beobachtet (Philips et al. 1998; Sergeant et al. 2001; Savkur et al. 2001; Leroy et al. 2006a). Sowohl Brunol2-, Etr-3- als auch Brunol4-Transkripte sind signifikant reduziert im Gehirn von an DM1 erkrankten Menschen im Vergleich zu Kontrollen. Brunol2 scheint jedoch zudem durch erhöhte Aktivität eine Fehlregulation des alternativen Spleißens des humanen ClC-1 (Muskel-spezifischer Chlorid-Kanal, auch CLCN-1) zu induzieren. Daraus resultiert ein ClC-1-Verlust im Skelettmuskel, welcher zu Myotonien im Rahmen der DM1 führt (Charlet-B et al. 2002b).

Es wurde außerdem gezeigt, dass die Expression von Etr-3 in HeLa-Zellen (eine humane Zervixkarzinom-Zelllinie) nach Schädigung durch Strahlenexposition heraufreguliert wird. Etr-3 bindet dann an eine A/U-reiche Sequenz der 3'-UTR der Cyclooxygenase 2-mRNA ( $C O X-2)$ und erhöht damit ihre Stabilität. Ihre Translation wird jedoch inhibiert. Damit ist Etr-3 eine wichtige Komponente der bestrahlungsinduzierten Apoptose (Mukhopadhyay et al. 2003a).

Brunol4 wurde des Weiteren als unabhängiger prognostischer Indikator im sporadischen Kolorektalen Karzinom beim Menschen identifiziert (Poulogiannis et al. 2010).

\subsection{Untersuchungen von für Mitglieder der Brunol-Familie defizienten Tieren}

Bezüglich der Abklärung der Funktion der Brunol/Celf-Familie gibt es bereits verschiedene Untersuchungen (s.o.). Allerdings existieren nur wenige Untersuchungen über die Funktion der Brunol-Gene in vivo. Durch die Herstellung einer KnockoutMaus für ein Gen ist es möglich, den ganzen Organismus betreffend rückwirkend Aussagen über die Funktionen eines Gens $\mathrm{zu}$ machen. Zur Zeit existieren Veröffentlichungen zu Knockout-Mäusen für Brunoll und Brunol2. Brunoll wird in der Maus sowohl im Gehirn als auch im Testis exprimiert (Dev et al. 2007). Brunoll ${ }^{-1}$ Mäuse zeigten im Vergleich zu Wildtyp-Mäusen bis auf eine Reduktion in der Spermienanzahl sowie Unterschiede in bestimmten Parametern der Spermienmotilität keine Auffälligkeiten. Die Fertilität der Tiere ist nicht beeinträchtigt (Dev et al. 2007). Die Ausschaltung des ubiquitär exprimierten Gens Brunol2 führt in Mäusen zu einer erhöhten perinatalen Mortalität, einer bereits in der Embryonalentwicklung auftretenden 
Wachstumsretardierung und zu einer Hypofertilität sowohl bei weiblichen als auch bei männlichen Tieren. Zwei Drittel der Männchen zeigten Beeinträchtigungen in der Spermatogenese und eine verstärkte Apoptose in verschiedenen Reifestadien (Kress et al. 2007). Es ist verwunderlich, dass die Brunoll-defizienten Mäuse einen vergleichsweise unauffälligen Phänotyp aufweisen. Da es jedoch sechs Brunol-Gene gibt, kann davon ausgegangen werden, dass eine Redundanz zwischen den Genen besteht. Für Etr-3, Brunol4, Brunol5 und Brunol6 sind noch keine Knockout-Mäuse beschrieben worden, so dass bezüglich deren Funktionen noch viele Fragen offen sind. Bei dem Versuch der Inaktivierung von Brunol4 (Dev 2006) konnten keine Brunol4 ${ }^{-{ }_{-}}$ Mäuse generiert werden. Dev (2006) hat vermutet, dass im Genom der Tiere mehr als eine Kopie des Brunol4-Gens vorliegen müsse. Es wurden jedoch epileptische Anfälle in Mäusen beschrieben, bei denen Brunol4 aufgrund von gene trap beeinträchtigt war (Yang et al. 2007). Die Abbildung 1.2 zeigt eine schematische Darstellung für die Insertion der gene-trap-Kassette in das Brunol4-Gen. Etwa $18 \mathrm{~kb}$ des Intron 1 wurden durch mehrere Kopien des Transgens ersetzt. Dies führte zu einer Verlängerung des Introns um mindestens $20 \mathrm{~kb}$. Das Transgen enthält multiple Spleiß-Donor- und Akzeptor-Stellen und könnte daher zu Alterationen im Spleißen geführt haben.

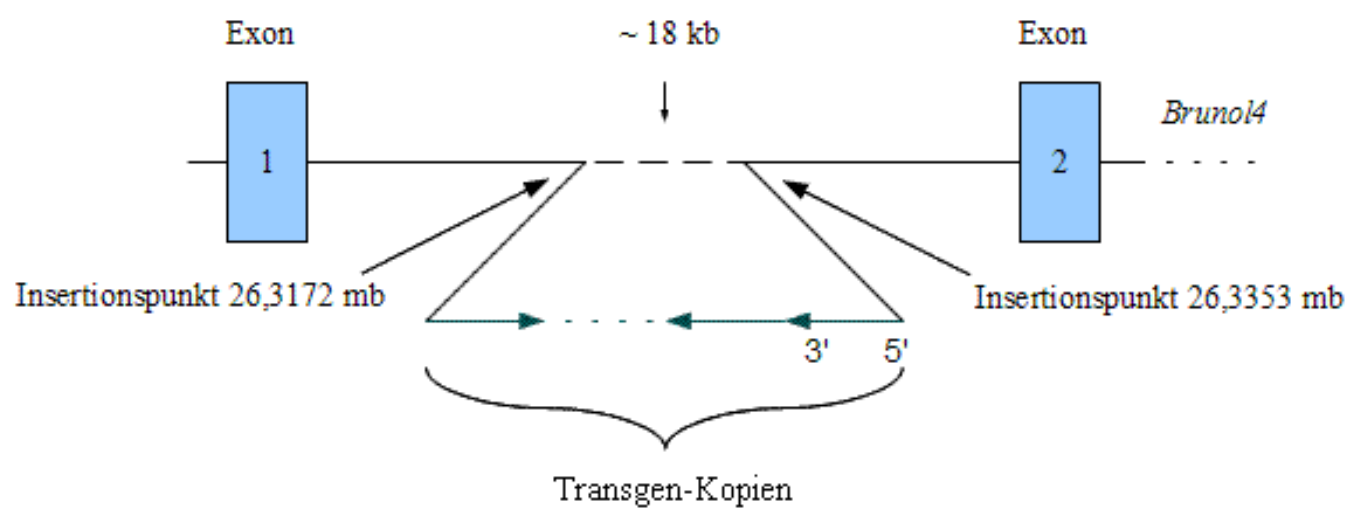

Abb. 1.2: Schematische Darstellung der Insertion der gene-trap-Kassette in Brunol4 (Yang et al, 2007)

Dargestellt ist die Lokalisation der Transgen-Insertion in das erste Intron von Brunol4. Die genaue Anzahl von inserierten Kopien ist nicht bekannt, jedoch handelt es sich um mehr als vier Kopien. Auffällig ist, dass zumindest ein Transgen invertiert inseriert worden ist. Es liegt eine Deletion von $18 \mathrm{~kb}$ der genomischen Sequenz vor. 
Heterozygote gene-trap-Mäuse mit einem genetischen C57B1/6-Hintergrund zeigten ab einem Alter von drei Monaten epileptische Anfälle und waren hyperaktiv. Des Weiteren waren sie im Säuglingsalter kleiner als Geschwistertiere, nahmen jedoch später deutlich an Gewicht zu und wurden etwas schwerer als Wildtyp-Geschwister. Die homozygoten Tiere für das transgene gene trap-Allel starben meist am ersten Lebenstag, nur ca. 1\% wurde älter als vier Wochen. $8 \%$ der homozygoten Tiere eines genetischen HybridHintergrundes (C57B1/6 x 129S1) jedoch wurden älter als vier Wochen und bekamen spontane tonisch klonische Krampfanfälle ab einem Alter von 8 Wochen sowie Absencen. Sie waren außerdem kleiner als Geschwistertiere. Die Northern-Blot-Analyse mit RNA aus Gehirnen von neugeborenen Mäusen ergab kein Brunol4-Transkipt bei für das transgene gene-trap-Allel homozygoten Tieren. Jedoch wurde berichtet, dass in micro-array-Untersuchungen neben anderen mRNAs das Brunol4-Transkript nachweisbar war. Somit bleibt unklar, ob Brunol4 in den gene trap-Mäusen tatsächlich ausgeschaltet worden ist. Daher war es notwendig, Brunol4-defiziente Tiere mittels zielgerichteter Inaktivierung herzustellen. Das dafür notwendige Knockout-Konstrukt für Brunol4 (Dev 2006) lag bereits vor.

\subsection{Ziele der vorliegenden Arbeit}

Das Ziel der vorliegenden Arbeit war die Analyse der Funktion des Brunol4-Gens sowie die Untersuchung auf eventuelle Redundanz in der Brunol-Familie mittels Generierung von Brunol1/Brunol4-Doppelt-Knockout-Mäusen. Im Einzelnen:

1. Herstellung von Brunol4-Knockout-Mäusen

2. Versuche zur Charakterisierung des Phänotyps von Brunol4-defizienten Mäusen

3. Herstellung und Analysen von Brunoll/Brunol4-Doppelt-Knockout-Mäusen. 


\section{Material und Methoden}

\subsection{Materialien}

\subsubsection{Chemikalien}

Agar

Agarose

Ampicillin

Ampuwa

Bacto-Pepton

Bacto-Hefe-Extrakt

Borsäure

Chloroform

Vectashield (DAPI)

Diethylpyrocarbonat (DEPC)

Dulbecco's Modified Eagle Medium

(DMEM)

Dimethylsulfoxid (DMSO)

DNA-Leiter (1kb)

dNTPs (100 mM)

EDTA

Essigsäure

Ethanol

Ethidiumbromide

FCS

Formaldehyde

Formamid

Gentamycin

Glyzerin
Roth, Karlsruhe

Peqlab, Erlangen

Sigma-Aldrich, Hamburg

Fresenius, Bad Homburg

Roth, Karlsruhe

Roth, Karlsruhe

Roth, Karlsruhe

J.T.Baker, Deventer, Niederlande

Vector, Burlingame

Sigma-Aldrich, Hamburg

PAN, Aidenbach

Sigma-Aldrich, Hamburg

Invitrogen, Karlsruhe

Invitrogen, Karlsruhe

Sigma-Aldrich, Hamburg

Merck, Darmstadt

J.T.Baker, Deventer, Niederlande

Roth, Karlsruhe

PAN, Aidenbach

Merck, Darmstadt

Sigma-Aldrich, Hamburg

PAN, Aidenbach

Invitrogen, Karlsruhe 
$\mathrm{HCl}$

HEPES

IPTG

Isopropanol

$\mathrm{KCl}$

$\mathrm{MgCl}_{2}$

MOPS

$\beta$-Mercaptoethanol

Natriumacetat

Natriumcitrat

$\mathrm{NaCl}$

$\mathrm{Na}_{2} \mathrm{HPO}_{4}$

$\mathrm{NaH}_{2} \mathrm{PO}_{4}$

$\mathrm{NaOH}$

NuPage ${ }^{\circledR}$ LDS Probenpuffer (4x)

NuPage ${ }^{\circledR}$ Mops SDS Laufpuffer

Orange $\mathrm{G}$

Paraplast-Einbettmedium

Pepton

Paraformaldehyd

Penicillin/Streptomycin

PBS

peqGOLDTriFast

Pferdeserum

Phenol

Pikrinsäure

Proteinase $\mathrm{K}$

Radioaktive Substanzen:

$\left[\alpha^{32} \mathrm{P}\right]-\mathrm{dCTP}$

Rapid-Hybridisierungspuffer

Ready primeTM II (DNA Labelling Kit)

RNase-Inhibitor

RNA-Leiter

RNAse-Exitus Plus
Roth, Karlsruhe

Merck, Darmstadt

Biomol, Hamburg

J.T.Baker, Deventer, Niederlande

Merck, Darmstadt

Merck, Darmstadt

Applichem, Darmstadt

Serva, Heidelberg

Merck, Darmstadt

Merck, Darmstadt

Applichem, Darmstadt

Merck, Darmstadt

Merck, Darmstadt

Merck, Darmstadt

Invitrogen, Karlsruhe

Invitrogen, Karlsruhe

Sigma-Aldrich, Hamburg

Sigma-Aldrich, Hamburg

Roth, Karlsruhe

Applichem, Darmstadt

PAN, Aidenbach

Invitrogen, Karlsruhe

Peqlab, Erlangen

Sigma-Aldrich, Hamburg

Biomol, Hamburg

Fluka, Neu Ulm

Applichem, Darmstadt

Amersham, Braunschweig

Amersham, Freiburg

Amersham, Freiburg

Boehringer, Mannheim

Invitrogen. Karlsruhe

Applichem, Darmstadt 
Lachs-Spermien-DNA

SDS

S.O.C Medium

Tris

Triton X-100

Viagen DirectPCR-Tail

X-Gal

Xylol
Sigma-Aldrich, Hamburg

Serva, Heidelberg

Invitrogen, Karlsruhe

Sigma-Aldrich, Hamburg

Serva, Heidelberg

Peqlab, Erlangen

Biomol, Hamburg

Merck, Darmstadt

Diejenigen Chemikalien, die oben nicht genannt werden, wurden von Merck, Darmstadt oder Roth, Karlsruhe bezogen.

\subsubsection{Lösungen und Puffer}

Alle gängigen Lösungen und Puffer wurden entsprechend Sambrook et al. (1989) hergestellt.

Bouin'sche Lösung

Denaturierungslösung

DEPC- $\mathrm{H}_{2} \mathrm{O}$

Depurinierungslösung

Digestionslösung
$15 \times$ Volumen Pikrinsäure (in $\mathrm{H}_{2} \mathrm{O}$ )

5 x Volumen Formaldehyd (37\%)

1 x Volumen Essigsäure

$1,5 \mathrm{M} \mathrm{NaCl}$

$0,5 \mathrm{M} \mathrm{NaOH}$

0,1\% (v/v) Diethylpyrocarbonat

$250 \mathrm{mM} \mathrm{HCl}$

$0,8 \mathrm{~g} \mathrm{NaCl}$

$0,037 \mathrm{~g} \mathrm{KCl}$

0,099 $\mathrm{g} \mathrm{Na}_{2} \mathrm{HPO}_{4}$

$0,035 \mathrm{~g} \mathrm{NaHCO}_{3}$

$100 \mathrm{ml} \mathrm{H}_{2} \mathrm{O}$

pH 7,3-7,4 einstellen 
Dissektionslösung

Erythrosin (Eosin)

Formalin-Fixierungslösung

Glycerol-Ladepuffer

HANKS-Lösung

IPTG

Ligasepuffer (10x)

Lysepuffer (DNA)
240 ml HANKS- Lösung

0,27 $\mathrm{g}$ bovines Albumin

$0,347 \mathrm{~g} \mathrm{MgSO}_{4}$

0,5\% Erythrosin in Ampuwa

4\% Paraformaldehyde in dPBS

$10 \mathrm{mM}$ Tris/ $\mathrm{HCl}(\mathrm{pH} 7.5)$

10 mM EDTA (pH 8.0)

$0,025 \%$ Orange $\mathrm{G}$

$30 \%$ Glycerol

Pulvermedium Sigma H2387 ohne Ca und $\mathrm{Mg}$ auf 11

$0,35 \mathrm{~g}$ Natriumbikarbonat

2,383 g (10 mM) HEPES

$6 \mathrm{~g}$ D-Glukose

$500 \mu 1(10 \mathrm{mg} / \mathrm{ml})$ Gentamycin

pH 7,3-7,4 einstellen

$100 \mathrm{ml}$ in Ampuwa

$600 \mathrm{mM}$ Tris/HCl $(\mathrm{pH} 7,5)$

$80 \mathrm{mM} \mathrm{MgCl}_{2}$

100 mM DTT

$100 \mathrm{mM}$ Tris- $\mathrm{HCl}$ (pH8)

$5 \mathrm{mM}$ EDTA

$0,2 \%$ SDS

$200 \mathrm{mM} \mathrm{NaCl}$

$100 \mu \mathrm{g} / \mathrm{ml}$ Proteinase K 
MOPS-Puffer (10x)

Neutralisierungslösung

PBS-Puffer (10 x)

$\operatorname{SSC}(20 x)$

5 x TBE-Puffer

TE-Puffer

Waschlösung I

Waschlösung II

X-Gal 2 x X-Gal in Dimethylformamid
41,8 g MOPS

16,6 ml 3 M Natriumacetat

$20 \mathrm{ml}$ 0,5 M EDTA

in 1 Liter DEPC $-\mathrm{H}_{2} \mathrm{O}$

pH 6,75 einstellen

$1,5 \mathrm{M} \mathrm{NaCl}$

$1 \mathrm{M}$ Tris/ $\mathrm{HCl}(\mathrm{pH} 7,0)$

$80 \mathrm{~g} \mathrm{NaCl}$

$2 \mathrm{~g} \mathrm{KCl}$

$26,8 \mathrm{~g} \mathrm{Na}_{2} \mathrm{HPO}_{4}-7 \mathrm{H}_{2} \mathrm{O}$

$2,4 \mathrm{~g} \mathrm{NaH}_{2} \mathrm{PO}_{4}$

$\mathrm{pH} 7,4$ einstellen

$3 \mathrm{M} \mathrm{NaCl}$

$0,3 \mathrm{M} \mathrm{Na}_{3} \mathrm{Citrat}(\mathrm{pH} 7,0)$

$450 \mathrm{mM}$ Tris

450 mM Borsäure

20 mM EDTA (pH 8,0)

$5 \mathrm{mM}$ Tris/ $\mathrm{HCl}(\mathrm{pH} 7,4)$

1 mM EDTA

$2 \times \mathrm{SSC}$

$0,1 \%$ SDS

$0,2 \times \mathrm{SSC}$

$0,1 \%$ SDS

\subsubsection{Sterilisation}


Lösungen wurden für $10 \mathrm{~min}$. bei $121^{\circ} \mathrm{C}$ und $10^{5} \mathrm{~Pa}$ im Dampfdruckautoklaven bzw. im Falle von hitzeempfindlichen Lösungen durch Sterilfiltration (Porengröße: 0,2 $\mu \mathrm{m}$ ) sterilisiert. Gebrauchswaren wurden entweder autoklaviert (Webeco, Bad Schwartau) oder für $8-12 \mathrm{~h}$ bei $180^{\circ} \mathrm{C}$ hitzesterilisiert.

\subsubsection{Medien, Antibiotika und Agarplatten}

\subsubsection{Medien für Bakterien}

LB-Medium ( $\mathrm{pH} 7,5)$ :

$1 \%$ Bacto-Pepton

$0,5 \%$ Hefeextrakt

$1 \% \mathrm{NaCl}$

LB-Agar:

$1 \%$ Bactopepton

$0,5 \%$ Hefeextrakt

$1 \% \mathrm{NaCl}$

$1,5 \%$ Agar

Das LB-Medium wurde mit destilliertem Wasser zubereitet und nach dem Autoklavieren bei $4^{\circ} \mathrm{C}$ gelagert.

\subsubsection{Medien für Zellkultur}

Fibroblasten (MEFs):

DMEM ergänzt durch Natriumpyruvat (1 $\mathrm{mM}$ )

10\% fetales Kalbsserum (FCS),

hitzeinaktiviert

$1 \%$ Glutamin $(200 \mathrm{mM})$,

$1 \%$ Penicillin $(50 \mathrm{U} / \mathrm{ml}) /$ Streptomycin

$(50 \mu \mathrm{g} / \mathrm{ml})$

ES:

DMEM

20\% FCS, hitzeinaktiviert 
$1 \mathrm{mM}$ nicht-essentielle Aminosäuren

$1 \mathrm{mM}$ Natriumpyruvat

$10 \mu \mathrm{M}$ ß-Mercaptoethanol

$2 \mathrm{mM}$ L-Glutamin

2\% Penicillin (50 U/ml)/ Streptomycin

$(50 \mu \mathrm{g} / \mathrm{ml})$

1000 U/ml Rekombinanter

Leukämieinhibierender Faktor (LIF)

Kulturmedium A:

$90 \mathrm{ml}$ MEM Eagle

0,5 ml D-Glukose

$10 \mathrm{mg}$ Transferrin

$10 \mathrm{mg}$ Insulin

$1 \mathrm{ml}(12,5 \mathrm{mg} / \mathrm{ml})$ GlutaMAX 1

$0,05 \mathrm{ml}(10 \mathrm{mg} / \mathrm{ml})$ Gentamycin

$10 \mathrm{ml}$ Pferdeserum

Kulturmedium B:

$100 \mathrm{ml}$ Neurobasal-A-Medium

$250 \mu 1$ L-Glutamin

$50 \mu 1(10 \mathrm{mg} / \mathrm{ml})$ Gentamycin

$125 \mu \mathrm{lb}-\mathrm{FGF}$

$2 \mathrm{ml}$ B27 Supplement

$125 \mu \mathrm{AraC}$

Für die Langzeitaufbewahrung der Zellen in flüssigem Stickstoff wurde das folgende Gefriermedium benutzt:

$$
\begin{aligned}
& 30 \% \text { Kulturmedium } \\
& 20 \% \text { DMSO } \\
& 50 \% \text { FCS }
\end{aligned}
$$

\subsubsection{Antibiotika}


Die Antibiotika wurden zu Lösungen verarbeitet, sterlil gefiltert und bei $-20^{\circ} \mathrm{C}$ gelagert. Das jeweilige Antibiotikum wurde zum autoklavierten Medium hinzugefügt, nachdem dieses auf mindestens $55^{\circ} \mathrm{C}$ heruntergekühlt war.

\subsubsection{IPTG/X-Gal - Platten}

Zum Herstellen von IPTG/X-Gal-Platten wurde LB-Agar mit $50 \mu \mathrm{g} / \mathrm{ml}$ Ampicillin, 100 $\mu \mathrm{M}$ IPTG und 0,4\% X-Gal in Petrischalen gegossen. Diese wurden bei $4{ }^{\circ} \mathrm{C}$ gelagert.

\subsubsection{Bakterienlinie}

E. coli DH5a Invitrogen, Karlsruhe

\subsubsection{Plasmid}

pGEM-T Easy Promega, Mannheim

\subsubsection{Synthetische Oligonukleotide}

Synthetische Oligonukleotide, die in dieser Arbeit als Primer dienten, wurden von OPERON bezogen und in $\mathrm{dH}_{2} \mathrm{O}$ (Ampuwa) in einer Konzentration von $100 \mu \mathrm{M}$ gelöst.

\subsubsection{Primer für Genotypisierungen}

Br4F2 (genom.PCR)
Br4R2 (genom. PCR)
GFP-R3 (genom. P CR)
Bru-1Gen-F
Bru1-14585Del-R
PGK352-R
SRYneuF2
SRYneuR2

\author{
5'-GGGCATATGAACGGATTAAGC-3' \\ 5'-GGCAAAGTTGAGAGGGAAAGG-3' \\ 5'-CGTCGTCCTTGAAGAAGATGG-3' \\ 5'-TGGCTGTTGAGCTCACTCCTCTCCAGCAA-3' \\ 5'-CAAGTTGCTGTTCTCTCAGAGACCGA-3' \\ 5'-GCCCAGAAAGCGAAGGAGCAAAGCT-3' \\ AGCCTGTTGATATCCCCACTG \\ ATGCTCACCAGTGTGTCAGC
}

\subsubsection{Primer zum Herstellen der Sonden für Northern-Blot-Analyse}


Similarexon12F

Similarexon13R

Brl4Exon2R4

Brl4NorthF4

Br14North4R4
5'-TGCAGATGTTCCTCCCTTTC-3'

5'-GGTAATCAAAGCGCCTCTCA-3'

5'-CTGACTCACGCTCGCAGTAG-3'

5'-CCAGCCTGTTTAAACCGAAA-3'

5'-AGCTCGTAGATCTTGCCGAA-3'

\subsubsection{Primer für RT-PCR}

$\begin{array}{ll}\text { Brl4Exon4R4 } & \text { 5'-AGTGCACTCCTCGATGTTCC-3' } \\ \text { Similarexon12F } & \text { 5'-TGCAGATGTTCCTCCCTTTC-3' } \\ \text { Brl4184-DelF4 } & \text { 5'-AATAGAACGAGAGCCCAGAGC-3' } \\ \text { Similarexon13R } & \text { 5'-GGTAATCAAAGCGCCTCTCA-3' } \\ \text { Br14Exon2R4 } & \text { 5'-CTGACTCACGCTCGCAGTAG-3' } \\ \text { Brl4NorthF4 } & \text { 5'-CCAGCCTGTTTAAACCGAAA-3' } \\ \text { Br14North4R4 } & \text { 5'-AGCTCGTAGATCTTGCCGAA-3' } \\ \text { Br14qPCRF4 } & \text { 5'-TGCAGCAGTATGCAGGACC-3' } \\ \text { Brl4qPCRR4 } & \text { 5'-AGGGAGGAACATCTGCATCA-3' }\end{array}$

\subsubsection{Primer für Sequenzierungen}

SP6

$\mathrm{T} 7$

SeqPCRintmidF

SeqPCRintmidR

SeqPCRex13R

SeqPCRex13F
5'-TTAGGTGACACTATAGAATACTCAAGC-3' 5'-AATACGACTCACTATAGGGCGAATTGG-3'

5'-ACTGACAGGGAGCGCACAAT-3'

5'-CAGGCCATTCATGTTGAGG-3'

5'-GGGACTAGGCCCCATTGTA-3'

5'-CAAGCTGACGACTCCAGACA-3'

\subsection{8 cDNA Proben für die Northern-Blot-Analyse}

B-actin

Brunol4 Exon 1

Brunol4 Exon 12/13

Brunol4 hergestellt von Dr. J. Nolte in dieser Studie hergestellt in dieser Studie hergestellt hergestellt von Dr. A. Dev 


\subsubsection{Eukaryontische Zelllinien}

RI Murine embryonale Stammzellen Dr. A. Nagi, Toronto, Canada

\subsubsection{Mauslinien}

Die Mauslinien C57B1/6J und 129/Sv wurden von den Charles River Laboratorien in Wilmington, USA bezogen und im Tierstall des Instituts für Humangenetik gezüchtet. Die Tiere leben in einem Hell-Dunkel-Rhythmus von je $12 \mathrm{~h}$ bei $22^{\circ} \mathrm{C}$ und $55 \pm 5 \%$ relativer Luftfeuchtigkeit. Das Futter wird von Ssniff-Spezialdiäten (Soest) bezogen.

\subsubsection{Antikörper}

\subsubsection{Primäre Antikörper}

Munc18-Antikörper (Kaninchen)

Max-Planck-Institut für biophysikalische Chemie, Abt.

Neurobiologie, Göttingen

Neuronenspezifischer beta-III-Tubulin-Antikörper Abcam, Cambridge, UK

(Maus)

\subsubsection{Sekundäre Antikörper}

Anti-Maus IgG Cy3 konjugierter Antikörper

Anti-Maus IgG FITC konjugierter Antikörper

\subsubsection{Enzyme}

Platinum-Taq-Polymerase

Invitrogen, Karlsruhe

Proteinase K

Restriktionsenzyme (inkl. Puffer)

DNase I, Amplification Grade
Sigma-Aldrich, Hamburg

Sigma-Aldrich, Hamburg
Sigma-Aldrich, Hamburg

Invitrogen, Karlsruhe

NEB, Frankfurt

Sigma-Aldrich, Hamburg 
Immolase-DNA-Polymerase

RNase-Inhibitoren

Superscript-II

T4-DNA-Ligase
Bioline, Luckenwalde

Invitrogen, Karlsruhe

Invitrogen, Karlsruhe

Promega, Mannheim

\subsubsection{Gebrauchsfertige Reaktionssysteme}

DYEnamic ET-Terminator mix

Immolase Taq

pGEM®T-easy Vector System I

ProbeQuant G-50 Micro Colums

QIAGEN Plasmid Mini Kit

QIAquick Gel Extraction Kit

Rediprime II DNA Labeling System

Superscript ${ }^{\mathrm{TM}} \mathrm{II} \mathrm{RNaseH}$

Reverse Transkriptase

TriReagent
Amersham Pharmacia,

Braunschweig

Bioline, Mannheim

DNA-Polymerase System

Promega, Madison, USA

Amersham Pharmacia,

Braunschweig

Qiagen, Hilden

Qiagen, Hilden

Amersham Pharmacia,

Braunschweig

Invitrogen, Groningen, Niederlande

Sigma-Aldrich, Hamburg

\subsubsection{Labormaterialien}

Die Labormaterialien, die nicht aufgelistet sind, wurden bei Schütt und Krannich (Göttingen) gekauft.

Deckgläser (24 x $60 \mathrm{~mm})$

Glaswaren

Hybond XL

Kühlzentrifugenbecher

Mikroliterpipetten

Objektträger Superfrost
Menzel-Gläser, Braunschweig

Schott, Mainz

Amersham, Braunschweig

Nalgene, Rochester, USA

Pipetman ${ }^{\circledR}$ Gilson Abimed,

Langenfeld

Menzel - Gläser, Braunschweig 
PCR-Gefäße

Petrischalen

Pipettenspitzen mit Filter

Pipettenspitzen ohne Filter

Quarz-Küvetten

Reaktionsgefäße

Reaktionsgefäße (RNase-frei)

RotiPlast-Paraffin

Transfekionsbehälter

Whatman-Blottingpapier

X-Ray-Filme
Molecular BioProducts, San Diego, USA

Greiner, Nürtingen

Biozym, Hessisch Oldendorf

Eppendorf, Hamburg

Hellma, Mühlheim

Eppendorf, Hamburg

Brand, Wertheim

Roth, Karlsruhe

Lab-Tek/Nalge, Nunc, IL, USA

Schleicher and Schüll, Dassel

Amersham, Braunschweig

\subsubsection{Gebrauchswaren für die Zellkultur}

Auslaufpipetten

Elektroporationsküvette

Falcon-Filter

Filtrationseinheit

Kryoröhrchen

Kulturschalen $(6 \mathrm{~cm}$ und $10 \mathrm{~cm})$

Objektträger für die Zellkultur

Pasteurpipetten

6-cm-Platten

Spritzen (5 $\mathrm{ml}$ und $10 \mathrm{ml}$ )

Sterilfilter

24-Loch-Platte

96-Loch-Platte

14-ml-Zentrifugenröhrchen

Zellkulturflaschen
Sarstedt, Nümbrecht

BioRad, München

BD Biosciences, Heidelberg

Nalgene, Rochester, USA

Greiner, Nürtingen oder Sarstedt,

Nümbrecht

Nunc, Wiesbaden

BD Biosciences, Heidelberg

Brand, Wertheim

Nunc, Wiesbaden

BD Biosciences, Heidelberg

Sartorius, Göttingen

Greiner, Nürtingen oder Nunc,

Wiesbaden

Greiner, Nürtingen oder Nunc,

Wiesbaden

Corning, New York, USA

Greiner, Nürtingen oder Sarstedt, Nümbrecht 


\subsubsection{Geräte}

Nicht gesondert aufgeführte Geräte wurden von den Firmen Schütt bzw. Krannich, Göttingen, bezogen.

Accu-Jet

Automated DNA-Sequencer

MegaBace 1000

Brutschrank IR Autoflow Incusafe

Dampfdruckautoklav

Einbettungsmaschine

Eppendorf-Zentrifuge 5415 D

Eppendorf-Zentrifuge $5417 \mathrm{R}$

FACScan $^{\mathrm{TM}}$ Durchflusscytometer

Fluoreszenzmikroskop BX60

Gene Pulser

Lichtmikroskop

Mikrotom

Mikrowelle

MWG Primus $96^{\text {plus }}$ Thermocycler

PTC-100 ${ }^{\text {TM }}$ Peltier Thermal Cycler

Sterilbank HERAsafe

Thermomixer

TurboblotterTM

Ultraspec 3000 pro Spektralphotometer

UV-Transilluminator

MXX-612 Waage

Zentrifuge Biofuge 13

Zentrifuge Hettich Universal

Zentrifuge Heraeus Megafuge 1.0
Brand, Wertheim

GE Healthcare, München

Sanyo, Tokyo, Japan

Webco, Bad Schwartau

Thermo Fisher, Waltham, USA

Eppendorf, Hamburg

Eppendorf, Hamburg

Becton - Dickinson, Heidelberg

Olympus, Planegg

BioRad, München

Zeiss, Göttingen

Leica, St. Gallen, Schweiz

Philips, Hamburg

MWG Biotech, Ebersberg

BioRad, München

Heraeus, Hanau

Eppendorf, Hamburg

Schleicher \& Schüll, Dassel

Invitrogen, Karlsruhe

Herolab, Wiesloch

Denver Instrument, Göttingen

Heraeus, Hanau

Hettich, Tuttlingen

Heraeus, Hanau 


\subsection{Methoden}

\subsubsection{Isolierung von Nukleinsäuren}

\subsubsection{Isolierung von Plasmid-DNA aus Escherichia coli}

(nach Sambrook et al. 1989)

$5 \mathrm{ml}$ LB-Medium mit einem entsprechenden Antibiotikum wurden mit einer einzelnen E.coli-Kolonie beimpft und in einem Inkubator bei $37^{\circ} \mathrm{C}$ für $16 \mathrm{~h}$ geschüttelt. Nach dieser Inkubation wurde das Medium bei $4.000 \mathrm{x} g$ für $10 \mathrm{~min}$. abzentrifugiert und der Niederschlag, welcher die Bakterien enthielt, in $100 \mu \mathrm{l}$ P1-Lösung resuspendiert. Mit $200 \mu 1$ P2-Lösung wurden die Zellen dann alkalisch gelöst und eine Neutralisierung und der Stopp der Reaktion erfolgten durch Zugabe von $150 \mu$ P3-Lösung. Um Proteine und genomische DNA von der Plasmid-DNA zu trennen, wurde zunächst $10 \mathrm{~min}$. bei 10.000 $\mathrm{x} g$ und $4^{\circ} \mathrm{C}$ zentrifugiert, der plasmidhaltige Überstand in ein neues Eppendorf-Gefäß überführt und nochmals zentrifugiert. Der Überstand wurde wiederum in ein neues ECup transferiert und die DNA mit 1ml 100\%-Ethanol ausgefällt. Anschließend wurde die Lösung für $30 \mathrm{~min}$. bei $-20^{\circ} \mathrm{C}$ gelagert, um dann erneut für $15 \mathrm{~min}$. bei maximaler Geschwindigkeit und $4^{\circ} \mathrm{C}$ zentrifugiert und der Überstand verworfen. Der Niederschlag wurde mit 70\%-Ethanol gewaschen und nach dem Trocknen an der Luft in $30 \mu \mathrm{l}$ Ampuwa gelöst.

P1:

$50 \mathrm{mM}$ Tris- $\mathrm{HCl},(\mathrm{pH} 8,0)$

$10 \mathrm{mM}$ EDTA

$100 \mu \mathrm{g} / \mathrm{ml}$ RNAse A

P2:

$200 \mathrm{mM} \mathrm{NaOH}$

$1 \%$ SDS

P3:

3,0 M Kaliumacetat, (pH 5,5)

\subsubsection{Isolierung genomischer DNA aus Geweben}

(nach Laird et al. 1991) 


\subsection{Isolierung genomischer DNA aus Geweben mittels Lysepuffer I}

$\begin{array}{ll}\text { Lysepuffer I: } & 100 \mathrm{mM} \text { Tris/ } \mathrm{HCl}(\mathrm{pH} 8,0) \\ & 100 \mathrm{mM} \text { EDTA } \\ & 0,5 \% \mathrm{SDS}\end{array}$

Biopsien von Mäuseschwänzen von einer Länge bis zu $0,5 \mathrm{~cm}$ wurden über Nacht in $700 \mu \mathrm{l}$ Lysepuffer und $35 \mu \mathrm{l}$ Proteinase $\mathrm{K}(10 \mu \mathrm{g} / \mu \mathrm{l})$ bei $55{ }^{\circ} \mathrm{C}$ inkubiert und geschüttelt. Der Ansatz wurde anschließend für 10 min. bei 8000 x $g$ zentrifugiert und der Überstand in ein neues E-Cup überführt. Nach Hinzufügen des gleichen Volumens an Isopropanol und einer 15-minütigen Inkubation auf Eis wurde für weitere $15 \mathrm{~min}$. zentrifugiert. Die DNA wurde mit 70\%-Alkohol gewaschen und nach dem Lufttrocknen in ca. $80 \mu \mathrm{l}$ Ampuwa gelöst und bei $4^{\circ} \mathrm{C}$ gelagert.

\subsection{Isolierung genomischer DNA mit Viagen DirectPCR-Tail (Peqlab, Erlangen)}

Das Gewebe wurde mit $150 \mu$ Viagen DirectPCR-Tail (Peqlab, Erlangen) und $5 \mu 1$ Proteinase $\mathrm{K}$ über Nacht bei $55^{\circ} \mathrm{C}$ unter Schütteln inkubiert und konnte nach weiteren 50 min. Inkubation bei $80^{\circ} \mathrm{C}$ mit anschließender Zentrifugation zur Polymerasekettenreaktion verwendet werden.

\subsubsection{Isolierung genomischer DNA aus ES-Zellen}

Um DNA aus ES-Zellen zu isolieren, wurde die ES-Zellkultur in einer 24-Loch-Platte mit PBS gewaschen und über Nacht bei $55^{\circ} \mathrm{C}$ mit $500 \mu$ l Lysepuffer II inkubiert. Nach Hinzugabe eines äquivalenten Volumens Isopropanol erfolgte ein Durchmischen der Suspension für 15 min. Nach dem Waschen mit 70\%-Ethanol wurde die DNA in ein Mikrozentrifugenröhrchen mit $80 \mu \mathrm{l}$ Ampuwa übertragen und für $10-20 \mathrm{~min}$. bei $60^{\circ} \mathrm{C}$ gelöst.

Lysepuffer II

$100 \mathrm{mM}$ Tris/HCl (pH 8.0)

5 mM EDTA

$200 \mathrm{mM} \mathrm{NaCl}$ 
$100 \mu \mathrm{g} / \mathrm{ml}$ Proteinase K

$0,2 \%$ SDS

\subsubsection{Isolierung von Gesamt-RNA aus Gewebeproben}

Für die RNA-Isolierung aus Geweben wurden diese nach der Präparation aus den Organismen in flüssigem Stickstoff schockgefroren und ggf. bis zur Bearbeitung bei $80^{\circ} \mathrm{C}$ gelagert. Vor Beginn der Isolation wurden der Arbeitsplatz und die Pipetten mit RNAse-Exitus Plus (Applichem, Darmstadt) behandelt. Zur Gesamt-RNA-Isolierung aus tierischen Geweben wurde peqGOLDTriFast (Peqlab, Erlangen) verwendet. 100$200 \mu \mathrm{l}$ Gewebe wurden mit einem Plastik-Mörser in 1-2 ml peqGOLD TriFast homogenisiert. Das Volumen der Probe sollte 10\% des Reagenz-Volumens nicht übersteigen. Nach 5-minütiger Inkubation bei Raumtemperatur, um die komplette Dissoziation von Nukleoproteinstrukturen zu gewährleisten, wurden pro ml TriFast 200 $\mu 1$ Chloroform hinzugegeben. Die Suspension wurde mit einem Vortex kräftig geschüttelt und für 10 min. bei RT inkubiert. Durch Zentrifugation bei 12000 x $g$ für 15 min. bei $4^{\circ} \mathrm{C}$ entstanden 3 Phasen, eine obere wässrige Phase, eine mittlere Interphase und eine untere organische Phase. Die farblose wässrige Phase, die die RNA enthielt, wurde in ein neues E-Cup überführt und mit $500 \mu$ I Isopropanol ausgefällt. Nach Waschen des Pellets mit 70\%-Ethanol und Trocknen wurde die RNA in 15-50 $\mu 1$ DEPC- $\mathrm{H}_{2} \mathrm{O}$ gelöst und bei $-80^{\circ} \mathrm{C}$ gelagert.

\subsubsection{Bestimmung der Konzentration von Nukleinsäuren}

Die Konzentration von Nukleinsäuren wurde photometrisch bestimmt, indem die Absorption durch die Proben bei $260 \mathrm{~nm}$ und $320 \mathrm{~nm}$ gegen steriles Wasser bestimmt wurde. Die Konzentration wurde mittels der erhaltenen Werte für die Absorption nach dem Lambert-Beer-Gesetz berechnet:

$\mathrm{C}=(\mathrm{E} 260-\mathrm{E} 320) \times \mathrm{f} \times \mathrm{c}$

$\mathrm{C}=$ Konzentration der Probe $(\mu \mathrm{g} / \mu \mathrm{l})$

E 260 $=$ Absorption bei $260 \mathrm{~nm}$

E $320=$ Absorption bei $320 \mathrm{~nm}$

$\mathrm{f}=$ Verdünnungsfaktor

$\mathrm{c}=$ Konzentration $($ Standard $) /$ Absorption $($ Standard $)$ 
für doppelsträngige DNA : $\mathrm{c}=0,05 \mu \mathrm{g} / \mu 1$

für RNA : $\mathrm{c}=0.04 \mu \mathrm{g} / \mu \mathrm{l}$

für einzelsträngige DNA : $\mathrm{c}=0,03 \mu \mathrm{g} / \mu \mathrm{l}$.

\subsubsection{Gelelektrophorese}

Mittels Gelelektrophorese können unterschiedlich geladene Makromoleküle wie etwa Nukleinsäuren oder Proteine voneinander getrennt werden. Die Verbindungen wandern entsprechend ihrer Beweglichkeit durch ein elektrisches Feld. Die Beweglichkeit ist dabei direkt proportional zu dem Verhältnis der Ladung zur Masse.

\subsubsection{Agarosegelelektrophorese von DNA}

Zum Auftrennen von DNA-Fragmenten verschiedener Länge wurden Agarosegele verwendet. Je nach Fragmentlänge wurden dabei 1-1,5 g Agarose in $100 \mathrm{ml}$ 0,5 x TBEPuffer durch Kochen gelöst. Nach Herunterkühlen auf ca. $60^{\circ} \mathrm{C}$ wurde ein Tropfen Ethidiumbromid $(0,5 \mu \mathrm{g} / \mu \mathrm{l})$ hinzugefügt, welches als interkalierende Substanz die DNA später unter UV-Licht bei $354 \mathrm{~nm}$ als Bande sichtbar macht. Das Gel wurde in eine horizontale Form gegossen und bei $4^{\circ} \mathrm{C}$ zum Aushärten gekühlt. Mit DNA und jeweils dem fünften Teil des Volumens der DNA an Ladepuffer sowie 1 kb-Leiter als Marker beladene Gele wurden in 0,5 x TBE-Puffer je nach Konzentration an eine Spannung von 60-130 V angeschlossen, um ein elektrisches Feld zu erzeugen, durch das die Moleküle dann gewandert sind.

\subsubsection{Agarosegelelektrophorese von RNA}

(nach Hodge 1994)

RNA-Moleküle haben oft komplementäre Regionen, so dass sie Doppelstränge bilden können. Um dies zu verhindern, wurde die RNA vor dem Beladen mit Formaldehyd und Formamid behandelt und auf ein denaturierendes Formaldehyd-haltiges Gel aufgetragen. Für eine große Gelkammer wurden $2 \mathrm{~g}$ Agarose durch Aufkochen in 148 $\mathrm{ml}$ DEPC-Wasser und $20 \mathrm{ml}$ 10x MOPS gelöst. Die auf $50^{\circ} \mathrm{C}$ herabgekühlte Lösung wurde dann mit 33,2 ml Formaldehyd (37\%) versetzt und nach Mischen in eine 
horizontale Gelkammer gegossen. Für eine kleinere Gelkammer wurde die Hälfte der Mengen verwendet. Als Laufpuffer fungierte 1x MOPS. Ca. $15 \mu \mathrm{g}$ RNA wurden mit DEPC-Wasser auf $6 \mu$ l aufgefüllt und mit dem doppelten Volumen an Proben-Puffer (45 $\mu 1$ 10x-MOPS-Puffer, $75 \mu$ l Formaldehyd und $180 \mu 1$ Formamid (40\%) für $200 \mu \mathrm{l}$ ) versetzt und bei $65^{\circ} \mathrm{C}$ für $10 \mathrm{~min}$. denaturiert. Anschließend wurde der Ansatz für 5 min. auf Eis abgekühlt. Nachdem ein Drittel des Ansatzvolumens an Lade-Puffer (enthält 0,1\% Ethidiumbromid) hinzugegeben worden war, konnte das Gel mit der RNA beladen werden. Um die Längen der Ribonukleinsäuren zu bestimmen, wurde als Marker eine Molekulargewicht-Leiter (0,5-10-kb-RNA-Leiter) mit aufgetragen. Bei $4^{\circ} \mathrm{C}$ wurde die RNA bei einer Spannung von $25 \mathrm{~V}$ ca. 16-20 h lang aufgetrennt.

\subsubsection{Isolierung von DNA-Fragmenten nach Auftrennung durch Gelelektrophorese}

Zur Extraktion bestimmter DNA-Fragmente einer Länge von 70 bp bis $10 \mathrm{~kb}$ nach Gelelektrophorese wurde das QIAquick ${ }^{\circledR}$ Gel Extraction Kit verwendet. Zu einem ausgeschnittenen DNA-Fragment in Agarosegel wurde das dreifache Volumen an QGPuffer gegeben und dieses unter mehrmaligem kräftigen Mixen für $10 \mathrm{~min}$. bei $50{ }^{\circ} \mathrm{C}$ inkubiert. Nach kompletter Lösung des Gels wurde je mg Gel 1ml Isopropanol zur Ausfällung der DNA hinzugegeben und die Flüssigkeit nach Schütteln in eine Säule (spin colum) überführt und für $1 \mathrm{~min}$. bei $22.000 \times \mathrm{g}$ zentrifugiert. Die Säule enthält einen Filter mit einer speziellen Silikon-Gel-Membran, an die selektiv DNA gebunden wird. Der Durchschlag wurde verworfen und die Säule mit 0,75 ml PE-Puffer gewaschen. Anschließend konnte die Säule in ein neues Zentrifugenröhrchen überführt und die DNA in zwei Schritten mittels 20-50 $\mu$ EB-Puffer durch weitere Zentrifugation eluiert werden.

\subsubsection{Enzymatische Modifikation von DNA}

\subsubsection{Spaltung von DNA mittels Restriktionsendonukleasen}


Zum Verdau von doppelsträngiger DNA wurde diese mit 5-10 U Restriktionsenzym pro $\mu \mathrm{g}$ DNA und dem vom Hersteller empfohlenen Puffer beim jeweiligen Temperaturoptimum von in der Regel $37^{\circ} \mathrm{C}$ ca. 1-3 h inkubiert.

\title{
2.2.5.2 Ligation von DNA Produkten in pGEM ${ }^{\circledR}$ T easy-Vektor (TA- Klonierung)
}

(nach Clark 1988; Hu 1993)

Zur Klonierung von DNA-Fragmenten wurde das Vektorsystem pGEM $^{\circledR} \mathrm{T}$ easy benutzt. Hierbei wird ausgenutzt, dass viele DNA-Polymerasen 3'- Adeninüberhänge produzieren. Dies tun sie durch ihre terminale Transferase-Aktivität, die zu einem nicht-komplementären Anfügen eines Nukleotids führt, wobei vor allem dATPs gebunden werden. Diese sind komplementär zum 5'-Thyminüberhang des linearisierten $\mathrm{pGEM}^{\circledR} \mathrm{T}$ easy-Vektors, so dass das PCR-Produkt integriert werden kann. Für die Ligation wurde folgender Ansatz über Nacht bei $4^{\circ} \mathrm{C}$ gekühlt:

\author{
$30 \mu \mathrm{g}$ Vektor-DNA \\ 50-100 $\mu$ g Insert DNA (1:3, Vector: Insert Verhältnis) \\ $5 \mu$ Ligase-Puffer $(2 \mathrm{x})$ \\ $1 \mu \mathrm{l}$ T4-DNA-Ligase $(5 \mathrm{U} / \mu \mathrm{l})$ \\ in einem Gesamtvolumen von $10 \mu 1$.
}

\subsubsection{Transformation kompetenter E-coli-Bakterien}

(nach Ausubel et al. 1994)

$\mathrm{Zu}$ 5-10 $\mu$ l Ligationsansatz wurden $50 \mu$ l einer Suspension kompetenter DH5 $\alpha$ (Hanahan, 1983) gegeben und vorsichtig gemischt. Nach einer 30minütigen Inkubation auf Eis, in der sich der Vektor außen an die Zellen anlagert, wurden die Bakterienmembranen durch einen Hitzeschock $\left(42^{\circ} \mathrm{C}\right.$ für $\left.45 \mathrm{~s}\right)$ durchlässig für den Vektor gemacht und dann für 2 min. auf Eis abgekühlt. Nach Zugabe von $950 \mu 1$ S.O.C-Medium (Invitrogen) wurden die transformierten Zellen zur Erholung für $1 \mathrm{~h}$ bei $37^{\circ} \mathrm{C}$ geschüttelt. 200 bis $400 \mu 1$ der transformierten Zellen wurden schließlich auf vorgewärmte LB-Agar-Platten ausplattiert, die je nach Resistenz des Vektors ein entsprechendes Antibiotikum sowie 1mM IPTG und $40 \mathrm{mg} / \mathrm{ml}$ X-Gal enthielten. 
Letztere dienen der Blau-Weiß-Selektion, mittels welcher erkannt werden kann, ob die Klone das Plasmid enthalten. Die Platten wurden bei $37^{\circ} \mathrm{C}$ für $12-16 \mathrm{~h}$ inkubiert.

\subsubsection{Polymerasekettenreaktion (PCR)}

(nach Saiki et al. 1988)

Eine der wichtigsten Methoden in der Molekularbiologie ist die Polymerasekettenreaktion (PCR), die zur exponentiellen in-vitro-Amplifikation von Nukleinsäuren benutzt wird und mit der wegen der großen Sensitivität selbst minimale Mengen an DNA nachgewiesen werden können. Für die Amplifikation des gewünschten Produktes werden anhand der Nukleotidsequenz spezifische Primer (kurze ss-DNA-Fragmente von ca. 20 bp Länge) gewählt, wobei es jeweils einen Vorwärts- und einen Rückwärtsprimer gibt, die die DNA-Synthese der komplementären Stränge führen. Die hitzestabile Taq-DNA-Polymerase (Chien et al. 1976) katalysiert die Synthese neuer DNA. Hierbei liest das Enzym die Basensequenz eines Stranges $\mathrm{ab}$ und synthetisiert eine hierzu komplementäre Nukleinsäure. Um beginnen zu können, benötigt das Enzym Primer, die, wie oben beschrieben, für beide Stränge vorliegen, so dass beide Teile der Doppelkette abgelesen werden und jeweils in 5'- nach 3'- Richtung neue Nukleotide angefügt werden können. Das PCR-Produkt ist folglich ein DNA-Fragment, welches von den Sequenzen bzw. komplementären Sequenzen beider Primer flankiert wird.

\subsubsection{PCR-Amplifikation von DNA-Fragmenten}

Die Amplifikation mittels PCR fand in einem automatischen Thermocycler statt. Folgende Protokolle für PCR-Reaktionen wurden verwendet:

Für Brunol4-Amplifikation

$$
\begin{aligned}
& \text { 1,0 } \mu 1 \text { DNA } \\
& 0,5 \mu 1 \mathrm{Br} 4-\mathrm{F} 2(10 \mathrm{mM}) \\
& 0,5 \mu \mathrm{l} \mathrm{Br} 4-\mathrm{R} 2(10 \mathrm{mM}) \\
& 0,5 \mu \mathrm{l} \mathrm{GFP-R3}(10 \mathrm{mM}) \\
& 0,5 \mu 110 \mathrm{mM} \text { dNTPs }
\end{aligned}
$$


2,5 $\mu \mathrm{l}$ 10x PCR buffer

$0,75 \mu \mathrm{l} 50 \mathrm{mM} \mathrm{MgCl} 2$

$0,3 \mu \mathrm{l}$ Immolase-Taq-DNA-Polymerase ( $5 \mathrm{U} / \mu \mathrm{l})$

mit Ampuwa auf $25 \mu$ aufgefüllt

Für Brunol1-Amplifikation

1,0 $\mu 1$ DNA

1,0 $\mu$ l B1-Gen-F(10 mM)

1,0 $\mu 1 \mathrm{~B} 1-14585 \operatorname{Del}(10 \mathrm{mM})$

1,0 $\mu$ l PGK-352-R (10 mM)

$0,5 \mu 110 \mathrm{mM}$ dNTPs

2,5 $\mu 1$ 10x PCR buffer

$1,5 \mu \mathrm{l} 50 \mathrm{mM} \mathrm{MgCl} 2$

0,3 $\mu \mathrm{l}$ Immolase Taq-DNA-Polymerase ( $5 \mathrm{U} / \mu \mathrm{l})$

mit Ampuwa auf $25 \mu$ l aufgefüllt

Für SRY-PCR

$1,0 \mu 1$ DNA

1,0 $\mu$ l SRYneuF2 (10 mM)

1,0 $\mu$ l SRYneuR2(10 mM)

$0,25 \mu 110 \mathrm{mM}$ dNTPs

2,5 $\mu 110 x$ PCR buffer

$0,5 \mu \mathrm{l} 50 \mathrm{mM} \mathrm{MgCl} 2$

$0,3 \mu$ Platinum-Taq-DNA-Polymerase ( $5 \mathrm{U} / \mu \mathrm{l})$

mit Ampuwa auf $25 \mu$ l aufgefüllt.

Der Reaktionsansatz durchlief in $200 \mu 1$ Reaktionsgefäßen in einem Thermocycler Zyklen verschiedener Temperaturen.

Für Brunol4-Amplifikation

Initiale Denaturierung $95^{\circ} \mathrm{C} 5 \mathrm{~min}$.

Denaturierung $95^{\circ} \mathrm{C} 30 \mathrm{~s}$

Primerhybridisierung $60^{\circ} \mathrm{C} 30$ s $35 \mathrm{x}$

Elongation $72^{\circ} \mathrm{C} 45 \mathrm{~s}$

Auffüllreaktion $72^{\circ} \mathrm{C} 10 \mathrm{~min}$. 
Speicher $8^{\circ} \mathrm{C}$

Für Brunol1-Amplifikation

Initiale Denaturierung $95^{\circ} \mathrm{C} 5 \mathrm{~min}$.

Denaturierung $94^{\circ} \mathrm{C} 30 \mathrm{~s}$

Primerhybridisierung $63^{\circ} \mathrm{C} 45$ s $35 \mathrm{x}$

Elongation $72^{\circ} \mathrm{C} 1 \mathrm{~min}$.

Auffüllreaktion $72^{\circ} \mathrm{C} 10 \mathrm{~min}$.

Speicher $8^{\circ} \mathrm{C}$

Für SRY-Amplifikation

Initiale Denaturierung $95^{\circ} \mathrm{C} 5 \mathrm{~min}$.

Denaturierung $94^{\circ} \mathrm{C} 30 \mathrm{~s}$

Primerhybridisierung $62^{\circ} \mathrm{C} 45$ s 30x

Elongation $72^{\circ} \mathrm{C} 1 \mathrm{~min}$.

Auffüllreaktion $72^{\circ} \mathrm{C} 5 \mathrm{~min}$.

Speicher $8^{\circ} \mathrm{C}$.

Außerdem wurde für RT-PCRs das Brunol4 Protokoll mit leicht veränderter Primerhybridisierungstemperatur verwendet.

\subsubsection{Reverse-Transkriptase-PCR (RT-PCR)}

Reverse-Transkriptase-PCR ist ein Verfahren, mit dem mittels RNA-Vorlagen cDNA hergestellt und mittels PCR amplifiziert werden kann. $5 \mu \mathrm{g}$ Gesamt-RNA wurden zunächst in einem RNAse-freien Reaktionsröhrchen in $8 \mu \mathrm{H}_{2} \mathrm{O}$ mit $1 \mu 1$ 10-xReaktionspuffer versetzt und mittels 15-minütigem Verdau durch $1 \mu$ Amplification Grade DNAse I von Verunreinigung durch DNA befreit. Anschließend wurde $1 \mu \mathrm{l}$ Stopp-Lösung hinzugegeben. Der Ansatz wurde dann für 10 min. auf $70^{\circ} \mathrm{C}$ erhitzt, um das Enzym und die RNA zu denaturieren, anschließend folgte eine Kühlung auf Eis. Nach dem DNAse-Verdau folgte die eigentliche Reverse-Transkriptase-Reaktion. Für die RT-PCR wurde Superscript II RT (Invitrogen) verwendet. Der Ansatz wurde mit 1 $\mu 1$ Oligo (dT) Primer (10 $\mu \mathrm{M}), 1 \mu 110 \mathrm{mM}$ dNTP-Mischung und Ampuwa auf $13 \mu \mathrm{l}$ aufgefüllt und für $5 \mathrm{~min}$. bei $65^{\circ} \mathrm{C}$ denaturiert und auf Eis abgekühlt. Nach einer kurzen Zentrifugation wurden folgende Komponenten hinzugegeben: 
$4 \mu 15 x$ First strand - Puffer

$2 \mu 10,1$ M DTT.

Der Inhalt des Röhrchens wurde gründlich gemischt und für $2 \mathrm{~min}$. bei $42^{\circ} \mathrm{C}$ inkubiert. Anschließend wurde $1 \mu \mathrm{l}$ Reverse Transkriptase (Superscript II RT, Invitrogen) zum Starten der Reaktion hinzugefügt und zur cDNA-Synthese für 50 min. auf $42{ }^{\circ} \mathrm{C}$ erwärmt. Die Reaktion wurde schließlich durch 15-minütiges Erhitzen auf $70^{\circ} \mathrm{C}$ gestoppt. Die cDNA konnte nun als Vorlage für die PCR (wie oben beschrieben) genutzt werden.

\subsubsection{Blot-Techniken}

\subsubsection{Southern-Blot-Technik für den Transfer von DNA auf Nitrozellulose-Filter}

(nach Southern 1975)

Für den Transfer von DNA auf Nitrozellulose-Filter nach Agarosegelelektrophorese mittels eines Turbo-Blot-Apparates (Schleicher \& Schuell, Dassel) wurde die hohe Löslichkeit von Nukleinsäuren in 20x SSC-Puffer genutzt. Die Flüssigkeit wird dabei durch Kapillarkräfte durch das Gel auf die Nitrocellulose-Membran gezogen und mit ihr die DNA, die dann in der Membran-Matrix hängen bleibt. Nach der Elektrophorese wurde das Gel zunächst für $10 \mathrm{~min}$. in $0,25 \mathrm{M} \mathrm{HCl}$ depuriniert, für 30 min. mit Denaturierungslösung behandelt und anschließend $45 \mathrm{~min}$. lang in Neutralisierungslösung gelegt. Zum Transfer der DNA auf die NitrozelluloseMembran im Turbo Blotter wurden etwa 20 Whatman-Papiere (GB003), 4 WhatmanPapiere (GB002) und ein mit 2x SSC angefeuchtetes GB 002 Whatman-Papier übereinander geschichtet und die ebenfalls in 2x SSC angefeuchtete Membran oben aufgelegt. Auf der Membran wurde das Agarosegel platziert. Die Schicht wurde mit drei mit 2x SSC angefeuchteten Whatman-Papieren ( GB002) bedeckt und als Puffer wurde 20x SSC hinzugegeben. Mittels eines weiteren mit 20x SSC angefeuchteten Whatman-Papiers als Brücke wurde eine Verbindung zwischen dem Puffer-Reservoir und der Gel-Filterschicht hergestellt. Für den Transfer wurde die Vorrichtung über Nacht belassen. Der Filter wurde dann kurz in 2x SSC gewaschen und zum Fixieren der DNA für $2 \mathrm{~h}$ bei $60^{\circ} \mathrm{C}$ gebacken. 


\subsubsection{Northern-Blot-Technik für den Transfer von RNA auf Nitrozellulose-Filter}

Für den Transfer von RNA auf Nitrozellulose-Papier wurde ein ähnliches Prinzip wie das des Southern Blots verwandt. Das Gel wurde zunächst in 2x SSC-Puffer gewaschen. In einer Schale wurden 27 trockene Whatmann-Papiere übereinander geschichtet, auf ein weiteres in 20x SSC-Puffer angefeuchtetes Papier wurde die in 2x SSC angefeuchtete Nitrozellulose-Membran ausgebreitet und auf dieser das Gel so ausgerollt, dass sich keine Luftblasen zwischen Gel und Membran befanden. Zum Abschluss wurden 3 in 20x SSC-Puffer angefeuchtete Whatman-Papiere aufgelegt und eine Brücke aus ebenfalls feuchtem Whatman-Papier in ein Reservoir mit 20x SSC-Puffer geleitet. Über Nacht wurde nun der Puffer durch Gel und Membran bis in den Speicher aus Whatman-Papieren gezogen und so die RNA auf die Membran transportiert. Zuletzt wurde die RNA durch zweistündiges Backen bei $80^{\circ} \mathrm{C}$ auf der Membran fixiert.

\subsubsection{Random-Prime-Methode zur Herstellung ${ }^{32}$ P-markierter DNA}

(nach Denhardt 1966; Feinberg and Vogelstein 1989)

Für die radioaktive Markierung von DNA-Proben wurde das Rediprime ${ }^{\mathrm{TM}}$ II Random Prime Labelling System (Amersham Pharmacia) verwendet. Diese Methode basiert auf dem von Feinberg und Vogelstein (1989) entwickelten Prinzip des random priming. 25-50 ng DNA wurden durch 10-minütiges Kochen in TE-Puffer (Gesamtvolumen $46 \mu \mathrm{l}$ ) denaturiert und nach dem Herunterkühlen auf Eis in ein Rediprime II Random Prime Labelling System-Röhrchen pipettiert. Dieses Röhrchen enthält dATP, dGTP, dTTP, 4-8 U Klenow-Fragment (ein Fragment der DNAPolymerase I aus E. coli mit 5' $\rightarrow 3^{\prime}$ '- Polymerase-Aktivität und 3' $\rightarrow 5^{\prime}$ 'ExonukleaseAktivität), und Oligodesoxyribonukleotide. $4 \mu \mathrm{l}\left[{ }^{32} \mathrm{P}\right] \mathrm{dCTP}(3000 \mathrm{Ci} / \mathrm{mmol})$ wurden hinzugefügt. Die Markierung der DNA fand für $45 \mathrm{~min}$. bei $37^{\circ} \mathrm{C}$ statt. Anschließend wurde die markierte Sonde durch Zentrifugation in speziellen Zentrifugensäulen von Amersham Pharmacia von nicht eingebautem $\left[{ }^{32} \mathrm{P}\right] \mathrm{dCTP}$ getrennt. 


\subsubsection{Hybridisierung von Nukleinsäuren}

(nach Denhardt 1966)

Die RNA, die zuvor auf eine Nitrozellulose-Membran transferriert wurde, kann mit den radioaktiv markierten Sonden hybridisiert werden. Dazu wurde die Membran nach dem Entfernen der RNA-Leiter durch Abschneiden des entsprechenden Bereichs der Membran zunächst in 2 x SSC-Puffer gewaschen und in eine Hybridisierungsröhre überführt. Um Fehlbindungen der Sonde vorzubeugen, folgte eine Vorhybridisierung mit $10 \mathrm{ml}$ Hybridisierungspuffer und $250 \mu \mathrm{l}$ denaturierter Lachs-DNA für $2 \mathrm{~h}$ bei $65^{\circ} \mathrm{C}$. Anschließend wurde die markierte Sonde für $10 \mathrm{~min}$. bei $95^{\circ} \mathrm{C}$ denaturiert und nach dem Abkühlen zur Hybridisierungslösung hinzugefügt. Die Hybridisierung erfolgte bei $65^{\circ} \mathrm{C}$ über Nacht in einem Hybridisierungsofen, in dem die Röhre permanent gedreht wurde. Nach Beendigung der Hybridisierung wurde die Membran für 10 min. in 2x SSC bei RT gespült. Schließlich wurde sie im bei $60^{\circ} \mathrm{C}$ vorgewärmten Wasserbad in 2x SSC mit 0,1\% SDS gewaschen und nach ca. 10 min. gemessen. Bei hoher Hintergrundstrahlung $\left(>1 \mathrm{~Bq} / \mathrm{m}^{2}\right)$ wurde die Membran anschließend in $0,2 \mathrm{x}$ SSC mit $0,1 \%$ SDS gewaschen. Nach dem Trocknen der Membran wurde diese in Plastikfolie geschweißt und zusammen mit einem Film bei $80^{\circ} \mathrm{C}$ gelagert. Der Film wurde im X-Ray Automatic Processor Curix 60 entwickelt.

\subsubsection{Sequenzierung von DNA}

(nach Sanger et al. 1977)

Die Sequenzanalyse erfolgte nach dem Kettenabbruchverfahren, bei dem es durch Einbau von mit Fluoreszenzfarbstoffen markierten Didesoxynukleotiden (ddNTPs) zu einem Abbruch der Elongation kommt. Dadurch erhält man unterschiedlich große DNA-Fragmente, an deren letzter Stelle sich ein fluoreszierendes ddNTP befindet. Die markierten ddNTPs senden bei Bestrahlung durch einen Argon-Laser fluoreszierendes Licht aus, welches erfasst werden kann. Zur Kettenabbruchreaktion wurde das Dye Terminator Cycle Sequencing-Kit (Applied Biosystems) verwendet.

Für die Reaktion wurde ein Ansatz mit einem Gesamtvolumen von $10 \mu$, welcher 200-800 $\mu \mathrm{g}$ Plasmid DNA, 10 pmol Primer und $4 \mu \mathrm{l}$ DYEnamic ${ }^{\mathrm{TM}}$ ET-Mix (dNTPS, markierte Didesoxynukleotide und Taq-DNA-Polymerase) enthält, bei folgendem Programm im Thermocycler katalysiert: 
Initiale Denaturierung $95^{\circ} \mathrm{C} 1 \mathrm{~min}$.

Denaturierung $95^{\circ} \mathrm{C} 20 \mathrm{~s}$

Primerhybridisierung $55^{\circ} \mathrm{C} 30$ s $25 \mathrm{x}$

Elongation $60^{\circ} \mathrm{C} 2 \mathrm{~min}$.

Auffüllreaktion $75^{\circ} \mathrm{C} 5 \mathrm{~min}$.

Speicher $8^{\circ} \mathrm{C}$.

Nach der Sequenzreaktion wurden die Proben mit Ampuwa auf $20 \mu$ laufgefüllt und durch den MegaBASE 1000 (Amersham) sequenziert. Die Analyse der Sequenzen erfolgte über den Vergleich mit der Referenzsequenz (www.ncbi.nlm.nih.gov).

\subsubsection{Histologische Arbeitsmethoden}

\subsubsection{Gewebepräparation und Fixierung für die Einbettung in Paraffin}

Für die histologische Betrachtung von Geweben wurden diese frisch präpariert nach kurzem Waschen in PBS für 24 h in 4\% Paraformaldehyd oder Bouin'scher Lösung fixiert. Anschließend wurde das Gewebe durch Durchlaufen einer Reihe von Lösungen mit aufsteigenden Ethanolkonzentrationen (70\%, 80\%, 90\%, 96\% und $100 \%$ ) jeweils eine Stunde bei RT für die Paraffineinbettung dehydriert. Zum Entfernen des Ethanols diente eine Inkubation in Isopropanol über Nacht. Nun folgten Behandlungen mit Isopropanol/Xylol im Verhältnis von 3:1, 1:1 und 1:3 für jeweils 3 $\mathrm{h}$ bei RT und schließlich eine Inkubation in reinem Xylol über Nacht. Nach Abgießen des Xylols wurde das Gewebe für eine weitere Nacht in Paraplast bei $60^{\circ} \mathrm{C}$ inkubiert. Dabei wurde das flüssige Paraplast dreimal gewechselt. Schließlich wurde das Gewebe mit geschmolzenem Paraffin übergossen und nach dem Abkühlen bei $4^{\circ} \mathrm{C}$ gelagert.

\subsubsection{Herstellen von Paraffinschnitten}

Aus den Paraffinblöcken wurden mit einem Mikrotom Schnitte mit einer Dicke von 5 $\mu \mathrm{m}$ angefertigt. Durch anschließendes Schwimmen auf $40{ }^{\circ} \mathrm{C}$ warmem Wasser wurde eine völlige Auseinanderfaltung der dünnen Schnitte erreicht, die dann mit Hilfe eines 
feinen Pinsels auf Superfrost-Objektträger aufgetragen werden konnten. Nachdem die Objekträger mit den Präparaten bei $40^{\circ} \mathrm{C}$ getrocknet und für $15 \mathrm{~min}$. auf $60^{\circ} \mathrm{C}$ erwärmt worden waren, um überschüssiges Paraffin zu schmelzen, konnten sie bei RT gelagert bzw. weiterverwendet werden.

\subsubsection{Hämatoxylin \& Eosin - Färbung histologischer Schnitte}

Zur lichtmikroskopischen Beurteilung histologischer Schnitte wurden Paraffinschnitte des Gehirns und der Hoden mit Hämatoxylin und Eosin angefärbt. Dafür wurden die Objektträger zunächst dreimal für je 5 min. in Xylol gewaschen, um letzte Reste an Paraffin zu entfernen. Danach folgte eine Entwässerung der Schnitte durch eine Ethanol-Reihe mit absteigenden Konzentrationen (100\%, 96\%, 80\%, 70\% und 50\%, je 3 min.). Nach einminütigem Waschen in $\mathrm{dH}_{2} \mathrm{O}$ wurden die Präparate für 5 min. mit 1,6\% Hämatoxylin gefärbt und überschüssige Farbe 10 min. unter fließendem Wasser abgewaschen. Je nach gewünschter Farbintensität wurde mit 70\% saurem Ethanol entfärbt. Nach erneutem Waschen in $\mathrm{dH}_{2} \mathrm{O}$ wurde für 2-10 s mit Eosin $(0,1 \%+2 \%$ Essigsäure) gefärbt und wiederum mit $\mathrm{dH}_{2} \mathrm{O}$ gewaschen (1 min.) und in einer aufsteigenden Ethanol-Reihe 50\%, 70\%, 80\%, 90\%, 96\% und 100\% je $3 \mathrm{~min}$. entwässert. Zum Schluss konnten die Schnitte nach zweimaliger Inkubation in Xylol (je 3 min.) mit einem Tropfen Eukitt unter einem Deckgläschen fixiert werden.

\subsubsection{Präparation von Hippocampus-Zellen für Immunhistochemie}

Nach dem Herauspräparieren der murinen Gehirne wurden diese in Dissektionslösung gegeben und unter zweimaligem Erneuern der Lösung die Hippocampi isoliert. Diese wurden dann in maximal $1 \mathrm{~mm}$ große Scheiben geschnitten und mit der Dissektionslösung in Zentrifugenröhrchen überführt bis sich ein Überstand gebildet hat. Nach dem Absetzen wurde der Überstand abgesaugt und das Gewebe zweimal in Dissektioslösung gewaschen. Es wurden $5 \mathrm{ml}$ HANKS- Lösung hinzugegeben und der Ansatz für $5 \mathrm{~min}$. auf Eis gekühlt. Zum Verdau wurden $6 \mathrm{mg}$ Trypsin und 1,5 mg DNAse in $2 \mathrm{ml}$ Digestionslösung gelöst und steril filtriert. Nach Absaugen der HANKS-Lösung wurde die vorbereitete Trypsinisierungslösung hinzugegeben und das Gemisch nach einminütiger Erwärmung mit der Hand für 4-5 min. bei Raumtemperatur stehengelassen. Das Gewebe wurde dann zweimal mit 
Dissektionslösung gewaschen, und es erfolgte eine Zugabe von 2,5 $\mathrm{ml}$ steril filtrierter Inhibitionslösung (2,4 mg Trypsin-Inhibitor gelöst in $4 \mathrm{ml}$ Dissektionslösung). Nach 5-minütiger Einwirkung wurde die Flüssigkeit abgesaugt, die restliche Inhibitionslösung hinzugegeben und weitere $5 \mathrm{~min}$. inkubiert. Es folgte erneutes Waschen mit Dissektionslösung, bevor $0,5 \mathrm{ml}$ Pferde-Serum gemischt mit 2,5 ml steril filtrierter Dissektionslösung hinzugegeben wurde und der Ansatz für $10 \mathrm{~min}$. bei RT inkubiert wurde. Anschließend erfolgte wiederum ein zwei- bis dreimaliges Waschen in Dissektionslösung. $1 \mathrm{mg}$ DNAse wurde in 2,5 $\mathrm{ml}$ Dissektionslösung gelöst und steril filtriert. $1 \mathrm{ml}$ dieser Lösung wurde dann auf die Schnitte gegeben. Nach 5-6 maligem Trituieren mit einer Pipette wurde das Gemisch auf Eis gelagert, bis sich das Gewebe abgesetzt hatte. Nun wurde die Zellsuspension in ein frisches Falcon-Röhrchen überführt und mit der restlichen DNAse-Lösung versetzt. Mit Pasteurpipetten in absteigendem Durchmesser wurde 2-3 mal trituiert bis die Suspension homogen war. Die Suspension der ersten Trituierung wurde hinzugeben und mit Dissektionslösung auf $6 \mathrm{ml}$ aufgefüllt. Nach Zentrifugation bei $4{ }^{\circ} \mathrm{C}$ und 144 x $g$ für 15 min. wurde $1 \mathrm{ml}$ Dissektionslösung hinzugegeben. $50 \mu$ l Suspension wurden mit $50 \mu 1$ Trypanblau gemischt. Nach 1 min. wurden noch lebende Zellen in einer Neubauerzählkammer ausgezählt. Die gewünschte Zellzahl wurde auf Kulturplatten mit Poly-D-Lysine/Laminin beschichteten Deckgläschen ausgesäht, für 30 min. auf der Sterilbank bei $37^{\circ} \mathrm{C}$ in $5 \% \mathrm{CO}_{2}$ inkubiert und mit Kulturmedium A aufgefüllt. Die Zellen wurden in einem Inkubator gelagert. Am vierten Tag wurden das Medium, die Zelltrümmer sowie tote Zellen durch Waschen mit PBS entfernt und durch neues Kulturmedium B ersetzt. Dieses wurde bis zur Verwendung der Zellen alle zwei Tage wiederholt.

\subsubsection{Färbung mit DAPI, Munc18-Antikörper und Beta-III-Tubulin-} Antikörper

Die präparierten und kultivierten Hippocampus-Neurone wurden für die Färbung mit Fluoreszenzsantikörpern zweimal mit PBS gewaschen und bei RT für 30 min. in 4\% Paraformaldehyd in PBS gewaschen. Für 10 min. wurden die Zellen dann mit $50 \mathrm{mM}$ $\mathrm{NH}_{4} \mathrm{Cl}$ in PBS inkubiert und jeweils $3 \times 4$ min. lang mit 0,2\% Triton $\mathrm{x}-100$ in PBS permeabilisiert. Primäre Antikörper gegen Munc18 und Beta-III-Tubulin wurden in einer Verdünnung von 1/100 für $1 \mathrm{~h}$ bei RT hinzugegeben. Anschließend folgte eine 
einstündige Inkubation mit Detektions-Antikörpern, welche mit Cy3 oder FITC konjugiert waren. Die Zellen wurden hinterher mit VectaShield, einem DAPI (4',6Diamidin-2-phenylindol )-enthaltenden Medium, gefärbt, um die Zellkerne sichtbar zu machen. Die immungefärbten Zellen wurden mit einem Fluoreszenzmikroskop (BX60, Olympus) untersucht.

\subsubsection{Untersuchung von Spermien - Parametern}

\subsubsection{Zählen von Spermien in der Cauda epididymidis}

Caudae epididymides von Mäusen wurden unter aseptischen Bedingungen herauspräpariert und in $0,4 \mathrm{ml}$ in-vitro-Fertilisationsmedium (IVF Medium) gelagert. Durch Eröffnen der Caudae konnten die Spermien für $1 \mathrm{~h}$ bei $37^{\circ} \mathrm{C}$ und $5 \% \mathrm{CO}_{2}$ frei in der Lösung schwimmen. Zum Zählen wurde die Spermiensuspension 1:40 mit PBS verdünnt. $5 \mu$ der Suspension wurde in eine Neubauerzählkammer gegeben. Hier wurden die Spermien in 8 unabhängigen Zählkammern (jeweils $0,0025 \mathrm{~mm}^{2}$ ) unter dem Mikroskop BX60 mit x 200 Vergrößerung gezählt. Aus der Anzahl an Spermien pro Zählkammer wurde dann mittels folgender Formel die Gesamtmenge berechnet:

Gesamtmenge $=$ durchschnittliche Anzahl pro Zählkammer $\mathrm{x} 10$ x $400 \mathrm{x}$ Verdünnungsfaktor.

\subsubsection{Spermienmotilität}

Die Spermienmotilität wurde mittels des Computer-assistierten-Spermien-Analyse (CASA)-Systems (CEROS version 10, Hamilton Thorne Research) untersucht. Im Einzelnen wurden die Weggeschwindigkeit (average path velocity, VAP), die progressive Geschwindigkeit (straight line velocity, VSL), Bahngeschwindigkeit (curvilinear velocity, VCL), die Breite des Kopfausschlages des Spermiums (lateral amplitude of the head, ALH), Schlagfrequenz des Spermiumschwanzes (beat cross frequency, BCF) und Geradlinigkeit (straightness, STR) betrachtet. Diese Parameter wurden bei Mutanten und Wildtyp-Tieren nach 1,5 h und 3,5 h verglichen.

\subsubsection{Methoden zur Herstellung von Knockoutmäusen}




\subsubsection{Methoden für die eukaryontische Zellkultur}

Embryonale Stammzellen wurden zusammen mit Mitomycin-C-behandelten embryonalen Feederzellen (EmFi) auf mit 0,2 \% Gelatine beschichteten Kulturschalen ausplattiert. Täglich wurde das Kulturmedium wegen der starken Ansäuerung durch die ES-Zellen gewechselt. Alle 2-3 Tage wurde eine erneute Passagierung der Zellen durchgeführt und Zellen in Trypsin/EDTA-Puffer 1:3 bis 1:8 geteilt. Vor erneutem Ausplattieren der Zellen wurde nach Zentrifugation bei $270 \mathrm{x} g$ für $5 \mathrm{~min}$. bei RT die Trypsinlösung entfernt. Bei jeder Passage wurden ES-Zellen in flüssigem Stickstoff kryokonserviert und als Stocks gelagert.

\subsubsection{Elektroporation und Selektion von ES-Zellen}

Durch die Einwirkung kurzer elektrischer Impulse können Membranen vorrübergehend permeabilisiert werden, ohne dabei zerstört zu werden. Währenddessen kann linearisierte Plasmid-DNA eindringen. Das Konstrukt als linearisierte DNA wurde mit Phenol/Chloroform extrahiert, mit 100\%-Ethanol präzipitiert und und in 70\%-Ethanol gewaschen. Das DNA-Pellet wurde bei RT unter der Sterilbank getrocknet und in $100 \mu$ Elektroporationspuffer gelöst. ES-Zellen wurden nach Trypsinisierung in $9 \mathrm{ml}$ Elektroporationspuffer gewaschen, in einer Neubauerzählkammer ausgezählt und $7 \times 10^{6}$ bis $2 \times 10^{7}$ exponentiell wachsende Zellen wurden in $700 \mu$ Elektroporationspuffer resuspendiert, mit der DNA-Lösung zusammen in eine Küvette gegeben und mit $240 \mathrm{~V}$ und $500 \mu \mathrm{F}$ bei RT elektroporiert (Gene Pulser, BIO RAD). Nach anschließender 20-minütiger Inkubation auf Eis wurden die ES-Zellen in 2x100 mm Kulturschalen auf embryonalen Fibroblasten ausplattiert. Nach 12 bis 16 h konnte die positive Selektion in G418 für 8-9 Tage bis zur Isolierung resistenter Klone und die negative Selektion in Gancyclovir für drei Tage begonnen werden.

\subsubsection{Isolierung und Kryokonservierung von ES-Zellklonen}

Die Zellen wurden für diesen Vorgang einmal mit PBS gewaschen und mit $10 \mathrm{ml}$ PBS bedeckt. Die Klone wurden mit einer sterilen Pipettenspitze von den Fibroblasten abgehoben und in Trypsin-EDTA (0,5 g/1 Trypsin, $0,2 \mathrm{~g} / 1$ EDTA) (PAN) bei $37^{\circ} \mathrm{C}$ in 
96-Loch-Platten dissoziiert. Die Trypsinaktivität wurde durch Zugabe von $50 \mu \mathrm{l}$ ESZellmedium gestoppt. Die einzelnen Klone wurden auf 24-Loch-Platten mit Fibroblasten und ES-Zellmedium übertragen und bei $37^{\circ} \mathrm{C}$ gezüchtet. Nach 2-3 Tagen und Konfluenz wurden die Zellen erneut trypsinisiert. Eine Hälfte der Zellen wurde wiederum auf Fibroblasten ausplattiert, während die restlichen Zellen für die DNAIsolierung auf einer duplicate plate (mit Gelatine behandelte Platte) inkubiert wurden. Erstere Zellen wurden nach dem Konfluieren für 5 min. bei $37^{\circ} \mathrm{C}$ mit $100 \mu \mathrm{l}$ Trypsin/EDTA dissoziiert und mit $100 \mu \mathrm{l} 2$-x-Gefriermedium bei $-80^{\circ} \mathrm{C}$ eingefroren. Die anderen Zellen wurden ebenfalls bis zur Konfluenz gezüchtet bevor DNA extrahiert werden konnte. Homolog rekombinante Klone wurden dann bei $37^{\circ} \mathrm{C}$ in 10 $\mathrm{ml}$ kaltes ES-Zellmedium gegeben, bei 270 x $g$ für 5 min. zentrifugiert und die Zellen auf einer Fibroblastenschicht in 24-Loch-Platten kultiviert. Nach Erreichen der Konfluenz erfolgte eine Trypsinisierung und das Einfrieren in 3-4 Aliquots.

\subsubsection{Herstellung von Chimären}

Für die Herstellung von Chimären wurde die Fähigkeit von Säugetier- Embryonen, fremde Zellen zu inkorperieren und sich zu Chimären zu entwickeln, genutzt. Die Isolierung von Blastozysten, die Injektion der ES-Zellen und der Retransfer in Uteri von pseudoschwangeren Mäusen wurden im Max-Planck-Institut für experimentelle Medizin in Göttingen durchgeführt. Die ES-Zellen stammen aus Mäusen der Linie 129/SvJ, welche eine braune Fellfarbe haben (agouti-Fellmarker). Sie wurden in die Höhlen 3,5 dpc alter Blastozysten, welche aus C57Bl/6J-Weibchen (schwarze Fellfarbe) isoliert wurden, injiziert. Die Embryonen wurden dann kurz (2-3 h) zum Wiederentfalten der Blastozystenhöhle kultiviert und in die Uteri pseudoschwangerer Mäuse implantiert. Der Anteil an Körperzellen der geborenen Chimären, die das rekombinante Allel enthielten wurden anhand des Anteils an brauner Fellfarbe geschätzt.

\subsubsection{Software und Computer Tools}

Genomische und transkriptomische Sequenzen und weitere Informationen über Transkripte und Proteine sowie verschiedene BLAST-Programme für die Analyse von Nukleotidsequenzen wurden vom National Center for Biotechnology Information 
(NCBI) benutzt (www.ncbi.nlm.nih.gov). Informationen über Mauslinien und Phänotypen wurden von der Homepage des Jackson Laboratory bezogen (www.informatics.jax.org). Für statistische Auswertungen wurde Statistica-Software verwendet. Zur Messung von Neuronenfortsätzen wurde die Software von ImageJ verwendet. 


\section{Ergebnisse}

\subsection{Expressionsanalyse von Brunol4}

Bereits 2002 wurde das murine Gen Brunol4 (GeneID 108013) durch Meins et al. identifiziert, charakterisiert und auf Chromosom 18 lokalisiert. Brunol4 wurde der Celf(CUG-BP and ETR-3 like factors) bzw. Brunol- (bruno like) Familie zugeordnet und ist wie die anderen Mitglieder dieser Familie nahe verwandt mit der ELAV-Familie (embryonic lethal abnormal vision). Die Datenbankrecherche (NCBI) der kürzlich aktualisierten Angaben zum Gen Brunol4 ergab eine Größe des Gens von 275 kb bei 13 Exons. Die ersten drei Introns machen mit $74 \mathrm{~kb}, 141,6 \mathrm{~kb}$ und 32,6 kb einen großen Teil des Gens aus. Wie die anderen Mitglieder der ELAV/Brunol-Familie bestehen die meisten Brunol4-Proteinisoformen aus drei RNA-bindenden Domänen (RBD oder RRM für RNA recognition motif) und einem Verbindungsstück (Linker, vgl. Abb.1.1). Für Brunol4 werden sechs Transkript-Varianten sowie sechs dazugehörige Proteinisoformen in NCBI und fünf in Ensembl (vgl. Tab. 3.1 und Abb. 3.1) beschrieben. Vier der Ensembl-Varianten (ENSMUST00000025117, ENSMUST00000035954, ENSMUST00000078609, ENSMUST00000115816) entsprechen jeweils einem in NCBI beschriebenen Transkript. In der 3'-UTR (Exon 13) von drei dieser vier Transkripte (Ensembl) fehlen jedoch 1,5 kb im Vergleich zu den in NCBI beschriebenen entsprechenden Transkripten. Eine weitere Transkriptvariante aus Ensembl (ENSMUST00000115815) ist in Abbildung 3.1 dargestellt. Beginn des ORF (open reading frame) ist in den Transkripten jeweils das Startcodon an Position 357-359 (Exon1). 


\begin{tabular}{|c|c|c|c|c|c|}
\hline Transkript & $\begin{array}{l}\text { Länge } \\
\text { (bp) }\end{array}$ & $\begin{array}{l}\text { Exons (im } \\
\text { Vergleich zu } \\
\text { Transkript- } \\
\text { variante 1) }\end{array}$ & Proteinisoform & $\begin{array}{l}\text { Länge } \\
\text { (aa) }\end{array}$ & $\begin{array}{l}\text { Struktur (im } \\
\text { Vergleich zur } \\
\text { Isoform A) }\end{array}$ \\
\hline $\begin{array}{l}1 \\
\text { NM } 001146292.1 \\
\end{array}$ & 4007 & Exon 1-13 & $\begin{array}{l}\text { A } \\
\text { NP } 001139764.1\end{array}$ & 504 & $\begin{array}{ll}55-132 & \text { RRM1 } \\
152-215 & \text { RRM2 } \\
420-494 & \text { RRM3 }\end{array}$ \\
\hline $\begin{array}{l}2 \\
\text { NM } 001146293.1 \\
\end{array}$ & 3950 & $\begin{array}{l}\text { Splicingvariante } \\
\text { des Exons } 11\end{array}$ & $\begin{array}{l}\text { B } \\
\text { NP } 001139765.1 \\
\end{array}$ & 485 & $\begin{array}{l}\text { Es fehlen } 20 \text { aa } \\
\text { in RRM3 }\end{array}$ \\
\hline $\begin{array}{l}3 \\
\text { NM } 001146294.1 \\
\end{array}$ & 3980 & $\begin{array}{l}\text { Splicingvariante } \\
\text { des Exons } 3\end{array}$ & $\begin{array}{l}\text { C } \\
\text { NP } 001139766.1 \\
\end{array}$ & 495 & $\begin{array}{l}\text { Es fehlen } 10 \text { aa } \\
\text { zwischen } \\
\text { RRM1 und } \\
\text { RRM } 2 \text { sowie } 5 \\
\text { aa in der } \\
\text { Linker-Region }\end{array}$ \\
\hline $\begin{array}{l}4 \\
\text { NM } 133195.3 \\
\end{array}$ & 3947 & $\begin{array}{l}\text { Splicingvariante } \\
\text { des Exons } 11\end{array}$ & $\begin{array}{l}\mathrm{D} \\
\mathrm{NP} 573458.2 \\
\end{array}$ & 484 & $\begin{array}{l}\text { Es fehlen } 20 \text { aa } \\
\text { in RRM3 }\end{array}$ \\
\hline $\begin{array}{l}5 \\
\text { NM } 001146295.1 \\
\end{array}$ & 2258 & $\begin{array}{l}\text { Exons } \\
\text { fehlen, enthält } \\
\text { dafür } 1,5 \mathrm{~kb} \text { des } \\
\text { Introns } 2\end{array}$ & $\begin{array}{l}\text { E } \\
\text { NP } 001139767.1 \\
\end{array}$ & 163 & $\begin{array}{l}\text { Es fehlen } 13 \text { aa } \\
\text { in RRM1, sowie } \\
\text { RRM2, Linker- } \\
\text { Region und } \\
\text { RRM3 } \\
\text { komplett }\end{array}$ \\
\hline $\begin{array}{l}6 \\
\text { NM } 001174074.1 \\
\end{array}$ & 3863 & Exon 11 fehlt & $\begin{array}{l}\text { F } \\
\text { NP } 001167545.1 \\
\end{array}$ & 456 & $\begin{array}{l}\text { Es fehlen } 5 \text { aa } \\
\text { in der Linker- } \\
\text { Region und } 42 \\
\text { aa in RRM3 }\end{array}$ \\
\hline
\end{tabular}

Tab. 3.1: Transkripte und Proteinisoformen von Brunol4

Um die Unterschiede zwischen den in der Datenbank NCBI beschriebenen Transkripten und Proteinisoformen zu verdeutlichen, sind diese hier tabellarisch aufgetragen. In der ersten bzw. vierten Spalte ist die jeweilige ID der Transkriptvariante bzw. der Proteinisoform angegeben. In der zweiten und fünften Spalte ist die Länge der Transkripte (bp für base pairs) bzw. die Länge des dazugehörigen Proteins (aa für amino acids) abzulesen. Variante $1 \mathrm{bzw}$. Isoform A stellen das längste Transkript und das längste Protein dar. Daher wurden in den Spalten drei und sechs die Unterschiede der restlichen Transkripte und Proteinisoformen im Vergleich zu Transkript 1 bzw. Isoform A beschrieben. 


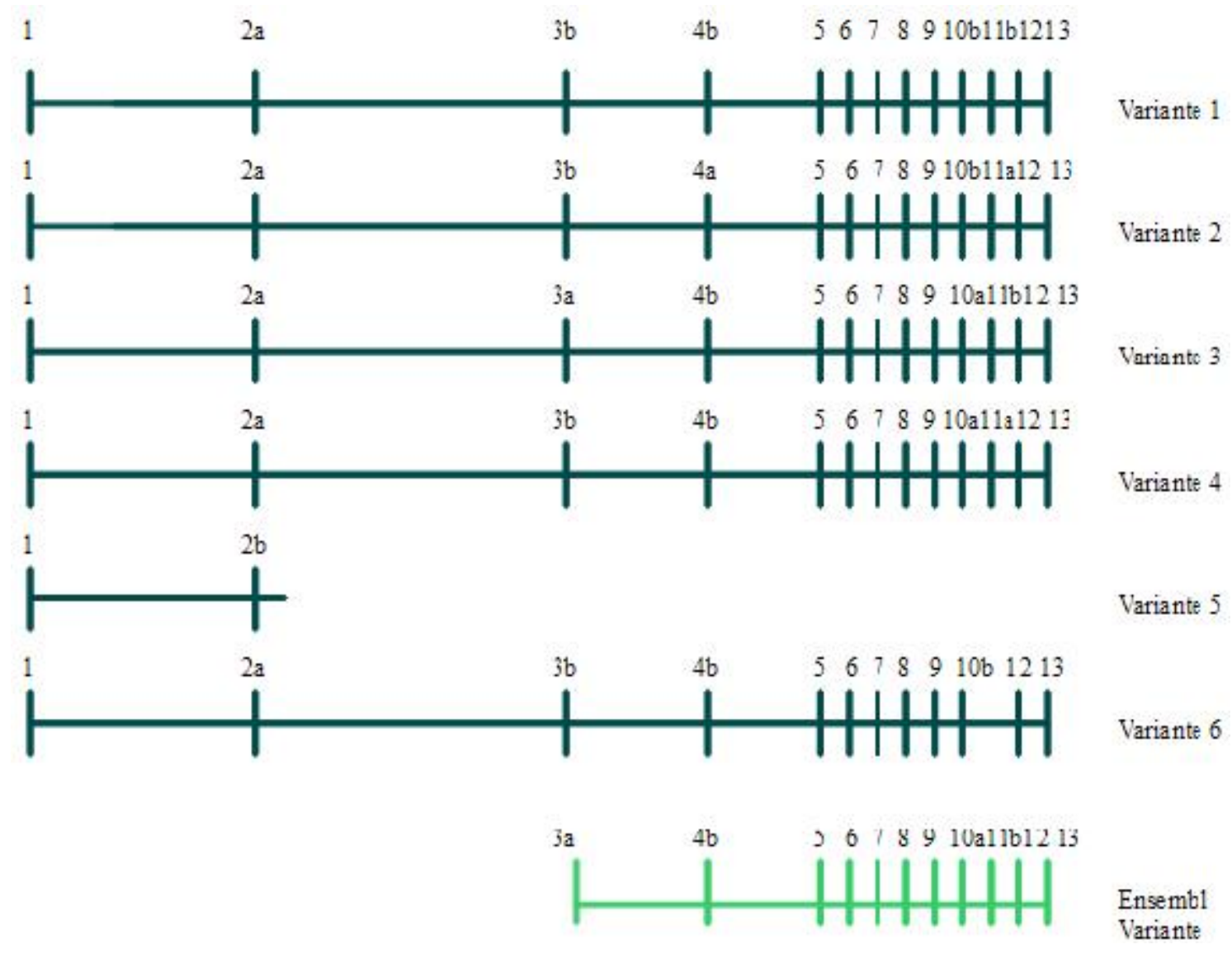

Abb. 3.1: Graphische Darstellung der 6 Transkriptvarianten nach NCBI

In der Abbildung ist das Gen mit den jeweils transkribierten Exons dargestellt. Die in den Transkripten variierenden Exons sind zur Unterscheidung mit kleinen Buchstaben versehen. Die Datenbank Ensembl beschreibt eine weitere Transkriptvariante (hellgrün, Brunol4-204 (ENSMUST00000115815)), welche die Exons 3 bis 13 und ebenfalls eine Splicingvariante des Exons 11 enthält. Im Exon 13 der 1670 bp langen Variante fehlen jedoch in 3'-Richtung etwa 1,5 kb im Vergleich zu den anderen Transkripten.

\subsection{Herstellung einer Brunol4-defizienten Maus}

Bereits für eine frühere Dissertation (Dev 2006) wurde im Institut für Humangenetik ein Konstrukt zur Inaktivierung des Brunol4-Gens hergestellt. Der Versuch, KnockoutMäuse für Brunol4 herzustellen war jedoch nicht erfolgreich (vgl. 1.1). Aufgrund einer Duplikation des Gens Brunol4 konnten in der o.g. Arbeit keine homozygoten Brunol4 ${ }^{-/}$Mäuse generiert werden. Der Targeting-Vektor wurde in eine Kopie des Gens inseriert, während an anderer Stelle das Wildtyp-Gen weiterhin intakt war. Möglicherweise handelte es sich bei dieser Duplikation um eine Neumutation. 
Bei dem verwendeten Konstrukt handelt es sich um einen Targeting-Vektor vom Replacement-Typ. Durch solch einen Vektor können Gensequenzen durch fremde DNA-Fragmente ausgetauscht werden. Für das Konstrukt war, wie in Abbildung 3.2 dargestellt, ein 800 bp langer Abschnitt des Exons 1 und eines nachfolgenden Teils des Introns 1 durch eine GFP-Neo-Kassette ersetzt worden. Neomycin wird für die positive Selektion benötigt, während GFP als Reporter-Gen dient.

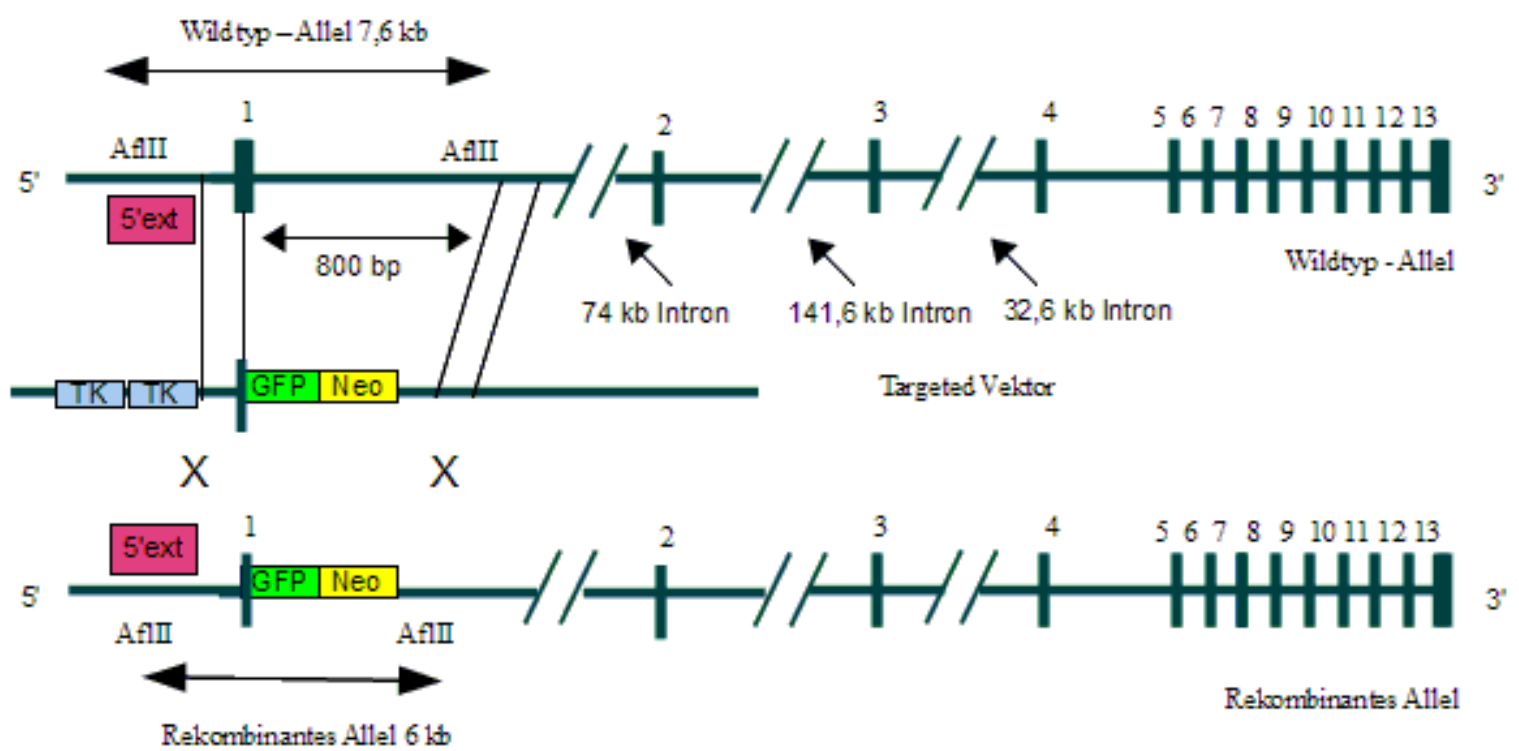

Abb. 3.2: Konstrukt für die zielgerichtete Inaktivierung des Brunol4-Gens (nach Dev 2006, S. 71)

Die Darstellung zeigt schematisch den Vorgang der homologen Rekombination für Teile von Exon 1 und Intron 1 des Brunol4-Gens. A zeigt das Wildtyp-Allel mit seinen 13 Exons. In B ist der Targeting-Vektor dargestellt. Unter $\mathrm{C}$ ist das rekombinante Allel mit dem deletierten Bereich, welcher durch eine GFPNEO Kassette ersetzt wurde, aufgezeichnet. TK: Herpes-simplex-Virus-Thymidinkinase-Kassette für die negative Selektion; 5'ext: Lokalisation der 5'-externen Sonde; AflII: Schnittstelle des Restriktionsenzyms. Der Verdau mit AflII resultierte in einem 7,6 kb großen Fragment im Falle des Wildtyp-Allels und in einem $6 \mathrm{~kb}$ großen Abschnitt des rekombinanten Allels, die durch eine 5'-externe Sonde (ext) im Southern Blot detektiert werden können.

3.2.1 Elektroporation von ES-Zellen mit dem Targeting-Vektor Brunol4 und Selektion homolog rekombinanter Brunol4 $\%-E S$ Zellen 
Für einen weiteren Versuch, eine Brunol4 $^{--}$-Knockout-Maus herzustellen, wurde das Konstrukt im Rahmen dieser Arbeit erneut in embryonale Stammzellen (ES-Zellen) der Linie 129/Sv transfiziert. Hierfür wurden R1-ES-Zellen (129/Sv; Nagy et al. 1993) auf einer konfluenten Lage aus kultivierten, mit Mitomycin $\mathrm{C}$ behandelten primären embryonalen Fibroblasten (EmFi) ausplattiert. Exponentiell wachsende ES-Zellen wurden auf einer Kulturschale (90 mm im Durchmesser) bis auf 7 x $10^{6}$ Zellen kultiviert und anschließend durch Trysinisierung geerntet. Nachdem der Brunol4 TargetingVektor mit dem Enzym PvuI linearisiert und aufgereinigt worden war, wurden diese R1-ES-Zellen mit $50 \mu \mathrm{g}$ der DNA elektroporiert. Anschließend wurden die Zellen nach 20 minütiger Inkubation auf Eis auf einem Nährboden mit EmFi-Zellen (s.o.) ausplattiert. Die positive (durch Neomycin) und negative Selektion (durch Thymidinkinase) begann nach 12 bis 16 h. Die Neomycin-Selektion erfolgte für fünf, die negative Selektion durch Thymidinkinase für zehn Tage. Es folgte die Isolierung positiver Klone, von denen eine Hälfte bei $-80^{\circ} \mathrm{C}$ kryokonserviert wurde. Die andere Hälfte der Zellen wurde so lange kultiviert, bis sich eine konfluente Schicht gebildet hatte, welche zur Genotypisierung verwendet wurde. Um mittels PCR zu screenen, ob die ES-Zellen das rekombinante Allel enthalten, wurden bestimmte Primer gewählt, die in Abbildung 3.3 dargestellt sind. Die isolierte genomische DNA der ES-Zell-Klone wurde für die Southern-Blot-Hybridisierung verwendet, wobei die DNA jedes einzelnen Klons mit AflII verdaut, elektrophoretisch aufgetrennt und auf eine NitrozelluloseMembran geblottet wurde. Die Southern Blots wurden dann mit einer ${ }^{32} \mathrm{P}$-markierten 5'externen Sonde (vgl. Abb. 3.2) hybridisiert. Im Falle eines rekombinanten Klons wurden ein 7,6 kb großes Wildtyp-Allel sowie ein $6 \mathrm{~kb}$ großes rekombinantes Allel detektiert. Unter 24 untersuchten Klonen wurden zwei homolog rekombinierte ESZellklone gefunden (vgl. Abb. 3.3). 


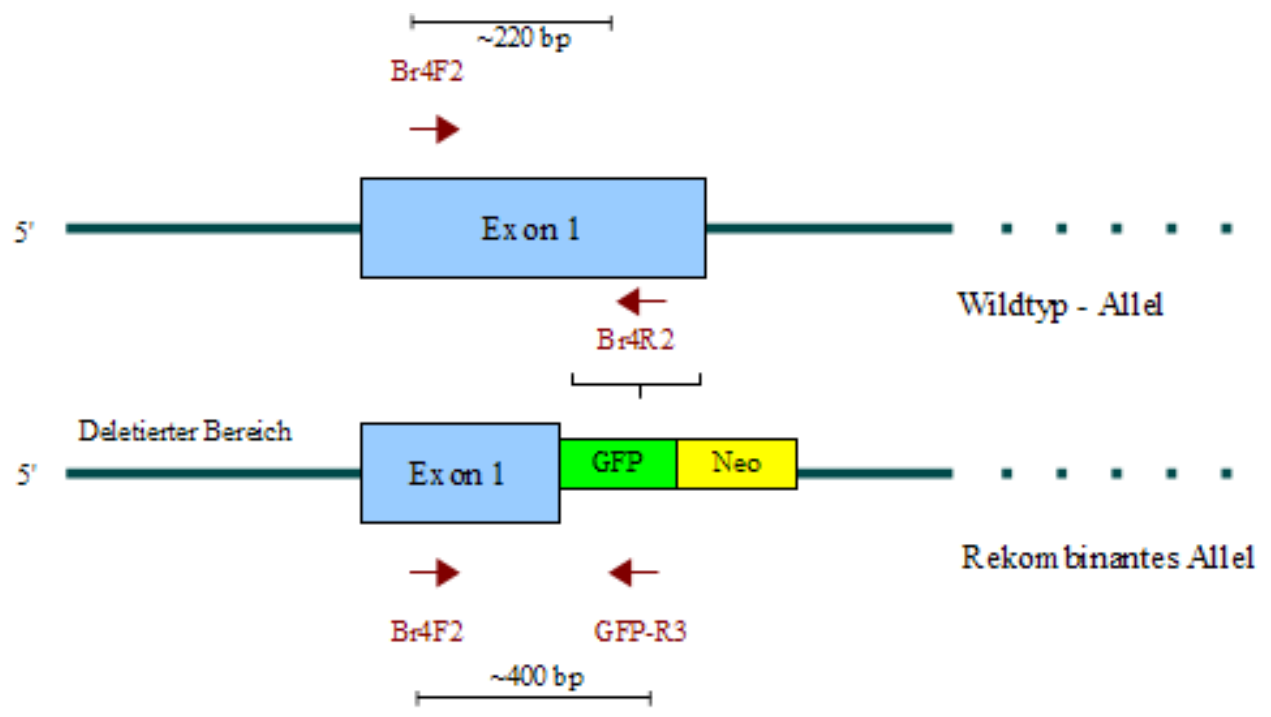

Abb. 3.3: Lokalisation der Primer für die genomische PCR

Dargestellt ist der 5'-Bereich des Gens Brunol4 mit Exon 1 und den Bindungsstellen der Primer für die genomische PCR. In rot sind die Namen der Primer angegeben. Im Falle des Wildtyp-Allels wird ein Fragment mit einer Länge von etwa 220 bp amplifiziert. Das rekombinante Allel führt zu einem etwa 400 bp langen Amplifikat (vgl. auch Abb. 3.4).

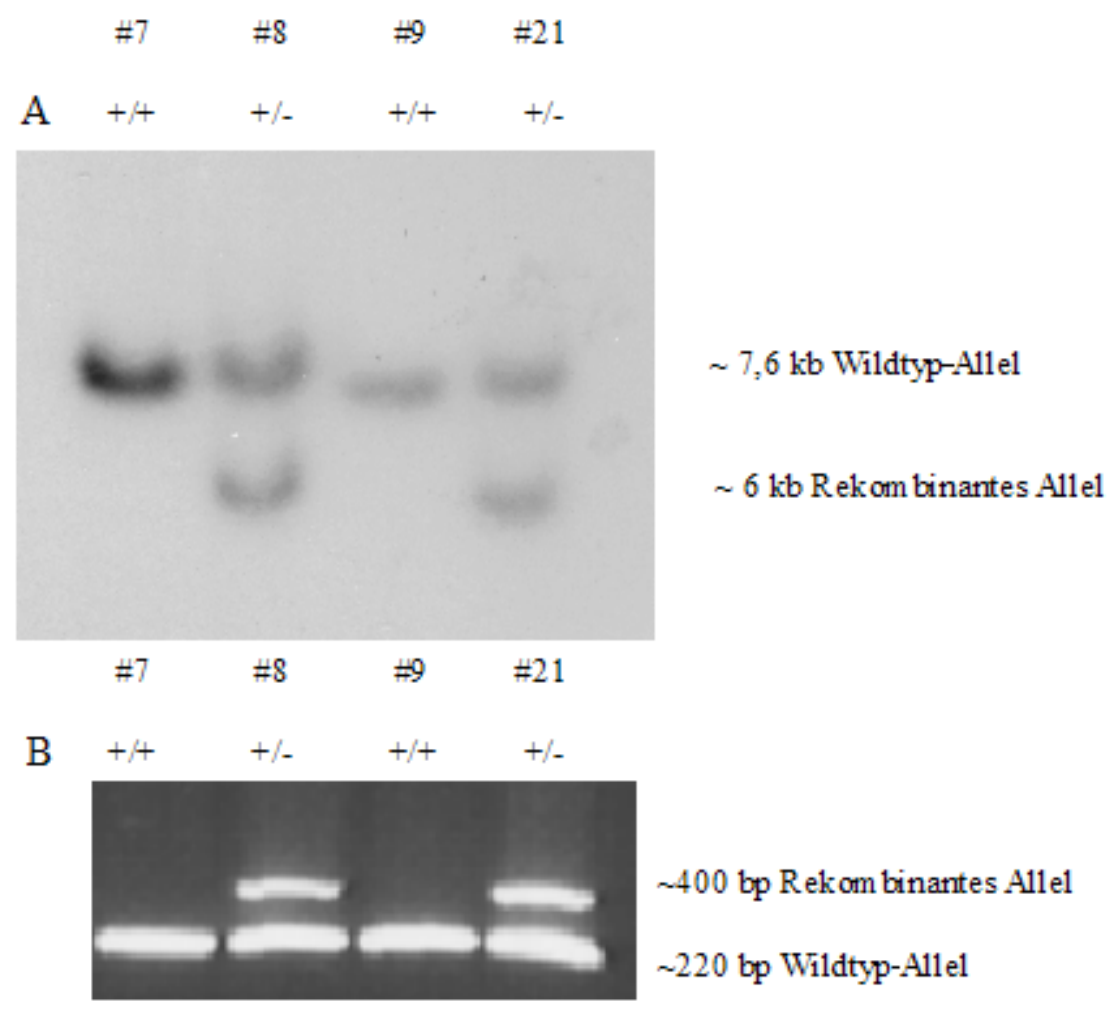

Abb. 3.4: Southern-Blot- und PCR-Analyse zur Untersuchung der ES-Zellen

A: Die Southern-Blot-Hybridisierung erfolgte mit einer 5'-externen Sonde (vgl. Abb. 3.2). Es zeigen sich die Signale eines 7,6 kb großen Wildtyp-Allels und zusätzlich ein $6 \mathrm{~kb}$ großes rekombinantes Allel im 
Falle von heterozygoten ES-Zell-Klonen. B:Die genomische PCR mit Br4F2, Br4R2 und GFP-R3 Primer (vgl. Abb. 3.3) ergab ein 400 bp großes Fragment des rekombinanten Allels und ein 220 bp großes Amplifikat im Falle des Wildtyp-Allels.

\subsubsection{Herstellung von chimären Mäusen durch Injektion von Brunol4+/--ES-Zellen in Blastozysten}

Um chimäre Mäuse zu generieren, wurden homolog rekombinierte ES-Zellen der Linie 8 in 3,5 dpc Blastozysten der Linie C57B1/6J injiziert. Diese Blastozysten wurden dann in die Uteri pseudoschwangerer C57B1/6J-Weibchen retransferiert. Die Blastozysteninjektionen wurden im Max-Planck-Institut für experimentelle Medizin Göttingen durchgeführt. Es wurden anhand des agouti-Fellmarkers drei Chimären identifiziert. Diese agouti-Fellfarbe erlaubt durch ihre Repräsentation im Fell der Maus einen Rückschluss auf den Anteil an rekombinanten Zellen im Tier. Ist ein besonders hoher Anteil des Fells agouti-farben, so ist eine Transmission des rekombinanten Allels über die Keimbahn wahrscheinlich. Die 70\%-, 40\%- und 25\%igen Chimären wurden zunächst mit C57B1/6JWildtyp-Weibchen verpaart. Nur das 70\%ige Männchen zeigte mit sechs agouti-Nachkommen von insgesamt acht Tieren Keimbahntransmission. Diese Nachkommen wurden wie in Abbildung 3.3 und Abbildung 3.4 beschrieben genotypisiert. Drei dieser Mäuse waren Brunol4 ${ }^{+/}$, während die restlichen Tiere homozygot für das Wildtyp-Allel waren.

\subsubsection{Züchtung und Genotyp-Analysen der Nachkommen in der F1- und F2-Generation}

Für die Genotypisierung der Tiere der F1- und F2-Generation wurde DNA aus Schwanzbiopsien isoliert. Die PCR zur Genotypisierung erfolgte mit 200 ng genomischer DNA und wie in Abbildung 3.3 beschrieben mit Brunol4- und GFPKassetten-spezifischen Primern (für die Sequenzen vgl. 2.1.7.1). Je nach Genotyp wurden Fragmente unterschiedlicher Länge amplifiziert (vgl. Abb. 3.5). 


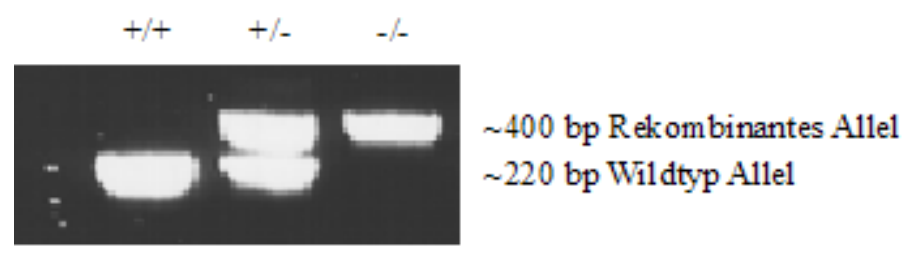

Abb. 3.5: Genotypisierung der Nachkommen in der F1- und F2-Generation

Exemplarisch ist hier das Gelfoto einer gelelektrophoretischen Auftrennung von PCR-Produkte gezeigt. Brunol4 $^{+/+}$-Mäuse zeigen eine 220 bp große Bande, während in Brunol4 ${ }^{-/-}$-Tieren ein 400 bp großes Fragment amplifiziert wird. Folglich führt die PCR bei Brunol4 $4^{+-}$zu einem 400 bp großen Abschnitt des Wildtyp-Allels und dem 200 bp großen Fragment des rekombinanten Allels.

Durch Verpaarung der 70 \%igen männlichen Chimäre, die das mutierte Brunol4-Gen in der Keimbahn trug, mit weiblichen Tieren der Linie C57B16J wurden in der F1-HybridGeneration heterozygote und Wildtyp-Mäuse generiert. Diese Tiere, die sowohl das Wildtyp-Allel als auch das veränderte Brunol4-Allel enthielten, wurden miteinander verpaart, um homozygote Brunol4-defiziente Mäuse zu erhalten. In der daraus resultierenden F2-Generation war jeder der drei möglichen Genotypen vertreten. Zunächst wurden die Nachkommen jeweils im Alter von etwa drei Wochen genotypisiert. In zwölf Würfen der Hybrid-Linie 129/Sv x C57Bl/6J mit insgesamt 100 Tieren betrug der Anteil an homozygoten Brunol4 $4^{-/}$-Tieren 6\%, an heterozygoten Tieren $52 \%$ und an Wildtyp-Tieren 42\% (vgl. Tab. 3.3). Da jedoch einige Tiere vor dem Alter von drei Wochen starben und vermutet wurde, dass es sich hierbei ebenfalls um Brunol4 ${ }^{-/}$-Tiere gehandelt haben könnte, wurden die Nachkommen bereits ab einem Alter von zwei bis drei Tagen genotypisiert. Hier zeigte sich bei 30 Würfen der HybridLinie mit 221 Nachkommen eine Verteilung von etwa 1:2:1 ( $\chi^{2}$-Test, $\left.\mathrm{p}=0,79\right)$, bei 58 Wildtyp-Mäusen, 112 heterozygoten Tieren und 51 Brunol4 ${ }^{-/}$-Tieren (vgl. Tab. 3.2). Dieses entspricht dem nach den Mendelschen Regeln zu erwartenden Verhältnis. Die Wurfgröße bei heterozygoten Verpaarungen wich mit 7,5 2 ,29 kaum von der als Referenz benutzten Verpaarung von Chimären mit Wildtyp-Weibchen ab.

\begin{tabular}{|l|l|l|l|l|}
\hline & $+/+$ & $+/-$ & $-/-$ & gesamt \\
\hline 0 & 33 & 62 & 26 & 121 \\
\hline & $27,3 \%$ & $51,2 \%$ & $21,5 \%$ & $54,75 \%$ \\
\hline+ & 25 & 60 & 25 & 110 \\
\hline & $22,7 \%$ & $54,5 \%$ & $22,7 \%$ & $45,25 \%$ \\
\hline
\end{tabular}




\begin{tabular}{|l|l|l|l|l|} 
gesamt & 58 & 112 & 51 & 221 \\
\hline & $26,2 \%$ & $50,7 \%$ & $23,1 \%$ & \\
\hline
\end{tabular}

Tab. 3.2: Quantitative Verteilung von Wildtyp-, heterozygoten und homozygoten Mäusen in der F2-Generation auf dem 129/Sv x C57Bl/6J-Hybridhintergrund (2-3 d)

Die 221 Nachkommen aus Heterozygoten-Verpaarungen wurden an Tag 2-3 nach der Geburt

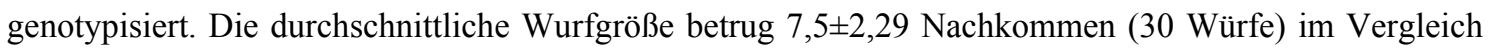
zu 7士2,9 Nachkommen bei Verpaarungen des 70\%igen Männchen mit WT-C57B1/6J-Weibchen.

\begin{tabular}{|l|l|l|l|l|}
\hline & $+/+$ & $+/-$ & $-/-$ & gesamt \\
\hline $0^{\pi}$ & 23 & 31 & 3 & 57 \\
\hline & $40,4 \%$ & $54,4 \%$ & $5,2 \%$ & $54,75 \%$ \\
\hline+ & 19 & 21 & 3 & 43 \\
\hline & $44,2 \%$ & $48,8 \%$ & $7 \%$ & $45,25 \%$ \\
\hline gesamt & 42 & 52 & 6 & 100 \\
\hline & $42 \%$ & $52 \%$ & $6 \%$ & \\
\hline
\end{tabular}

Tab. 3.3: Quantitative Verteilung von Wildtyp-, heterozygoten und homozygoten Mäusen in der F2-Generation mit 129/Sv x C57BI/6J-Hybridhintergrund (drei Wochen)

Diese 91 Nachkommen wurden im Alter von drei Wochen genotypisiert.

Um das Brunol4-mutierte Allel in einen Inzucht-genetischen Hintergrund zu integrieren, wurde die 70\%ige Chimäre mit einem Wildtyp-Weibchen des Stammes 129/Sv verpaart. In 9 Würfen dieser Linie mit insgesamt 49 Tieren betrug der Anteil der Brunol4 $^{-/-}$-Tiere 12,2\%, der der Brunol4 ${ }^{+/}$- Tiere 55,1\% und der der Brunol4 ${ }^{+/+}$-Mäuse $32,7 \%$ (vgl. Tab. 3.5). Auch in dieser Zucht starben einige Nachkommen vor dem Alter von drei Wochen. Daraufhin wurde der Zeitpunkt der Genotypisierung auf den 2.-3. Lebenstag vorgezogen. Es zeigte sich eine Verteilung mit 11 Wildtyp-Tieren, 19 heterozygoten und 11 Brunol4-defizienten Mäusen $\left(\chi^{2}\right.$-Test, $\left.p=0,94\right)$, wie in Tabelle 3.4 dargestellt. Mit 3,2 $\pm 0,67$ etwa um die Hälfte reduziert war die Anzahl der nach 2-3 Tagen gezählten Nachkommen dieses 129/Sv-Hintergrundes. Zweimal wurden die Embryonen trächtiger heterozygoter 129/Sv-Weibchen (10,5 dpc und 11,5 dpc) präpariert und genotypisiert. Die Verteilung in diesen zwei Schwangerschaften betrug 10 Brunol $^{+/+}$-Mäuse, 8 heterozygote und 4 Brunol4 $^{-/-}$-Tiere. Um eine Aussage über eine erhöhte intrauterine Mortalität machen zu können, müssen mehr Embryonen untersucht werden. 


\begin{tabular}{|l|l|l|l|l|}
\hline & $+/+$ & $+/-$ & $-/-$ & gesamt \\
\hline 0 & 7 & 8 & 5 & 20 \\
\hline & $35 \%$ & $40 \%$ & $25 \%$ & $48,8 \%$ \\
\hline+ & 4 & 11 & 6 & 21 \\
\hline & $19 \%$ & $52,4 \%$ & $28,6 \%$ & $45,25 \%$ \\
\hline gesamt & 11 & 19 & 11 & 41 \\
\hline & $26,8 \%$ & $46,4 \%$ & $26,8 \%$ & \\
\hline
\end{tabular}

Tab. 3.4: Quantitative Verteilung von Wildtyp-, heterozygoten und homozygoten Mäusen in der F2-Generation mit 129/Sv-Inzuchthintergrund (2-3 d)

Die 41 Nachkommen aus Heterozygoten-Verpaarungen wurden an Tag 2-3 nach der Geburt genotypisiert. Die durchschnittliche Wurfgröße betrug 3,2 $\pm 0,67$ Nachkommen (9 Würfe) im Vergleich zu 6,25 $\pm 3,96$ Nachkommen bei Wildtyp-Verpaarungen.

\begin{tabular}{|l|l|l|l|l|}
\hline & $+/+$ & $+/-$ & $-/-$ & gesamt \\
\hline 0 & 9 & 16 & 2 & 27 \\
\hline & $33,3 \%$ & $59,3 \%$ & $7,4 \%$ & $54,75 \%$ \\
\hline+ & 7 & 11 & 4 & 22 \\
\hline & $31,8 \%$ & $50 \%$ & $18,2 \%$ & $45,25 \%$ \\
\hline gesamt & 16 & 27 & 6 & 49 \\
\hline & $32,7 \%$ & $55,1 \%$ & $12,2 \%$ & \\
\hline
\end{tabular}

Tab. 3.5: Quantitative Verteilung von Wildtyp-, heterozygoten und homozygoten Mäusen in der F2-Generation mit 129/Sv-Inzuchthintergrund (drei Wochen)

Die 49 Nachkommen aus Heterozygoten-Verpaarungen wurden drei Wochen nach der Geburt genotypisiert.

\subsection{Kontrolle der Inaktivierung des Brunol4-Gens}

Brunol4 wird im murinen Gehirn exprimiert. Um zu untersuchen, ob die Brunol4 ${ }^{-{ }_{-}}$ Mäuse tatsächlich kein Transkript mehr produzieren, wurden Untersuchungen mit Northern Blots und RT-PCRs durchgeführt.

\subsubsection{Northern-Blot-Analyse}


Für die Northern-Blot-Analysen wurden drei Sonden verwendet, deren Hybridisierungsstellen in Abbildung 3.6 dargestellt sind. Für die Sonden \#2 und \#3 (vgl. Abb. 3.6 A) wurde Gesamt-RNA aus Gehirnen von Mäusen isoliert und mittels RTPCR in cDNA umgeschrieben. Mit speziellen Primern (vgl. 2.1.7.2) wurden dann Fragmente amplifiziert, die als Sonden dienten. Die Sonde \#1 (vgl. Abb. 3.6A) wurde im Rahmen einer anderen Dissertation hergestellt (Dev 2006).

A
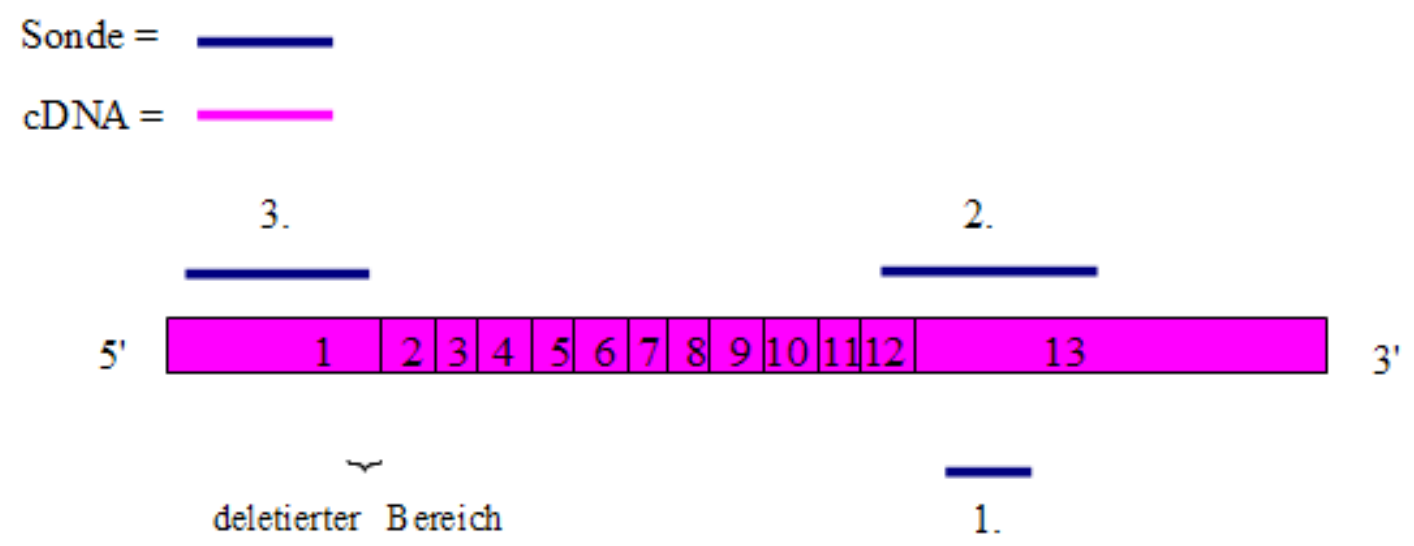

B

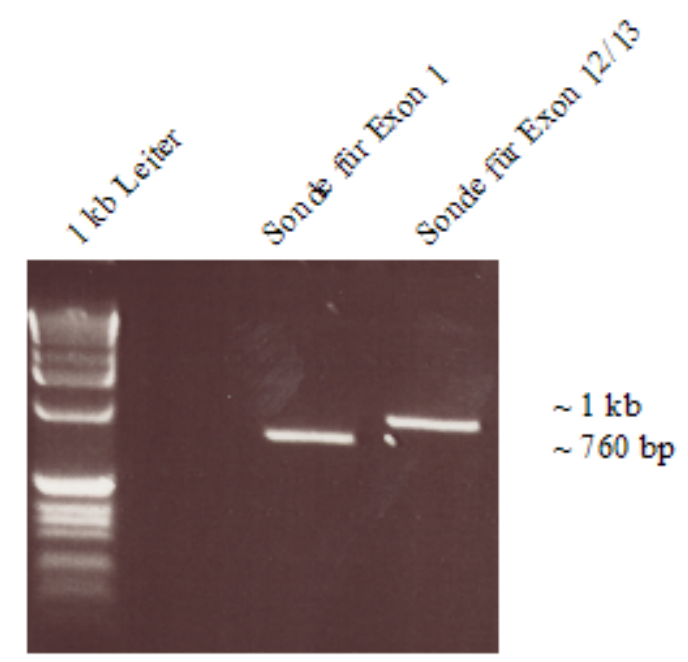

Abb. 3.6: A: Graphische Darstellung der cDNA und der Northern-Blot-Sonden mit Lokalisation der Hybridisierung; B: cDNA-Sonden

A: Die Sonde \#1 ist ca. 480 bp lang und hybridisiert an Exon 13. Sonde \#2 ist ca. $1 \mathrm{~kb}$ groß und hybridisiert an Exon 12 und Exon 13; Sonde \#3 ist ca. 760 bp lang und hybridisiert an Exon 1.

B: Aufgetragen ist der Längenstandard $(\mathrm{kb})$ und jeweils $3 \mu \mathrm{l}$ der aufgereinigten Sonden für Exon 1 und für Exon 12/13. Die Sonden wurden mittels PCR amplifiziert. Die Sonde \#1 (vgl. A) wurde im Rahmen einer früheren Arbeit hergestellt (Dev 2006). 
Gesamt-RNA wurde aus Gehirnen von Brunol4 ${ }^{+/+}$-, Brunol4 $^{+/}$-, und Brunol4 ${ }^{-/}$-Mäusen des C57B1/6J x 129/Sv-Hintergrundes sowie aus der Niere von Wildtyp-Geschwistern isoliert und nach elektrophoretischer Auftrennung $\mathrm{zu}$ je $20 \mu \mathrm{g}$ auf eine Membran geblottet. Zunächst wurde die RNA mit der Sonde \#1 hybridisiert, die komplementär zu einem Bereich des Exons 13 ist (vgl. Abb. 3.6). 4 kb und 2,8 kb Transkripte konnten detektiert werden. Verglichen mit den Daten aus NCBI und Ensembl handelt es sich um die Varianten 1-4 und 6. Bei dem 2,8 kb großen Produkt könnte es sich um eine weitere Splicingvariante handeln. Es zeigten sich deutliche Banden bei allen drei Tieren, auch im Gehirn der homozygoten Maus lassen sich Produkte nachweisen, das längere Produkt scheint jedoch im Vergleich zum Wildtyp etwas kürzer (ca. 3,9 kb).

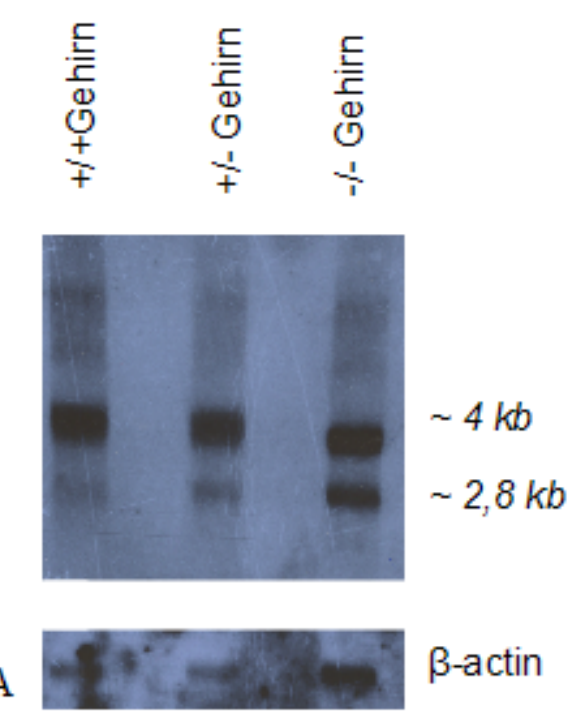

Abb. 3.7: Northern-Blot-Analyse mit Sonde \#1

Bei Hybridisierung mit einer 3'-Sonde (A, \#1, vgl. Abb. 3.6) werden Transkripte sowohl bei Wildtyptieren als auch bei heterozygoten und Brunol4 ${ }^{-/}$-Mäusen detektiert. Nachhybridisierung mit $\beta$ Actin zeigt, dass der RNA-Gehalt der Brunol4 ${ }^{-/}$-Probe höher ist, als die der anderen Proben, was den höheren Gehalt des 2,8-kb-Produkts erklärt. Um zu zeigen, dass die Sonde nicht unspezifisch bindet, wurde ein Northern Blot mit RNA aus verschiedenen Wildtyp- Geweben hybridisiert (B).

Eine Hybridisierung von Wildtyp-RNA verschiedener Gewebe (Großhirn, Kleinhirn, Niere, Testis) zeigte keine unspezifische Hybridisierung mit RNA dieser Gewebe (Abb. 3.7). Auch die Hybridisierung mit einer anderen Sonde, die Exon 12 und Exon 13 überspannt, hybridisierte an ein Produkt in RNA aus dem Gehirn von Mäusen, die 
homozygot für das rekombinante Allel sind, wie in den Abbildungen 3.8 und 3.9 gezeigt ist.

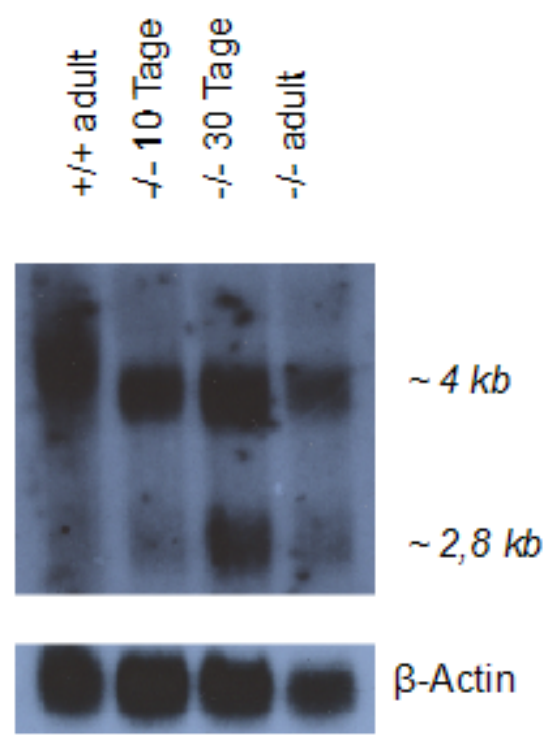

Abb. 3.8: Hybridisierung mit Sonde \#2

Die Sonde, die Exon 12 und Exon 13 überspannt (\#2), bindet an Transkripte sowohl bei WT-Mäusen als auch bei Brunol4 ${ }^{-/}$-Tieren verschiedenen Alters. Nachhybridisierung mit $\beta$-Actin weist auf einen verminderten RNA-Gehalt in der Brunol4 ${ }^{--}$-Probe hin, was mit der Signalstärke beider Hybridisierung mit Sonde \#2 korreliert.

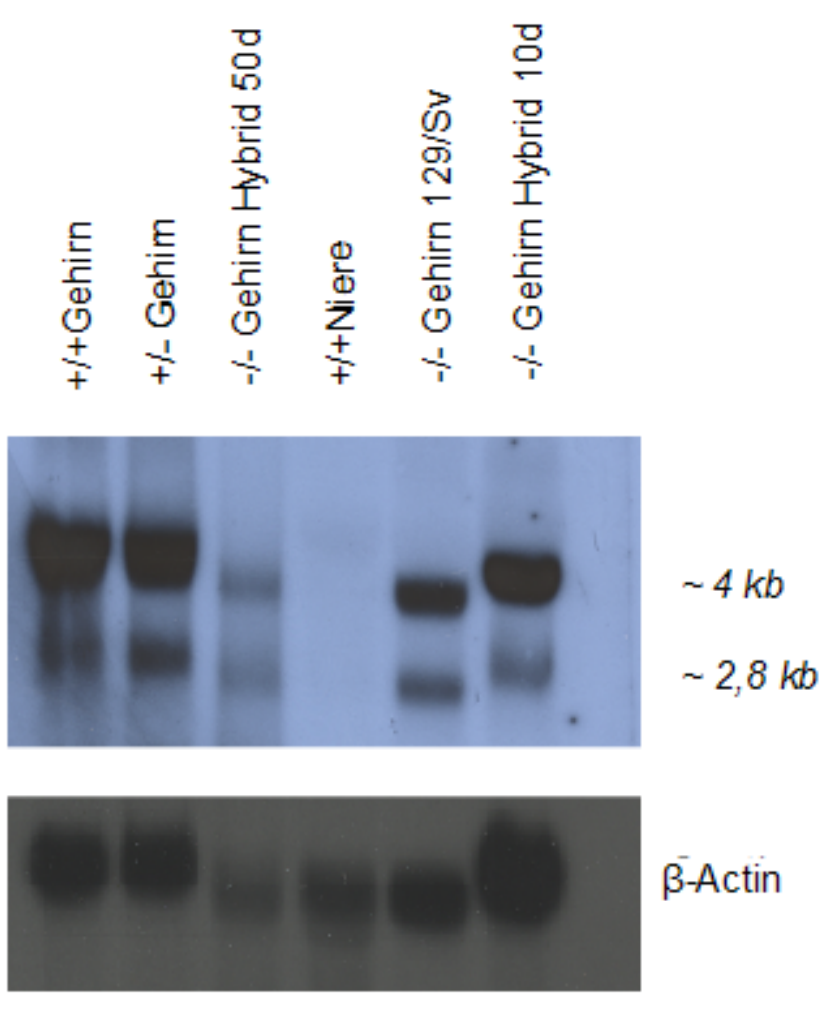

Abb. 3.9: Northern-Blot-Hybridisierung mit Sonde \#2 
Die Hybridisierung der RNA verschiedener Brunol4 ${ }^{-/}$-Tiere sowie einer Wildtyp-Maus zeigt Transkripte bei allen Genotypen. Zum Vergleich wurde Gesamt-RNA einer Brunol4 ${ }^{--}$-Maus der Linie 129/Sv mit geblottet und hybridisiert. Auch hier zeigt sich ein Transkript. Das schwache Signal der Brunol4 ${ }^{-/}$-RNA Hybrid 50d korreliert mit einer schwachen Qualität der RNA, wie die Nachhybridisierung mit $\beta$-Actin zeigt.

Bei Hybridisierung mit einer 5'-Sonde, die komplementär zu Exon 1 ist, ließ sich dagegen kein Transkript in Brunol4 ${ }^{--}$-Mäusen nachweisen.
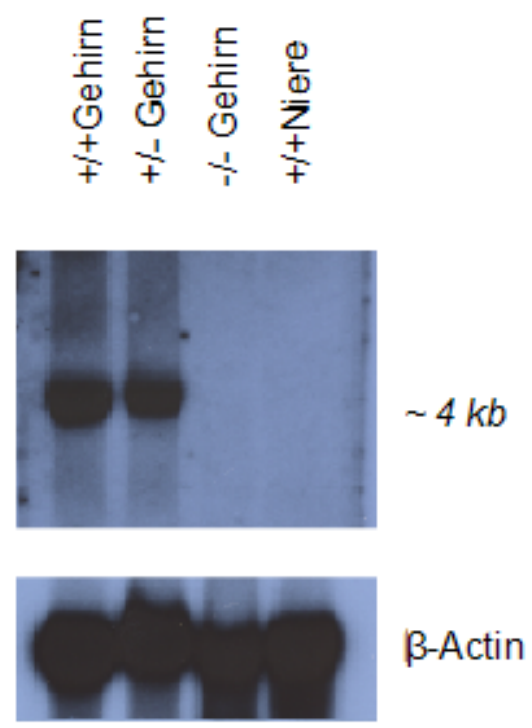

Abb. 3.10: Hybridisierung mit Sonde \#3

Brunol4 ${ }^{-1}$-Tiere zeigen kein Transkript, das durch eine Sonde, die dem Exon 1 entspricht (\#3), hybridisiert werden kann. Die kräftigen Signale durch die Nachhybridisierung mit $\beta$-Actin lassen auf eine gute und gleichmäßige Qualität und Quantität aller vier RNA-Proben schließen.

\subsubsection{RT-PCR-Analyse}

Um zu untersuchen, welche Bereiche des Gens in Brunol4 ${ }^{-/}$-Tieren transkribiert werden, wurde Gesamt-RNA aus dem Gehirn von Mäusen der Linie C57Bl/6J in cDNA umgeschrieben und mittels RT-PCR amplifiziert. Die Auswahl der Primer erfolgte anhand der Brunol4-cDNA-Sequenz (NM_133195.2). Da Northern-Blot-Analysen ein 4 kb langes Transkript ergaben, wurde vermutet, dass es in 3'-Richtung des zum Zeitpunkt der Versuche aktuellen Exon 13 (o.g. cDNA) eine weitere Poly-A-Sequenz gibt und der Bereich downstream des Gens (GeneID: 108013) transkribiert wird. Daher 
wurde der Primer \#10 so gewählt, dass er downstream von Exon 13 bindet. Als template wurde die nachfolgende genomische Sequenz gewählt (vgl. Abb. 3.11).

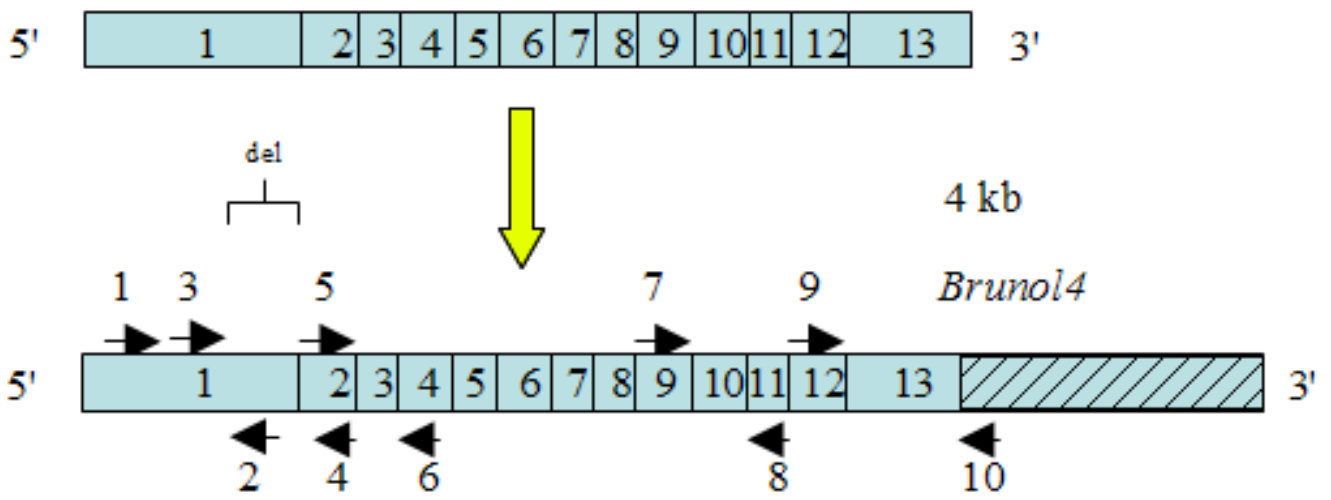

Abb. 3.11: Darstellung der Primerbindungsstellen für die RT- PCR

Für die RT-PCR wurden diverse Primerkombinationen benutzt. Dargestellt ist schematisch die Brunol4cDNA (NM_133195.2), mit um 1,5 kb genomischer Sequenz am 3'-Ende verlängertem Exon 13 (schraffierter Teil), sowie die Bindungsstellen der Primer und die deletierte Region. Den mit Nummern versehenen Primern werden in Tabelle 3.6 Namen zugeordnet (vgl. 2.1.7.3 für Sequenzen).

\begin{tabular}{|l|l|}
\hline$\# 1$ & Brl4NorthF4 \\
\hline$\# 2$ & Brl4NorthR4 \\
\hline$\# 3$ & Brl4184-DelF4 \\
\hline$\# 4$ & Brl4Exon2R4 \\
\hline$\# 5$ & Brl4Exon2F4 \\
\hline$\# 6$ & Brl4Exon4R4 \\
\hline$\# 7$ & Brl4qPCRF4 \\
\hline$\# 8$ & Brl4qPCRR4 \\
\hline$\# 9$ & Similarexon12F \\
\hline$\# 10$ & Similarexon13R \\
\hline
\end{tabular}

Tab. 3.6: Zuordnung der Nummern zu den jeweiligen Namen der Primer

Ein Produkt in Brunol4 ${ }^{-/}$-Tieren konnte in den Kombinationen Primer \#5 und \#6, \#7 und $\# 8$ sowie $\# 9$ und \#10 detektiert werden (vgl. Abb. 3.12F, 3.12E, 3.12D). Kein Produkt wurde dagegen bei Amplifikation mit den Primern \#1 und \#2, \#1 und \#4 sowie \#3 und \#4 nachgewiesen (vgl. Abb. 3.12C, 3.12A, und3.12B). Die Untersuchungen lassen Rückschlüsse auf die Brunol4-Transkripte zu. So lässt sich zum einen zeigen, dass der 5'-Bereich der cDNA (NM_133195.2), welcher 175 Basen mehr in 5'Richtung enthält als die 6 Varianten nach NCBI, ebenfalls transkribiert wird, da die 
PCR mit den Primern \#1 und \#2 sowie \#4 in Wildtyp und heterozygoten Tieren zu Produkten führen. Des Weiteren lässt sich zeigen, dass kein Transkript detektiert werden kann, das Exon 1 enthält, was zum Ergebnis der Northern-Blot-Analyse passt. Es liegen jedoch in Brunol4 ${ }^{-/}$-Tieren Transkripte vor. RT-PCR-Analysen für Bereiche downstream von Exon 1 ergaben Produkte, deren Länge der PRIMERblast Ergebnisse (NCBIblast) entsprechen.

\section{A Exons 1-2}

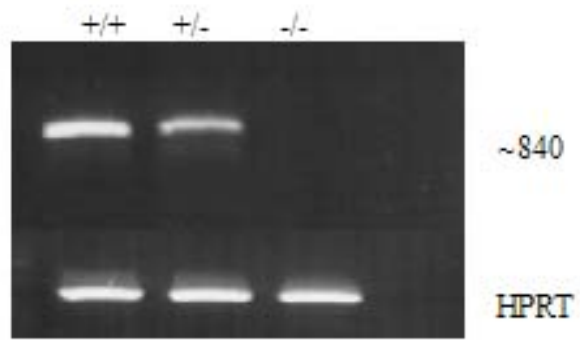

B Exons 1-2

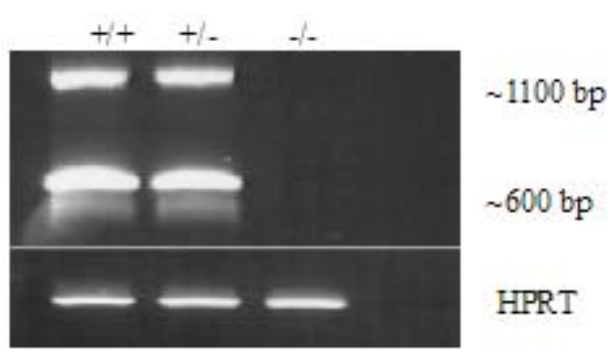

C Exon1

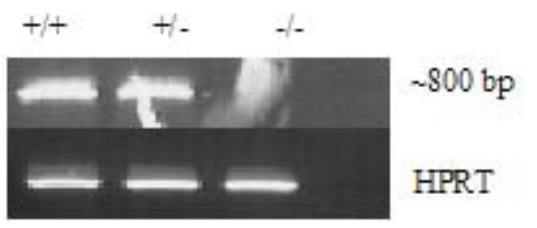

D Exons $12-13$

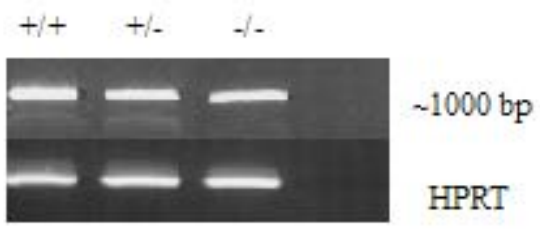

E Exons 9-11

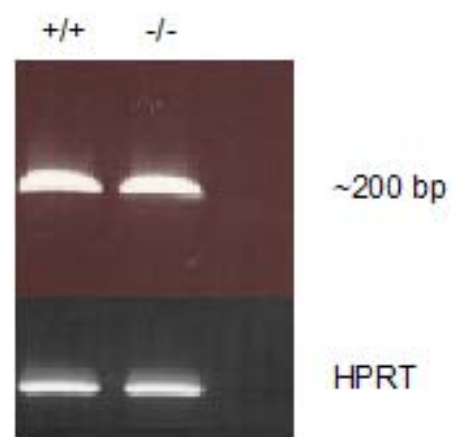




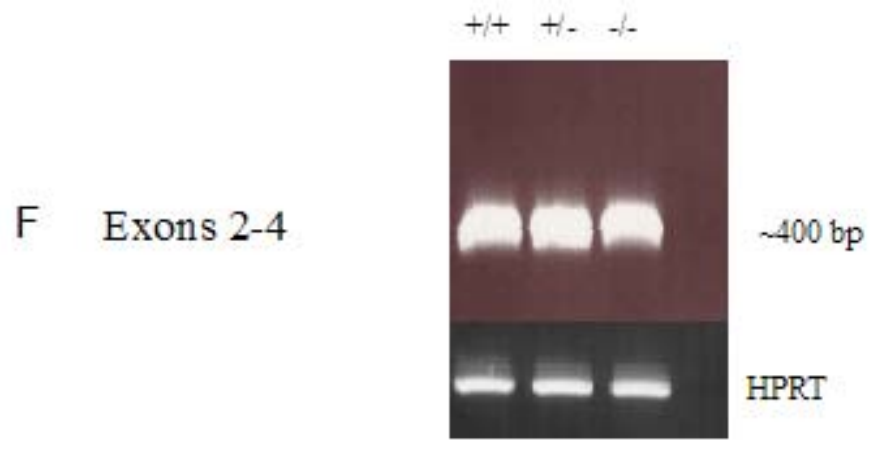

Abb. 3.12: Die RT-PCR mit cDNA aus Gehirnen von Wildtyptieren und Brunol4 ${ }^{+/}$- sowie Brunol4 ${ }^{-/-}$ -Mäusen

A: RT-PCR mit den Primern \#1 (Exon1, cDNA NM_133195.2) und \#4 (Exon2) ergab kein Produkt bei Brunol4 ${ }^{-/}$-Tieren. B: Auch bei der RT-PCR mit den Primern \#3 (Exon1) und \#4 (Exon2) entstand bei Brunol4 $^{-/}$-Tieren kein Produkt. Zwei Banden zeigen sich jedoch bei Wildtyp und heterozygoter Maus. C: bei Verwendung von Primer \#1 und \#2 (beide Exon 1) erhielt man ebenfalls kein RT-PCR-Produkt bei Brunol4 ${ }^{--}$-Mäusen. D: RT-PCR mit den Primern \#9 und \#10 (Exon 12 und Exon 13) ergab ein Produkt bei Brunol4 ${ }^{-/-}$-Tieren. E: Für diese PCR wurden Primer \# 7 und \#8 benutzt (Exon 9 und Exon11). Dieser Abschnitt des Gens wird auch in Brunol4 ${ }^{-/}$-Mäusen transkribiert. F: Diese Abbildung zeigt das Ergebnis einer PCR mit den Primern \#5 und \#6 (Exon 2 und Exon4). In Brunol4 ${ }^{-/}$-Mäusen lässt sich hier ein Produkt detektieren. Die Gütekontrolle der cDNA wurde durch Amplifikation der cDNA des housekeeping-Gens HPRT durchgeführt.

\subsection{Phänotyp- Analyse}

\subsection{1 Überlebenszeit der Brunol4 \%-Tiere}

Es wurde beobachtet, dass Tiere, die für das Brunol4-Knockout-Allel homozygot waren, eine deutlich verkürzte Lebenszeit haben, so dass, wie oben beschrieben, die Genotypisierungen auf den 2.-3. Lebenstag vorgezogen wurden. Von 35 Brunol4defizienten Mäusen und 40 Mäusen mit heterozygotem Genotyp der Hybrid-Linie 129/Sv x C57B1/6J sowie von 17 Brunol4 ${ }^{-/-}$-Tieren und 20 heterozygoten Mäusen der Inzucht-Linie 129/Sv wurde das Überleben dokumentiert und in Form von KaplanMeier-Kurven (vgl. Abb. 3.13 und Abb. 3.14) aufgetragen. Hier wird jeweils der prozentuale Anteil der überlebenden Mäuse in einem Zeitraum von 50 Tagen angegeben. 
Überleben von Brund4 - - vs. H- Tieren

C5/BL $6 \mathrm{~J}$

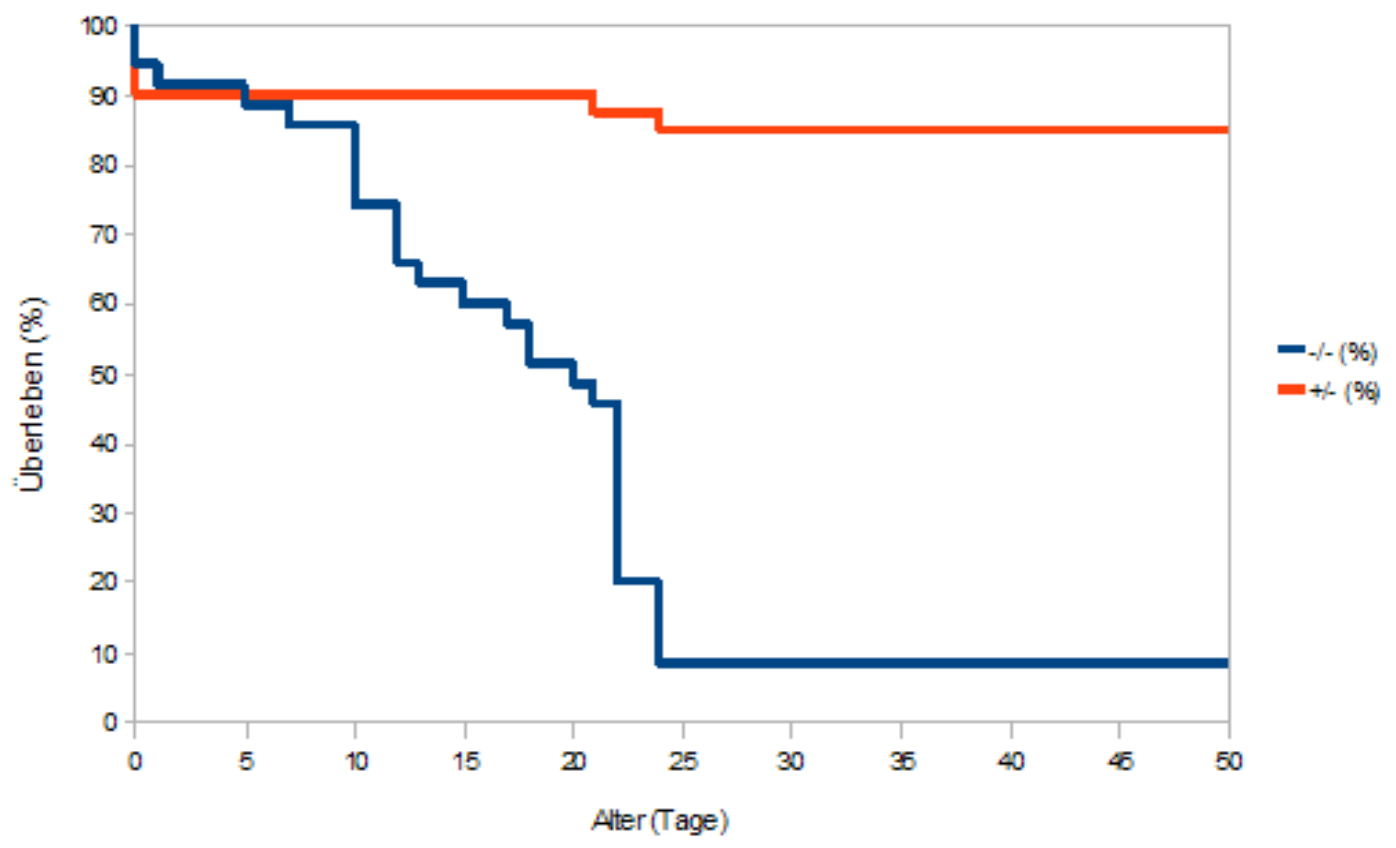

Abb. 3.13: Kaplan-Meier-Kurve, Hybridhintergrund

Aufgetragen ist das Überleben von homozygoten Brunol4-defizienten Mäusen und heterozygoten Geschwistern mit Hybrid-Hintergrund. Im Vergleich zu heterozygoten Geschwistern, die nach 50 Tagen noch zu 85\% leben, liegt das mediane Überleben bei Brunol4 ${ }^{-/}$-Tieren bei 20 Tagen.

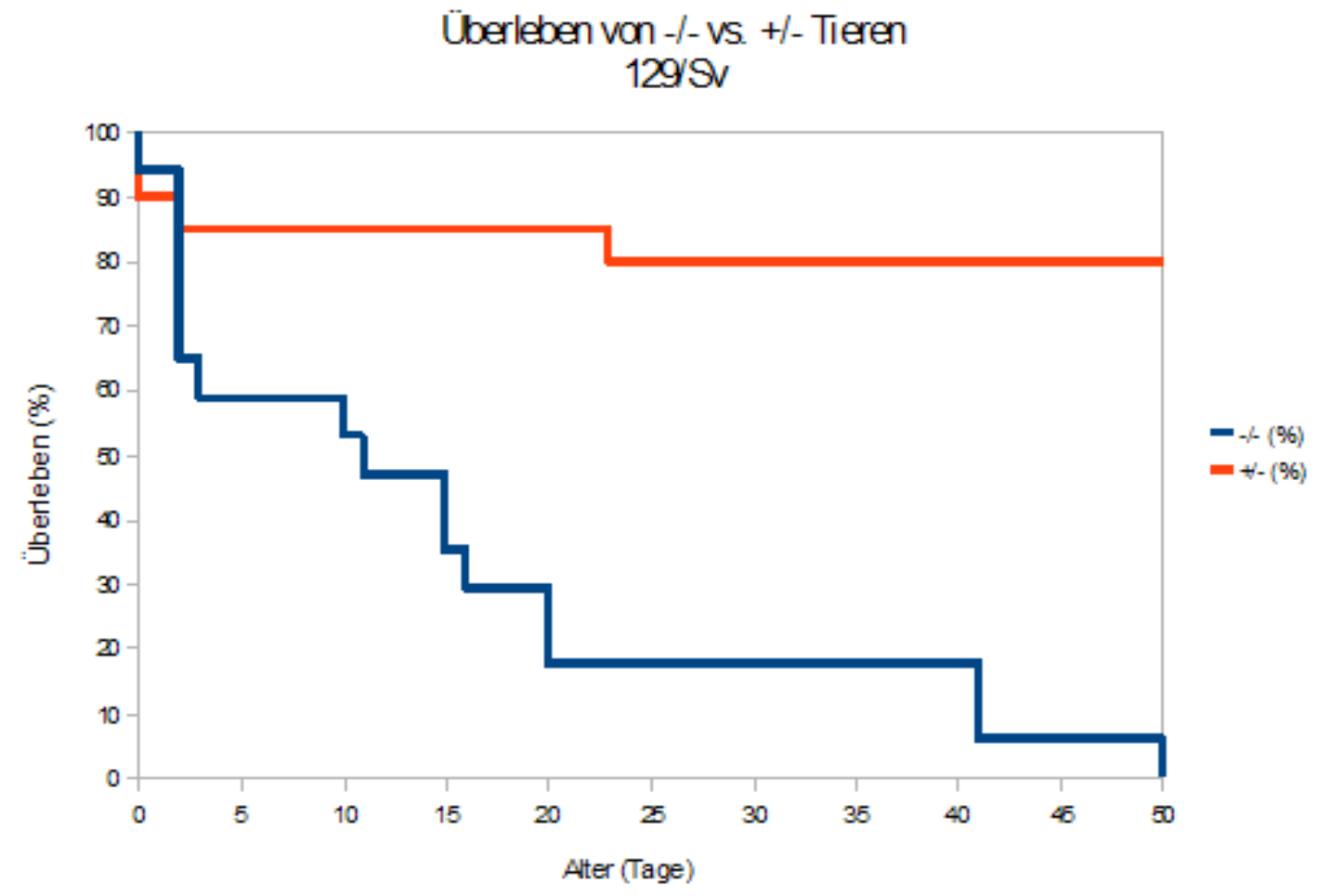

Abb. 3.14: Kaplan-Meier-Kurve, Inzucht-Linie 
Ergebnisse

Auch in der Linie 129/Sv liegt die 50\% Perzentile für das Überleben der Brunol4 ${ }^{-/}$-Tiere mit 11 Tagen deutlich niedriger als bei heterozygoten Geschwistertieren, von denen nach 50 Tagen noch 80\% lebten. Die beobachteten Nachkommen der Linie 129/Sv starben zu 40\% bereits in den ersten 4 Tagen.

\subsubsection{Vergleich der Körpergewichte von Brunol4-defizienten Mäusen und Geschwistertieren}

Unter den Würfen der Heterozygotenverpaarungen fiel auf, dass einige Nachkommen sowohl der 129/Sv-Linie als auch der Hybrid-Linie 129/Sv x C57B1/6J eine Wachstumsretardierung zeigten (Abb. 3.15). Die Genotypisierung der Tiere zeigte, dass es sich bei diesen Mäusen um homozygote Brunol4 ${ }^{-/-}$-Tiere handelte.
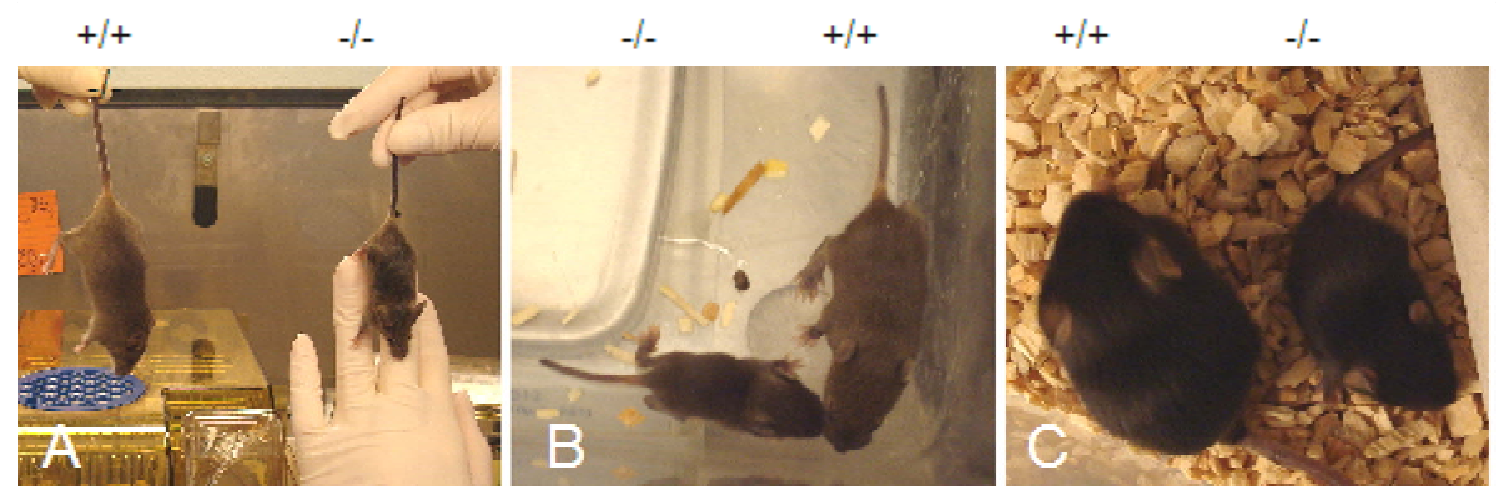

Abb. 3.15: Unterschiedliche Größe von Brunol4 ${ }^{-/-}$-Mäusen und WT-Geschwistern

A: Weibchen (129/Sv) im Alter von 28 Tagen zeigen deutliche Größenunterschiede. (Wildtyp-Weibchen: 16,36g; Brunol4 ${ }^{-/}$-Weibchen 8,1g); B: Auch Brunol4-Weibchen (129/Sv) im Alter von 12 Tagen zeigen bereits deutliche Größenunterschiede. (Wildtyp-Weibchen: 9.42g Brunol- ${ }^{-/}$-Weibchen 3,1g); C: Hier abgebildet sind 129/Sv $x$ C57BL/6J-Männchen im Alter von 17 Tagen. Die unterschiedliche Größe ist deutlich sichtbar. (Wildtyp-Männchen: 10,18g; Brunol4 ${ }^{-/}$-Männchen 4,16g).

Über einen Zeitraum von mehreren Monaten wurden daher 129/Sv x C57Bl/6J-Mäuse unterschiedlichen Genotyps gewogen. Hierbei wurden je Geschlecht im Mittel 6-10 Wildtyptiere und heterozygote Mäuse sowie je nach Alter 1-9 homozygote Brunol4 $^{-/}$Mäuse gewogen. In höherem Alter standen aufgrund des reduzierten Überlebens weniger Brunol4 ${ }^{-/}$-Tiere zur Verfügung. Ab einem Alter von wenigen Tagen bis zu einer Woche waren in unterschiedlichem Ausmaß Gewichtsunterschiede zwischen Brunol4 $^{-/-}$-Tieren und ihren Geschwistern erkennbar. Die Brunol4 ${ }^{-/-}$-Mäuse zeigten eine generelle Entwicklungsverzögerung und hatten ein deutlich geringeres Gewicht als ihre 
Geschwister (vgl. Abb. 3.16 und 3.17. So waren homozygote weibliche Tiere bis zum Alter von 15 Tagen signifikant leichter als Wildtyp-Geschwister $(p<0,05$ für 3 und 9 Tage und $p<0,001$ für 15 Tage), ebenso im Alter von $27(p<0,05)$ und $42(p<0,01)$ Tagen. Die gemessenen Gewichte an den Tagen 21, 37 und 65 unterschieden sich nicht signifikant. Im Vergleich zu heterozygoten Tieren bestand eine Signifikanz in jedem gemessenen Alter ( $p<0,01$ im Alter von 9, 42 und 56 Tagen, $p<0,05$ im Alter von 27 und 37 Tagen), außer an den Tagen 3 und 21. Nicht messbar aufgrund von zu wenigen Mäusen war die Signifikanz im Alter von 75 Tagen. Im Alter von 27 Tagen bis 65 Tagen waren heterozygote Weibchen signifikant schwerer als Mäuse mit Wildtyp-Allel $(p<0,05)$. Männliche homozygote Mäuse waren in jedem gemessenen Alter signifikant leichter als ihre Wildtyp-Geschwister $(p<0,001$ im Alter von 9, 15, 65 und 75 Tagen, $p$ $<0,01 \mathrm{im}$ Alter von 3 Tagen und $p<0,05$ für die restlichen Altersstufen) und immer signifikant leichter als heterozygote Mäuse $(p<0,001 \mathrm{im}$ Alter von 3, 9 und 15 Tagen und $p<0,01$ im Alter von 21, 37, 42, 65 und 75 Tagen). Wildtyp-Männchen unterschieden sich in ihrem Gewicht nicht signifikant von heterozygoten Männchen.

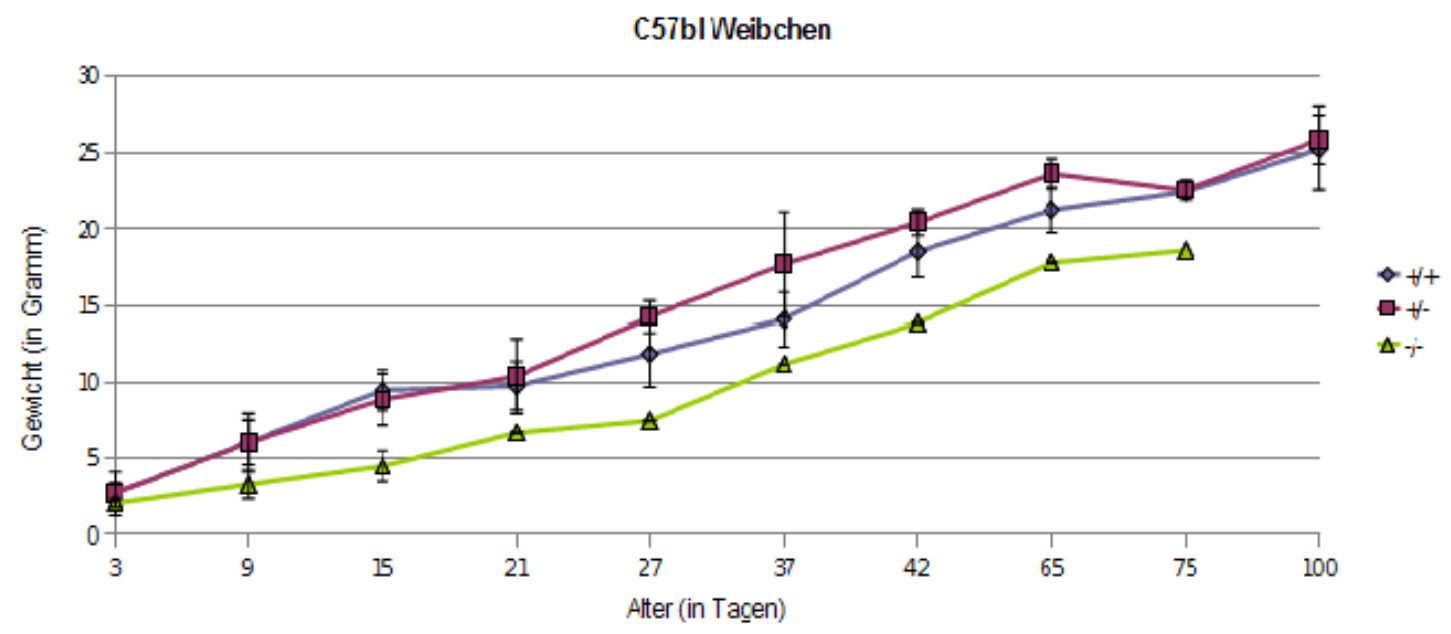

Abb. 3.16: Gewichte, Hybridhintergrund, Weibchen

Im Alter von 2, 9, 15, 21, 27, 37, 42, 65, 75 und 100 Tagen wurden je 3-12 homozygot defiziente Weibchen (grün) sowie Heterozygote (violett) und Wildtypen (blau) gewogen und miteinander verglichen. Aufgetragen sind die Gewichtsverläufe. 


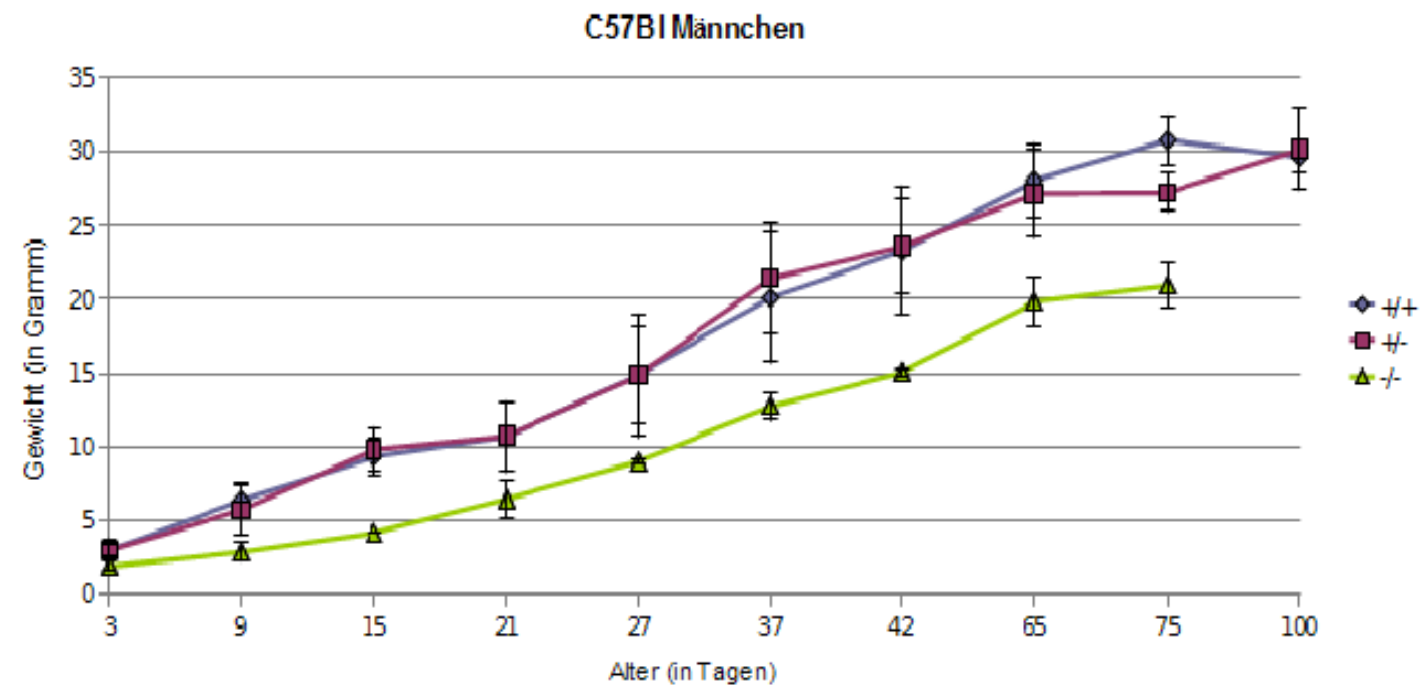

Abb. 3.17: Gewichte, Hybridhintergrund, Männchen

Aufgetragen sind die Gewichtsverläufe von je 3-12 männlichen C57B1/6J-Mäusen für Wildtyp (blau), heterozygote (violett) und defiziente Mäuse (grün).

\subsubsection{Auftreten von Krampfanfällen bei adulten Brunol4\% - Tieren}

Bei etwa $75 \%$ der Brunol4 $4^{-/}$-Tiere fiel während der ersten zwei Lebenswochen ein starkes Zittern auf. Auch wurden bei einzelnen Tieren zeitweise krampfartige Bewegungen des Schwanzes mit Ausstrecken und Heben beobachtet. Fünf Brunol4 ${ }^{-{ }_{-}}$Mäuse der Hybrid-Linie 129/Sv x C57Bl/6J (drei Männchen und zwei Weibchen) erreichten das adulte Alter. Bei vier von ihnen (2 Männchen, 2 Weibchen) wurden ab einem Alter von 3 Monaten je bis zu dreimal Krampfanfälle beobachtet. Diese ereigneten sich jeweils beim Umsetzen und äußerten sich in Sprüngen, Fallen und Strecken der hinteren Extremitäten. Die zwei Männchen und ein Weibchen waren Geschwister. Die Anfälle bei diesem Weibchen wurden mit 91 und 98 Tagen beobachtet. Die Männchen krampften jeweils mit 98, 100 und 105 Tagen. Das Weibchen starb nach 126 Tagen, die Männchen nach 119 bzw. 126 Tagen. Das Weibchen wurde bereits im Alter von 50 Tagen mit einem der Männchen verpaart. Aus dieser Verpaarung entstanden jedoch auch nach 76 Tagen keine Nachkommen. Ein weiteres Brunol4 $^{-/}$-Weibchen wurde im Alter von 129, 130 und 141 Tagen bei Krämpfen beobachtet. Danach wurden keine Anfälle mehr erfasst. Nachdem bei einer Brunol4 $^{-/}$x Brunol4 ${ }^{-/-}$-Verpaarung unter Geschwistern keine Nachkommen gezeugt worden waren, wurde das zuletzt genannte Brunol4 ${ }^{-/}$-Weibchen mit einem Brunol4 ${ }^{+/+}$- 
Männchen verpaart. Ein Brunol4 ${ }^{-/-}$-Männchen, bei welchem keine Krämpfe beobachtet wurden, wurde mit einem Brunol4 ${ }^{+/+}$-Weibchen verpaart. In der erstgenannten Verpaarung wurden viermal je 2-3 Nachkommen geboren, welche jedoch nach Geburt von den Eltern aufgefressen worden sind. Aus der Verpaarung des Brunol4-defizienten Männchens gingen keine Nachkommen hervor. Auch zeigte sich bei dem Weibchen kein Vaginalpfropf. Dieses Männchen starb im Alter von 10 Monaten. Bei über 80 Brunol4 $^{+/}$-Tieren, die länger als 3 Monate, und über 50 Mäusen, die länger als 6 Monate und zum Teil bis $\mathrm{zu}$ 1,5 Jahre beobachtet wurden, zeigte lediglich ein Männchen einen einzelnen Krampfanfall im Alter von 10 Monaten.

\subsection{Morphologische Untersuchungen des Gehirns}

\subsubsection{Histologie des Gehirns bei Brunol4-defizienten Mäusen}

Da Brunol4 im Gehirn und v.a. im Hippocampus exprimiert wird (Yang et al. 2007) und die veränderte Expression einen ausgeprägten Phänotyp zur Folge hat (s.o.), wurden die Gehirne von Brunol4-defizienten Mäusen auf morphologische Besonderheiten untersucht. Dazu wurden von Gehirnen von 6 und 50 Tage alten Mäusen (je Brunol4 ${ }^{-/-}$ und Wildtyp-Kontrolle) HE-gefärbte Koronar- bzw. Saggitalschnitte angefertigt. Diese Schnitte wurden mit Hilfe der Abteilung Neuroanatomie des Zentrums für Anatomie in Göttingen beurteilt. Es konnten keine deutlichen Unterschiede der HippocampusStruktur zwischen Wildtyp und defizienter Maus festgestellt werden (vgl. Abb 3.19, 3.20 und 3.21). Die Unterschiede in der Purkinjezellschicht der Kleinhirnringe können mit der Fixierung bzw. der Färbung zusammenhängen. 

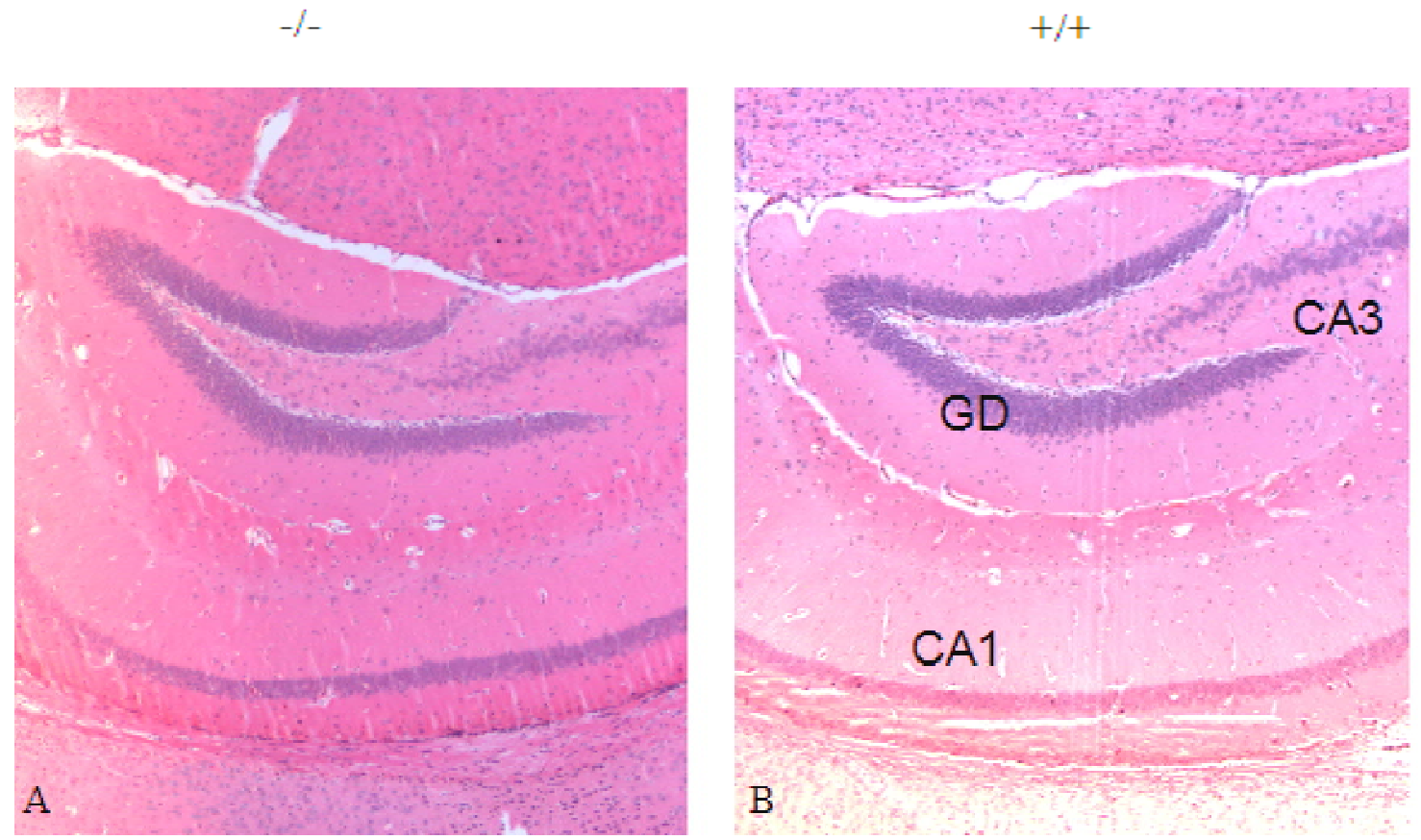

Abb. 3.18: Histologischer Vergleich der Hippocampus-Region von Wildtyp und Brunol4-defizienter Maus

Es wurden keine Unterschiede zwischen 50 Tage alten Brunol4 ${ }^{-/-}$-Mäusen (A) und Wildtyp-Kontrollen (B) bei der histologischen Untersuchung des Hippocampus gefunden. GD: Gyrus dentatus CA1 und CA3: entsprechende Regionen des Cornu ammonis, HE x4 

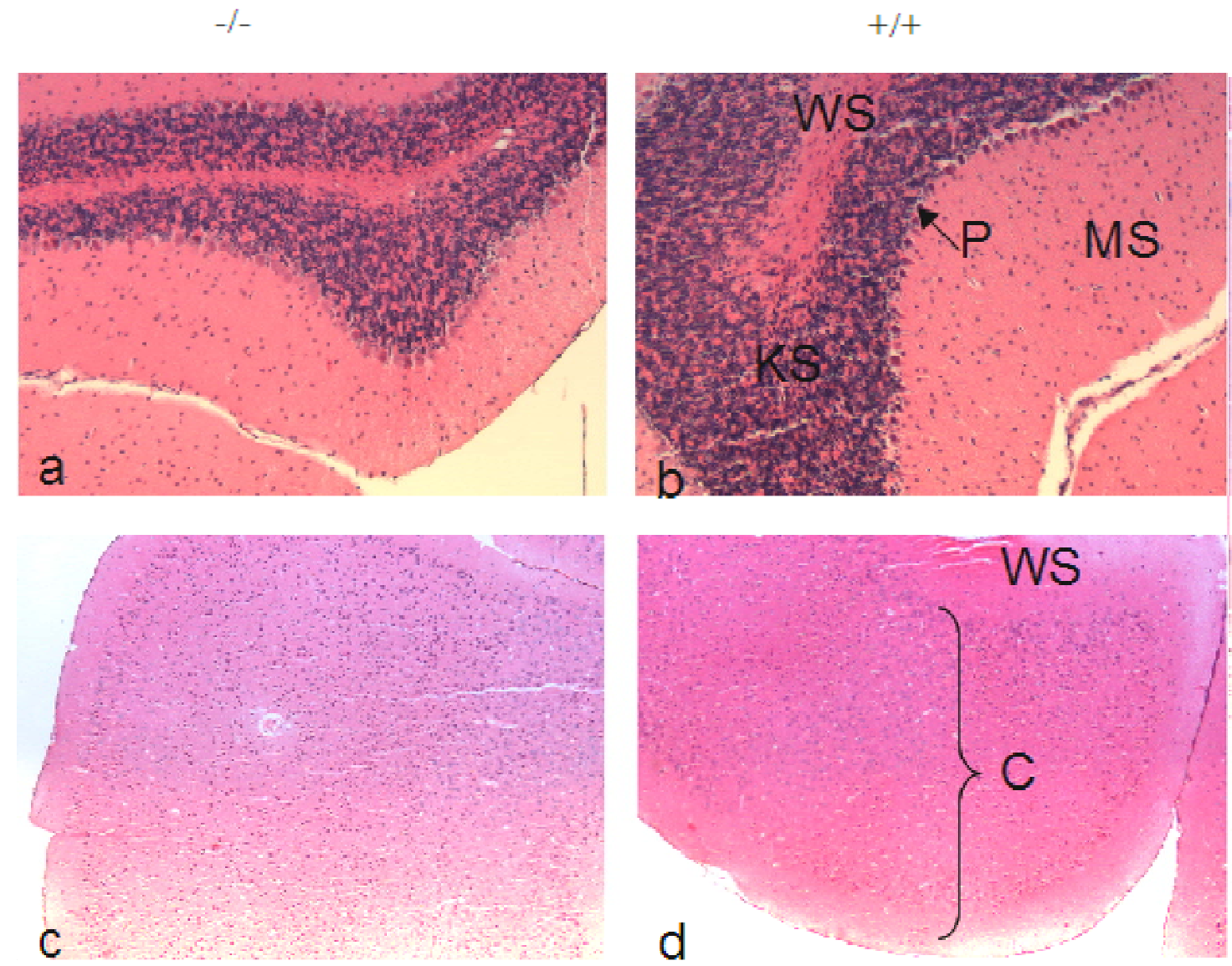

Abb. 3.19: Histologischer Vergleich der Kleinhirnrinde und der Frontalhirnrinde von Wildtyp und Brunol4-defizienter Maus

Es wurden 2 Brunol4 $^{-1}$-Tiere im Alter von 6 Tagen und 50 Tagen zusammen mit Brunol4 $^{+/{ }_{-}}$Geschwistern auf Anomalien des Gehirns untersucht. Brunol4 ${ }^{-/-}$(a) und Brunol4 ${ }^{+/+}$(b) Kleinhirnrinde und Mark, $50 \mathrm{~d}$; Brunol4 ${ }^{-/-}$(c) und Brunol4 ${ }^{+/+}$(d), Frontalhirnrinde, $50 \mathrm{~d}$ alt. WS (weiße Substanz), MS (Molekularschicht), P (Purkinjezellschicht), KS (Körnerzellschicht), C (Cortex), HE x10 (Cerebellum), x4 (Cortex) 


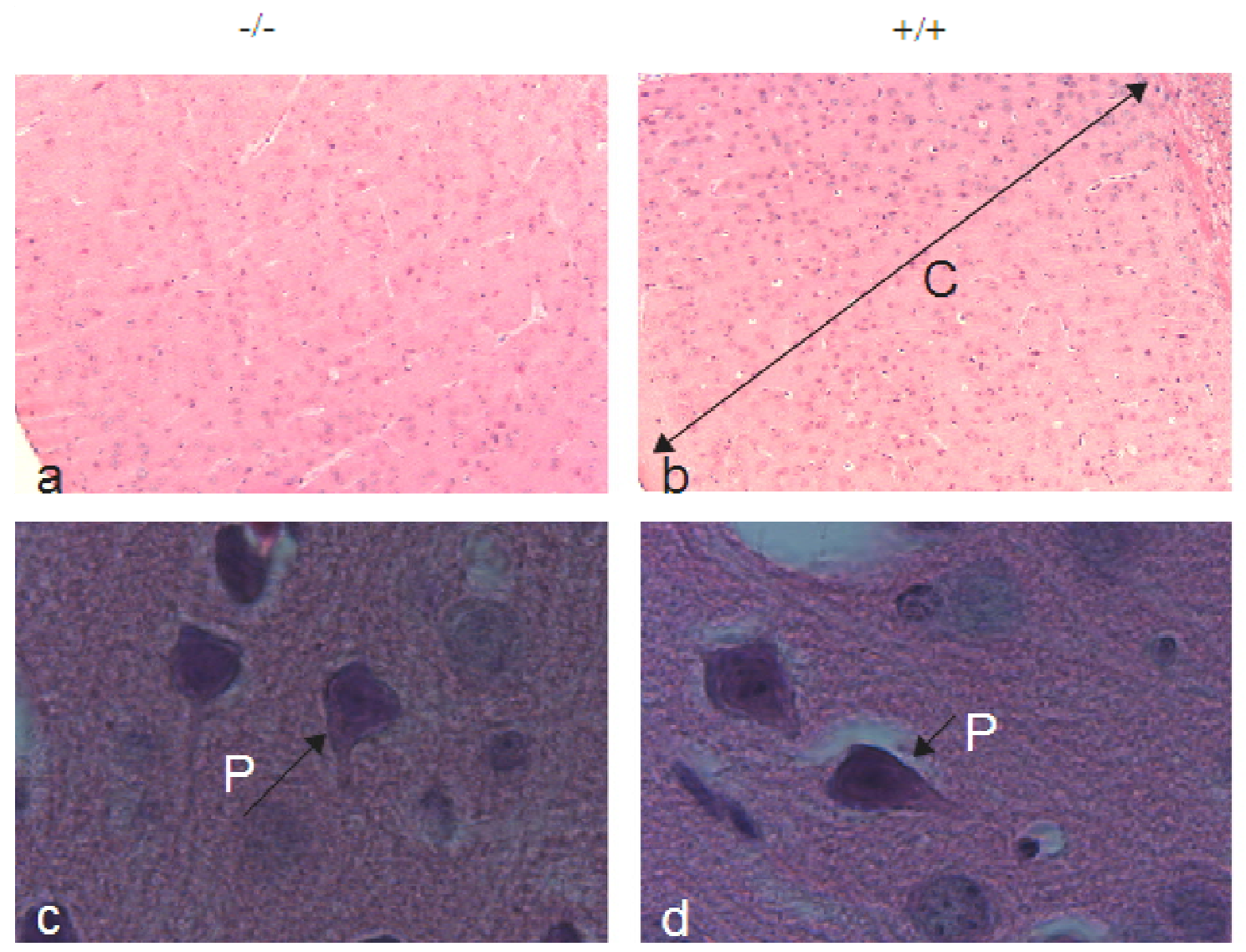

Abb. 3.20: Histologischer Vergleich der Großhirnrinde und der Pyramidenzellen von Wildtyp und Brunol4-defizienter Maus

50 d alte Mäuse a) Brunol4 ${ }^{-/-}$und b) Brunol4 ${ }^{+/+}$und Großhirnrinde (C, Cortex), HE x4c) und d) Pyramidenzellen (P) der Großhirnrinde, HE x100

\subsubsection{Untersuchungen auf Unterschiede in der Verteilung und} Expression von munc-18 und beta-Tubulin sowie in der Länge der Neuronenfortsätze bei Brunol4\%-Mäusen

Im Zusammenhang mit dem Auftreten des Ohtahara-Syndroms (frühkindliche epileptische Enzephalopathie) sind missense Mutationen des Proteins munc-18 (auch synaptic binding protein 1, STXBP1) beschrieben worden (Saitsu et al. 2008), welches zum synaptischen Fusionskomplex gehört. Eine erniedrigte Abbaurate von munc-18, d.h. eine Stabilisierung, könnte mit einer höheren Sekretionsrate an der Synapse einhergehen. Auch Hoch- bzw. Herunterregulation von beta-Tubulinen korreliert mit dem Auftreten von Epilepsie (Guo und Kuang 1993; Yang et al. 2007). Brunol4 wird im Hippocampus stark exprimiert und aufgrund seiner Funktion als RNA-Bindungsprotein 
wird vermutet, dass Brunol4 eine Rolle beim Abbau von RNA spielt. Ob die Funktionsminderung oder -änderung von Brunol4 zu einer Herunter- oder Heraufregulation von munc-18 oder beta-Tubulin führt, wurde mittels Immunfluoreszenzfärbung mit Antikörpern gegen munc-18-1 und beta-Tubulin untersucht. Bei beta-III-Tubulin handelt es sich um eine neuronspezifische betaTubulin-Isoform. beta-Tubuline bilden zusammen mit alpha-Tubulinen als Dimere die Grundstruktur für Mikrotubuli. Mikrotubuli sind röhrenförmige Proteinfilamente, die einen Bestandteil des Zytoskeletts darstellen. Für die Untersuchungen wurden Hippocampi von fünf Tage alten Mäusen (Brunol4 $^{-/}$des Hybridhintergrunds und Kontrolle) präpariert und trypsinisiert. Hippokampale Nervenzellen wurden isoliert, angezüchtet und mit Antikörpern gegen munc-18-1 und beta-III-Tubulin, markiert. Es wurden keine Intensitätsunterschiede beim Vergleich von Wildtyp-Neuronen mit Nervenzellen von Brunol4 ${ }^{-/-}$-Tieren festgestellt (vgl. Abb. 3.21).
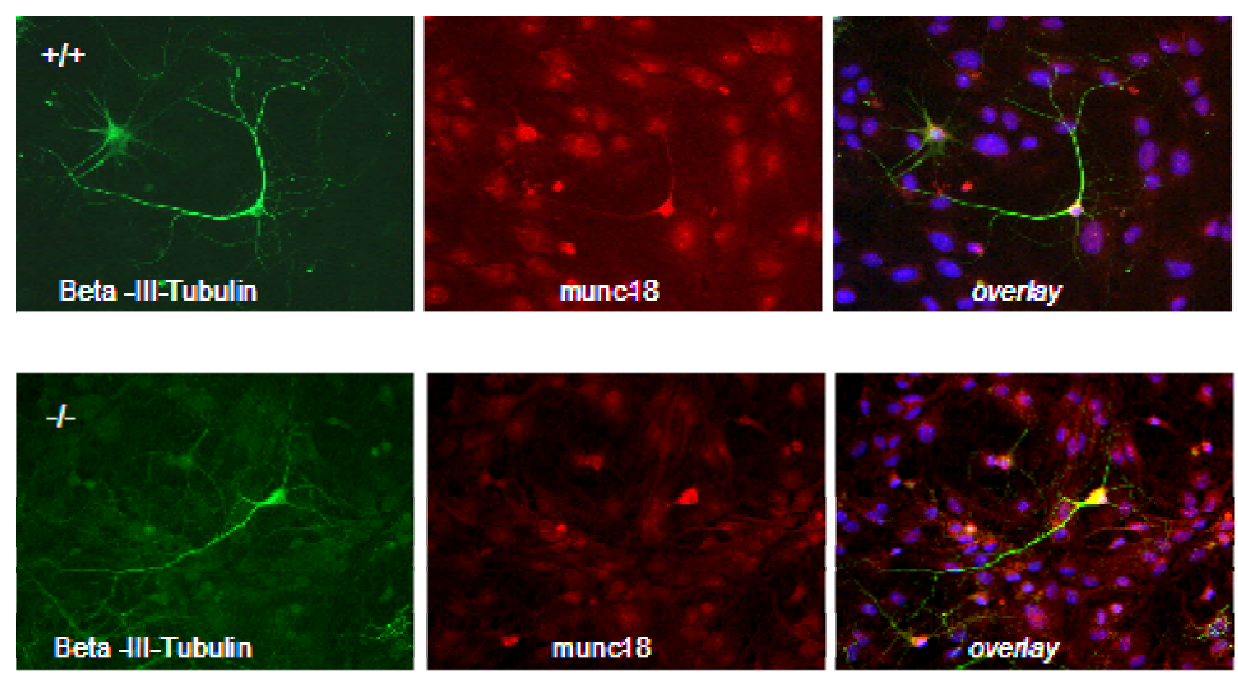

Abb. 3.21: Immunfluoreszenzfärbung von hippokampalen Neuronen von Wildtyp und Brunol4defizienter Maus

Immunfluoreszenzfärbung hippokampaler Neurone von Wildtyp (+/+) und Knockout-Maus (-/-) mit Antikörper gegen beta-III-Tubulin (grün) und munc18 (rot), sowie Überlagerung von beiden mit DAPI (blau), FM, x200

Auch konnten keine Unterschiede der neuronalen Zellen bezüglich Expression von betaIII-Tubulin und munc-18-1 zwischen Wildtyp und Brunol4-defizienter Maus detektiert werden. Um herauszufinden, ob die Fortsätze der neuronalen Zellen sich in der Länge von denen des Wildtyps unterscheiden, wurden Fortsätze von je 15 Neuronen mit dem Programm imageJ (NIH, USA) gemessen. Es zeigten sich keine signifikanten 
Unterschiede zwischen Brunol4 ${ }^{-/}$-Tieren und Wildtyp (Abb. 3.22). In beiden Fällen zeigte sich eine mittlere Länge von $500 \mu \mathrm{m}$.

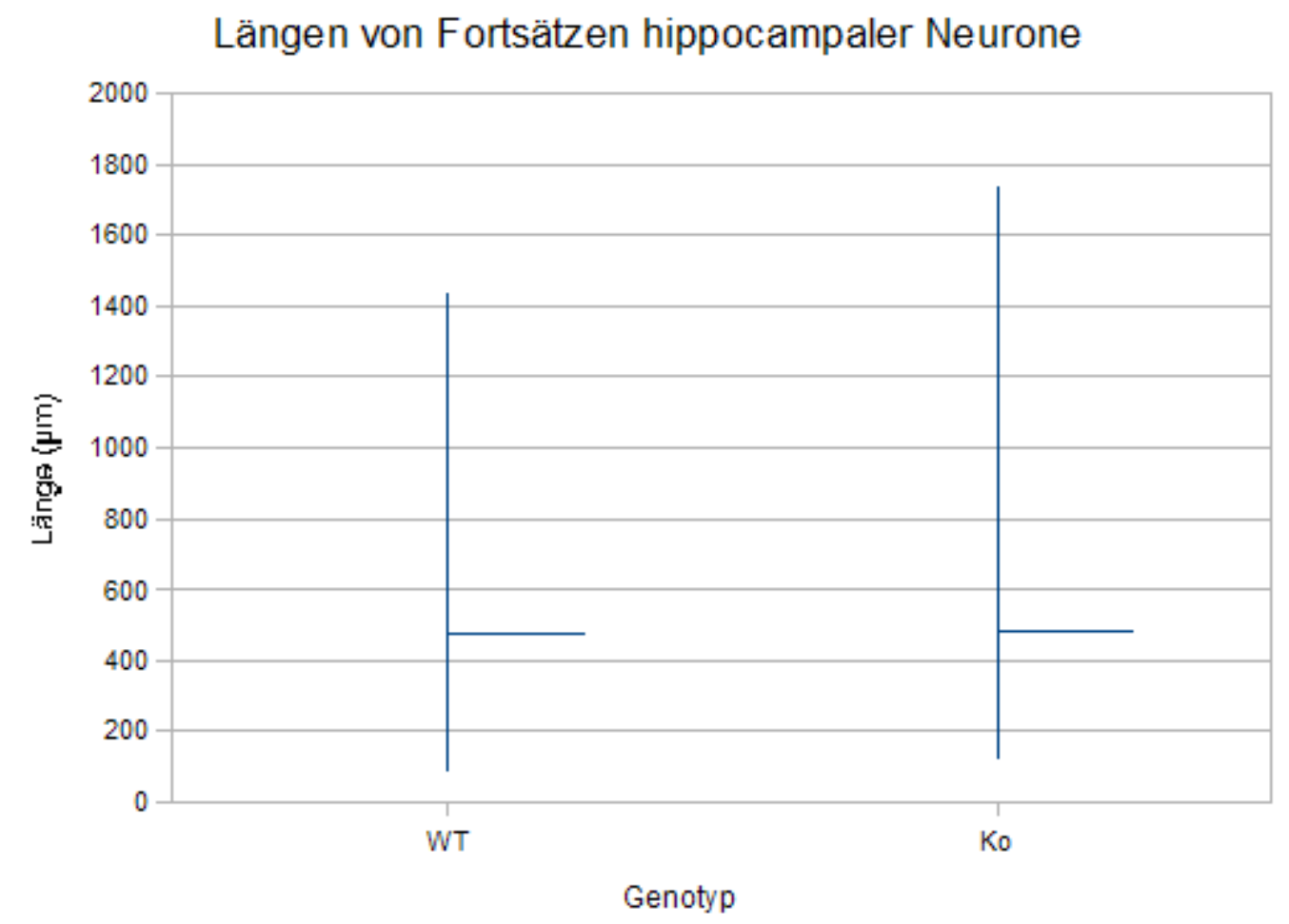

Abb. 3.22: Auftragung der Verteilung der Fortsatzlängen einer Brunol $4^{--}$-Maus und einer WildtypKontrolle

Mit imageJ wurden die Fortsätze von 15 Neuronen einer 5 Tage alten Brunol4 ${ }^{-/-}$-Maus gemessen und mit denen einer gleichaltrigen Wildtyp-Kontrolle verglichen.

\subsection{Generierung und Untersuchung von Brunol1/Brunol4-Doppelt- Knockout-Mäusen}

\subsubsection{Generierung und Genotypisierung}

Das murine Brunol1-Gen, welches im Gehirn und im Testis exprimiert wird, spielt eine Rolle in der Spermatogenese (Dev et al. 2007). Analysen der Brunoll-Knockout-Mäuse zeigten eine signifikante Reduktion der Spermienzahl. Allerdings waren die männlichen Brunol1 $^{-/}$-Mäuse fertil. Brunol1 und Brunol4 gehören als RNA-Bindungsproteine beide einer Subfamilie der elav-Familie an. Um $\mathrm{zu}$ untersuchen, welchen Effekt das kombinierte Ausschalten der Gene Brunol1 und Brunol4 hat, wurden Mäuse gezüchtet, 
die sowohl das rekombinante Brunol4-Allel als auch ein Nullallel des Brunoll-Gens enthalten. Hierfür wurden Brunoll-defiziente Mäuse der Linie 129/Sv (Dev et al. 2007) mit heterozygoten Brunol4 ${ }^{+/-}$-Tieren des Inzuchthintergrunds 129/Sv verpaart. Die Verpaarungen der Brunol1 ${ }^{-/}$-Tiere mit den Brunol4 $^{+/-}$-Mäusen zeigten im Vergleich zu Wildtyp-Verpaarungen keine Reduktion in der Nachkommenzahl bei durchschnittlichen Wurfzahlen von $5,8 \pm 2$ bei 10 beobachteten Würfen. Daraus hervorgegangene doppelt heterozygote Tiere $\left(\right.$ Brunol1 $^{+/} /$Brunol4 $^{+/}$) wurden dann miteinander verpaart, um für das jeweilige ausgeschaltete Allel in der F2-Generation doppelt homozygote Mäuse, d.h. Mäuse, die sowohl für Brunoll als auch für Brunol4 defizient sind, zu generieren. Dafür wurden alle Nachkommen ca. drei Tage nach der Geburt genotypisiert.

\begin{tabular}{|l|l|l|l|l|l|}
\hline Brunol1//Brunol4 & $+/+/ /+/+$ & $-/-/ /+/+$ & $+/+/ /-/-$ & $-/-/ /-/-$ & gesamt \\
& $+/-/ /+/$ & $-/-/ /+/-$ & $+/-/ /-/-$ & & \\
& $+/+/ /+/-$ & & & & \\
& $+/-/ /+/-$ & & & & \\
\hline O & 35 & 11 & 7 & 3 & 56 \\
\hline & $62,5 \%$ & $19,6 \%$ & $12,5 \%$ & $5,4 \%$ & \\
\hline+ & 42 & 7 & 6 & 1 & 56 \\
\hline & $75 \%$ & $12,5 \%$ & $10,7 \%$ & $1,7 \%$ & \\
\hline gesamt & 77 & 18 & 13 & 4 & 112 \\
\hline & $68,7 \%$ & $16,1 \%$ & $11,6 \%$ & $3,6 \%$ & \\
\hline
\end{tabular}

Tab. 3.7: Quantitative Verteilung verschiedener Genotypen von Mäusen der F2-Generation mit 129/Sv-Inzuchthintergrund (2-3 d alt)

Die 112 Nachkommen (F2-Generation) der doppelt heterozygoten Mäuse der Linie 129/Sv wurden spätestens am dritten Lebenstag nach Geburt genotypisiert.

Tabelle 3.7 zeigt die Nachkommenstatistik. Insgesamt wurden 112 Mäuse spätestens am dritten Lebenstag genotypisiert. Der nach Mendelscher Verteilung erwartete Wert für Brunol1 ${ }^{-/} /$Brunol4 $^{-/-}$-Tiere liegt mit 8,75\% $(1 / 16)$ über dem beobachteten Anteil von 3,6\%. Die Verteilung von heterozygoten oder Wildtyp-Tieren (1. Spalte) zu Tieren, die homozygot für Brunol1, Brunol4 oder beide Gene sind, zeigt ein Verhältnis von ca. 19,25: 4,5:3,5: 1 (bei männlichen Tieren 11,6:3,6:2,3:1 und bei Weibchen $42: 7$ : $6: 1$ ) im Vergleich zu einem erwarteten Verhältnis von $9: 3: 3: 1$. Die Verteilung der 
Männchen weicht nicht signifikant von den Erwartungswerten ab $\left(\chi^{2-T e s t, ~} p=0,729\right)$. Die Verteilung der Weibchen unterscheidet sich jedoch signifikant von den erwarteten Werten $(\chi 2$-Test, $p<0,05)$. Die durchschnittliche Wurfgröße ist mit fünf Nachkommen bei 26 Würfen nur geringfügig niedriger verglichen mit 5,28 Nachkommen in zehn Wildtyp-Verpaarungen. Alle geborenen acht Mäuse mit Brunol1 ${ }^{+/} /$Brunol4 $^{-/-}$-Genotyp

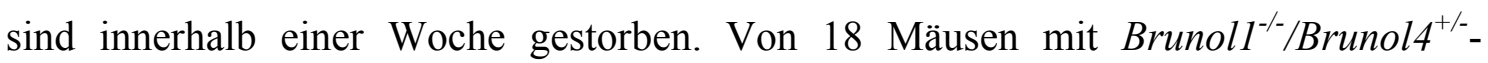
Genotyp ist ein Tier im Alter von drei Tagen gestorben. Die restlichen Tiere lebten länger als drei Monate und Männchen wie Weibchen waren fertil. Drei doppelt heterozygote Tiere sind im Alter von zwei (gesamter Wurf verstoßen), fünf und 25 Tagen verstorben, dagegen überlebten 20 beobachtete Tiere länger als drei Monate. Vier Mäuse mit Brunol1 $1^{-/} /$Brunol4 $^{-/}$-Genotyp sind nach max. zwei Tagen gestorben. Bei anderen Verpaarungen (Brunol1 $1^{-/} /$Brunol4 $^{+/}$als Eltern) sind bisher keine Brunol1 ${ }^{-/}$ /Brunol4 ${ }^{-/}$-Tiere aufgetreten.

\subsubsection{Untersuchungen der Testes und Spermien einer Brunol1+/-/Brunol4+/--Maus}

Sechs Verpaarungen doppelt heterozygoter Mäuse wurden über einen längeren Zeitraum beobachtet. Alle bis auf eine Verpaarung waren fertil. Brunoll wird in der Maus im Gehirn und in den Testes exprimiert und spielt eine Rolle in der Spermatogenese, Brunoll-defiziente Mäuse zeigen jedoch keine verminderte Fertilität (Dev 2006). Die o.g. verpaarten Mäuse sind nicht nur heterozygot für Brunoll sondern auch für Brunol4. Möglicherweise können Störungen vorliegen, die in Brunoll ${ }^{+/}$Mäusen durch Brunol4 kompensiert worden sein könnten. Um zu untersuchen, ob morphologische Auffälligkeiten der Testes oder funktionelle Auffälligkeiten der Spermien bestanden, wurde das 8,5 Monate alte Brunoll $^{+/-} /$Brunol4 $^{+/-}$-Männchen untersucht (vgl. 3.6.2.1 - 3.6.2.4). Bei der Präparation fiel auf, dass einer der zwei Hoden sehr klein war. Von dieser Maus wurden Hoden und Nebenhoden histologisch bzw. funktionell untersucht. Von neun weiteren Brunol1 ${ }^{+/} /$Brunol4 $^{+/}$-Männchen wurde das Genitale untersucht. Makroskopisch gab es keine Veränderungen der herauspräparierten Testes. 


\subsubsection{Histologie der Testes}

Die Testes der Brunol1 ${ }^{+/} /$Brunol4 $^{+/-}$-Maus (8,5 Monate) mit dem kleinen Hoden und einer Wildtyp-Kontrolle wurden fixiert und zur Untersuchung an Herrn Prof. Meinhardt (Zentrum für Anatomie, Justus-Liebig-Universität Gießen) geschickt. Der normal große Hoden der doppelt heterozygoten Maus unterschied sich nicht von WT-Hoden und war morphologisch unauffällig. Der kleinere Hoden bot ein histologisch stark verändertes Bild (vgl. Abb. 3.23). Lediglich am Rand lagen einige wenige Tubuli seminiferi, die in sehr wenigen Fällen noch weitgehend normale Spermatogenese zeigten, häufiger jedoch Spermatogenese in Regression. Die Tubuli machten jedoch nur etwa 5\% des Anschnittes aus (vgl. Abb. 3.23). Der größte Teil des Anschnittes (>90-95\%) war fibrosiert und/oder von großen Zysten durchzogen, die ein proteinreiches Exsudat enthielten. Spermatogenese oder auch nur die Trennung von Keimepithel zum Interstitium war nicht mehr $\mathrm{zu}$ erkennen. Das Organ wurde von dichten bindegewebsartigen Zügen durchzogen, in denen sich umkapselte Zysten befanden. Zudem war eine Ödembildung erkennbar.

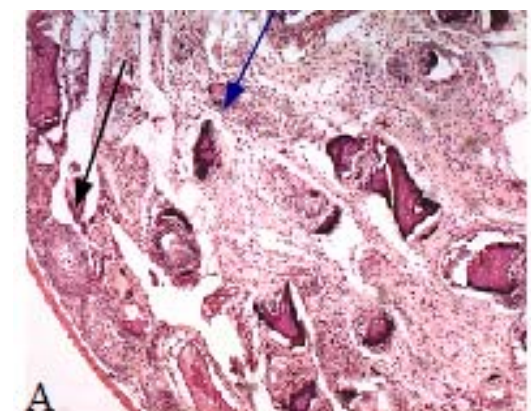

Brunoll/Brunol4, kleiner Testis

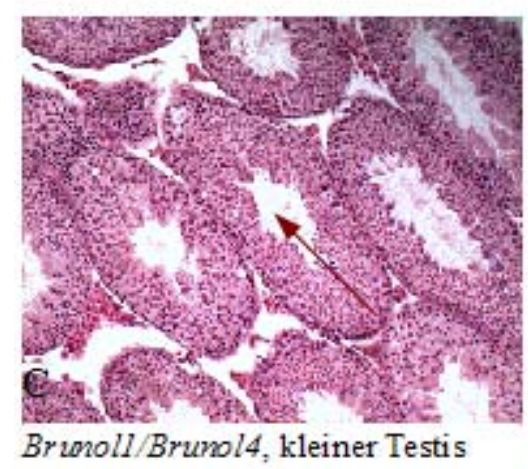

Abb. 3.23: Histologische Untersuchung eines Testis

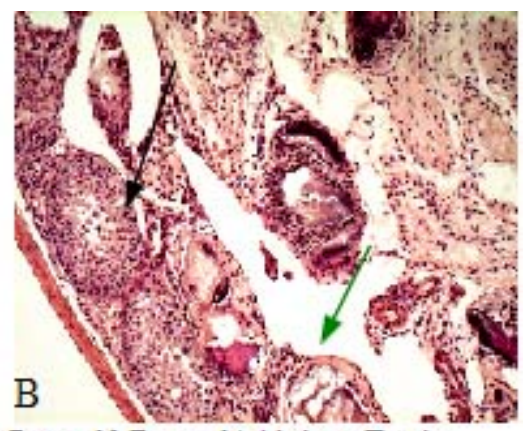

Brunoll/Brwol4, kleiner Testis

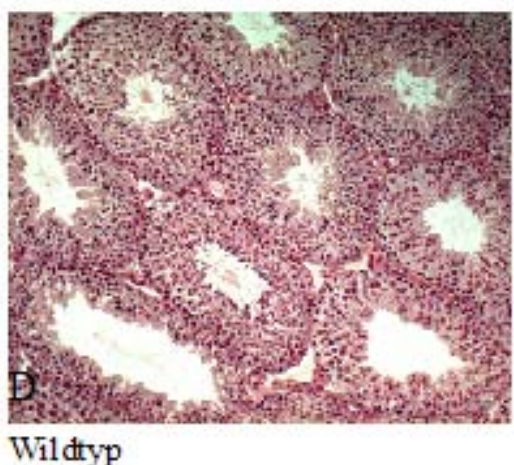

Wildtyp

Deutlich auffälliger Testis der infertilen Brunol1 ${ }^{+/}$Brunol4 $^{+/}$-Maus (A,B,C) im Vergleich zur Wildtyp-

Kontrolle (D). In A sind vereinzelte Tubuli seminiferi (schwarzer Pfeil) sowie fibrosierte Tubuli seminiferi (blauer Pfeil) umgeben von Bindegewebe zu sehen. In B zeigen sich neben randständigen 
Tubuli seminiferi (grüner Pfeil) Zysten. In C sind normale Tubuli seminiferi zu sehen (roter Pfeil). HE, x5 bzw. x10 (Bilder: Prof. Meinhardt, Gießen)

\subsubsection{Morphologische Untersuchung der Spermien nach DAPI-Färbung}

Zum Zweck der morphologischen Untersuchung der Spermien des 8,5 Monate alten Brunol1 $^{+/} /$Brunol4 $^{+/}$-Männchens und einer Wildtyp-Kontrolle wurden je $20 \mu 1$ Zellsuspension aus der Cauda epididymidis auf Objektträger gegeben, in Formaldehyd fixiert und mit DAPI-enthaltendem Medium bedeckt. Die Präparate wurden dann unter einem Fluoreszenz-Mikroskop BX 60 (Olympus) begutachtet (vgl. Abb. 3.24).
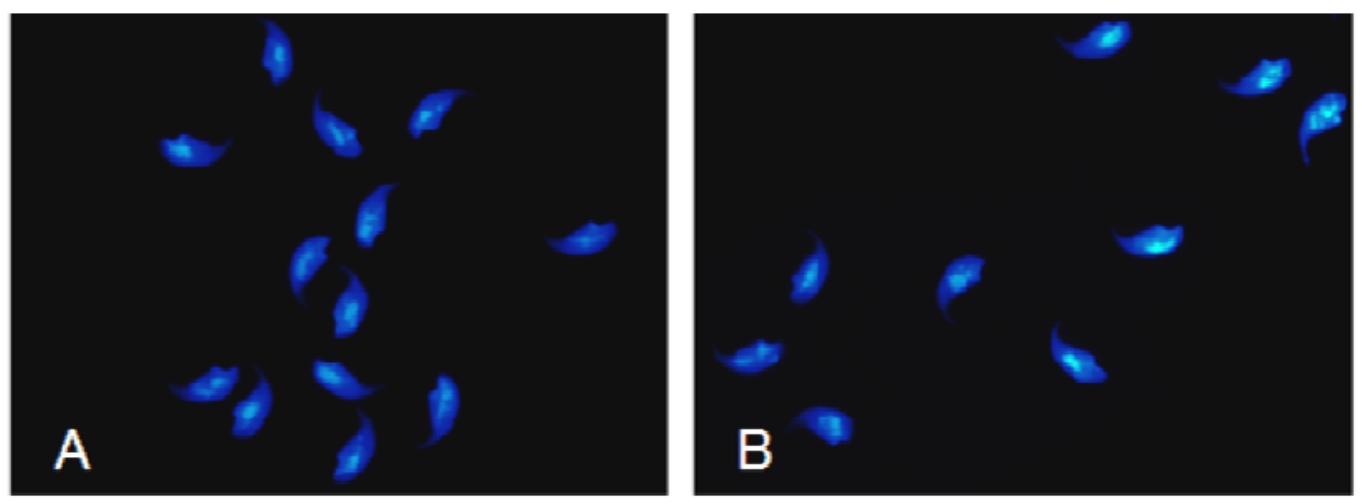

Abb. 3.24: Spermienköpfe einer 8,5 Monate alten Brunol1 ${ }^{+/-} /$Brunol4 $^{+/-}$-Maus (A) und einer gleichaltrigen Wildtyp-Kontrolle (B)

Die Spermien der Brunol1 $1^{+/} /$Brunol4 $^{+/-}$-Maus unterscheiden sich morphologisch nicht von denen des Wildtyps. DAPI, FM, x100

\subsubsection{Spermienzählung:}

Von dem 8,5 Monate alten Brunol1 $1^{+/} /$Brunol4 $^{+/}$-Männchen und einer WildtypKontrolle wurden Spermien aus dem Nebenhoden in IVF-Medium resuspendiert und für 15 min. bei $37^{\circ} \mathrm{C}$ inkubiert. In einer Neubauerzählkammer wurde die Spermienzahl bestimmt. Es wurden $24 \times 105 / \mathrm{ml}$ Spermien der 8,5 Monate alten Brunoll $^{+/-}$Brunol4 $^{+/-}$ Maus gezählt, eine im Vergleich zur Wildtyp-Kontrolle mit 14,2 x 10\% $/ \mathrm{ml}$ deutlich reduzierte Anzahl. Für eine statistische Auswertung müssten mehrere Mäuse untersucht werden. 


\subsubsection{Analyse der Motilität der Brunol1+/-/Brunol4+/- -Mäuse}

Es wurde die Spermienmotilität nach 1,5 h und nach 3,5 h mit dem Programm computer assisted semen analysis (CASA) gemessen. Nach 1,5 h waren 51\% der Spermien der Brunol $^{+/-} /$Brunol4 $^{+/-}$-Maus motil. $29 \%$ zeigten eine progressive Motilität. $\mathrm{Zu}$ dieser Zeit zeigten sich die Spermien der Kontrollmaus zu 58\% motil und zu 35\% progressiv. Nach 3,5 h zeigte sich eine Reduktion der Motilität der Spermien der doppelt heterozygoten Maus auf 7\% motile und 3\% progressiv motile Spermien im Vergleich zu 45\% motilen und $30 \%$ progressiv motilen Spermien der WT-Kontrolle. Weiter wurde eine umfassende Untersuchung der Spermienmotilität durchgeführt. Dazu gehören die Weggeschwindigkeit (average path velocity, VAP), die progressive Geschwindigkeit (straight line velocity, VSL), Bahngeschwindigkeit (curvilinear velocity, VCL), die Breite des Kopfausschlages des Spermiums (lateral amplitude of the head, ALH), Schlagfrequenz des Spermiumschwanzes (beat cross frequency, BCF) und Geradlinigkeit (straightness, STR). Abbildung 3.25 zeigt Box-Plot-Analysen der Motilitätsparameter der beiden Mäuse jeweils nach 1,5 und 3,5 h. Es ließ sich feststellen, dass die Brunol1 ${ }^{+/} /$Brunol4 $^{+/}$-Maus in allen Parametern bis auf die Gradlinigkeit geringere Werte zeigte. Da jeweils nur eine Maus untersucht wurde, kann keine Angabe zur Signifikanz gemacht werden.

$1,5 \mathrm{~h}$

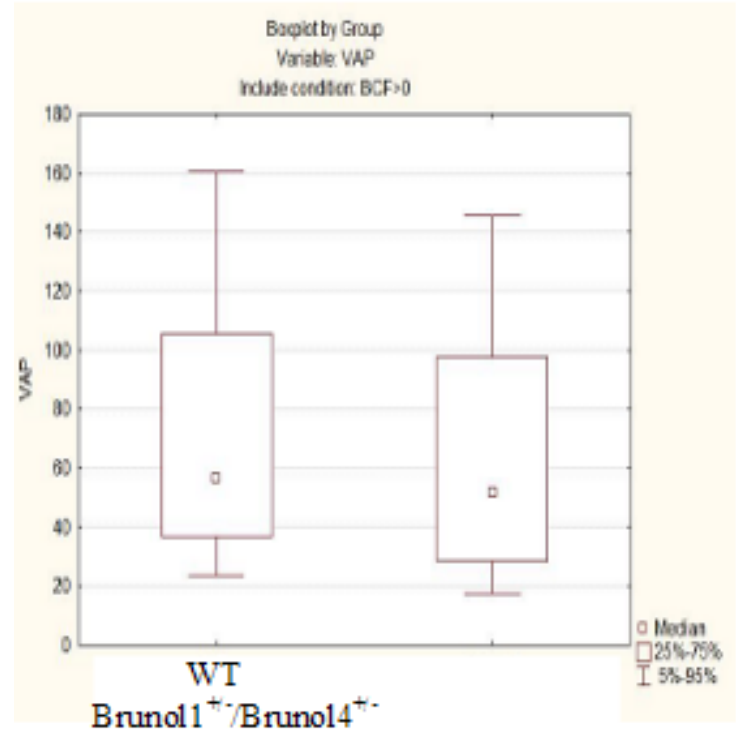

$3,5 \mathrm{~h}$

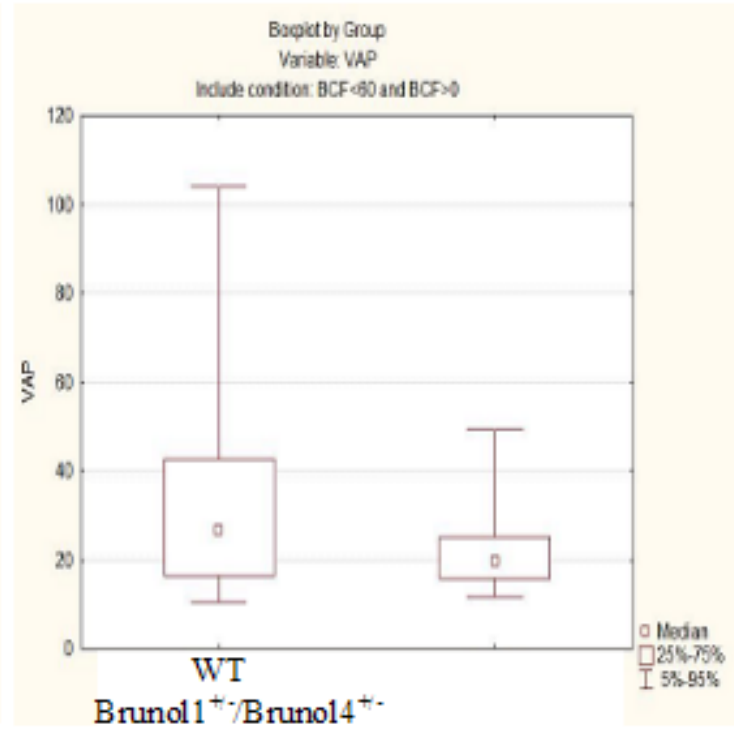



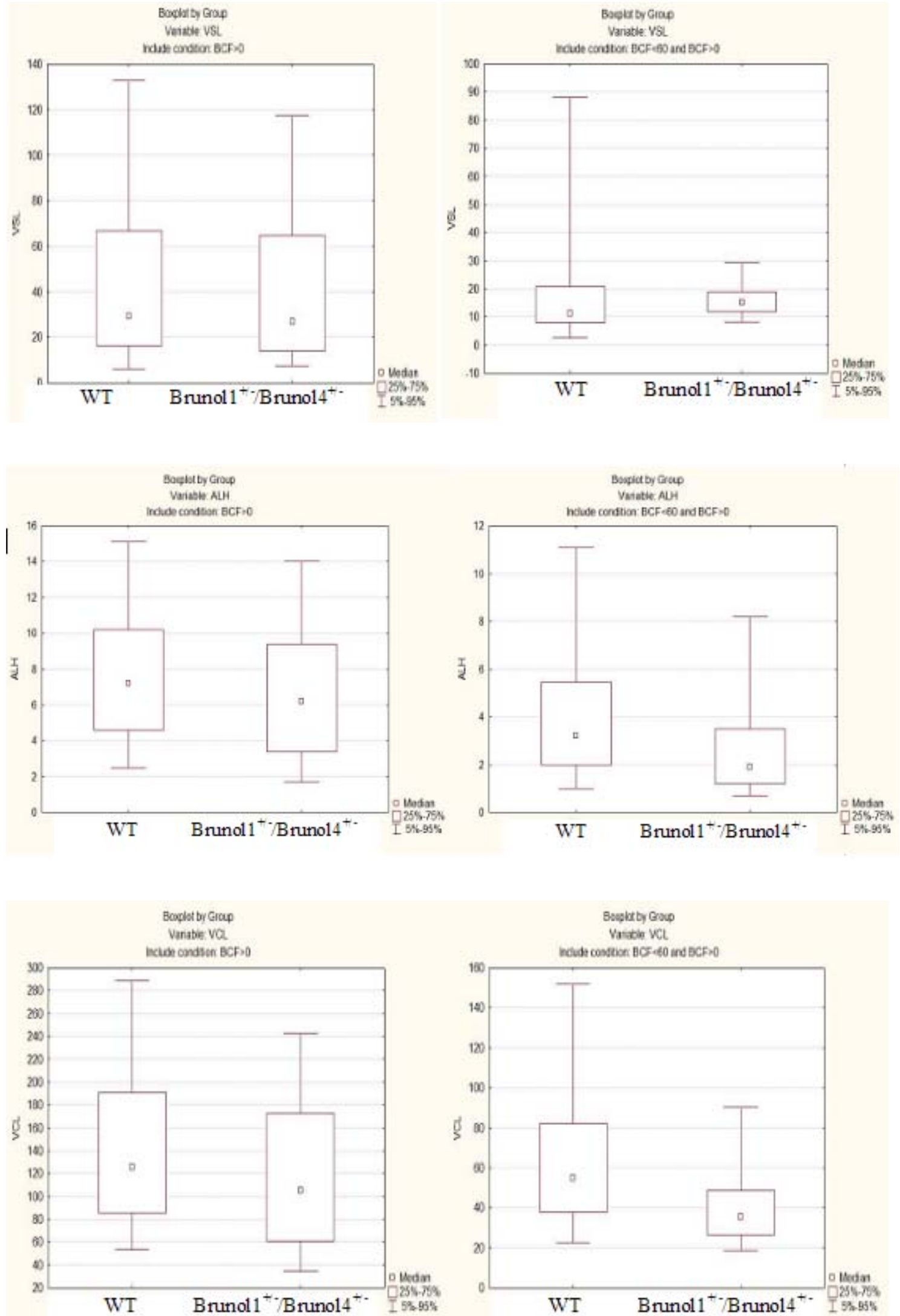

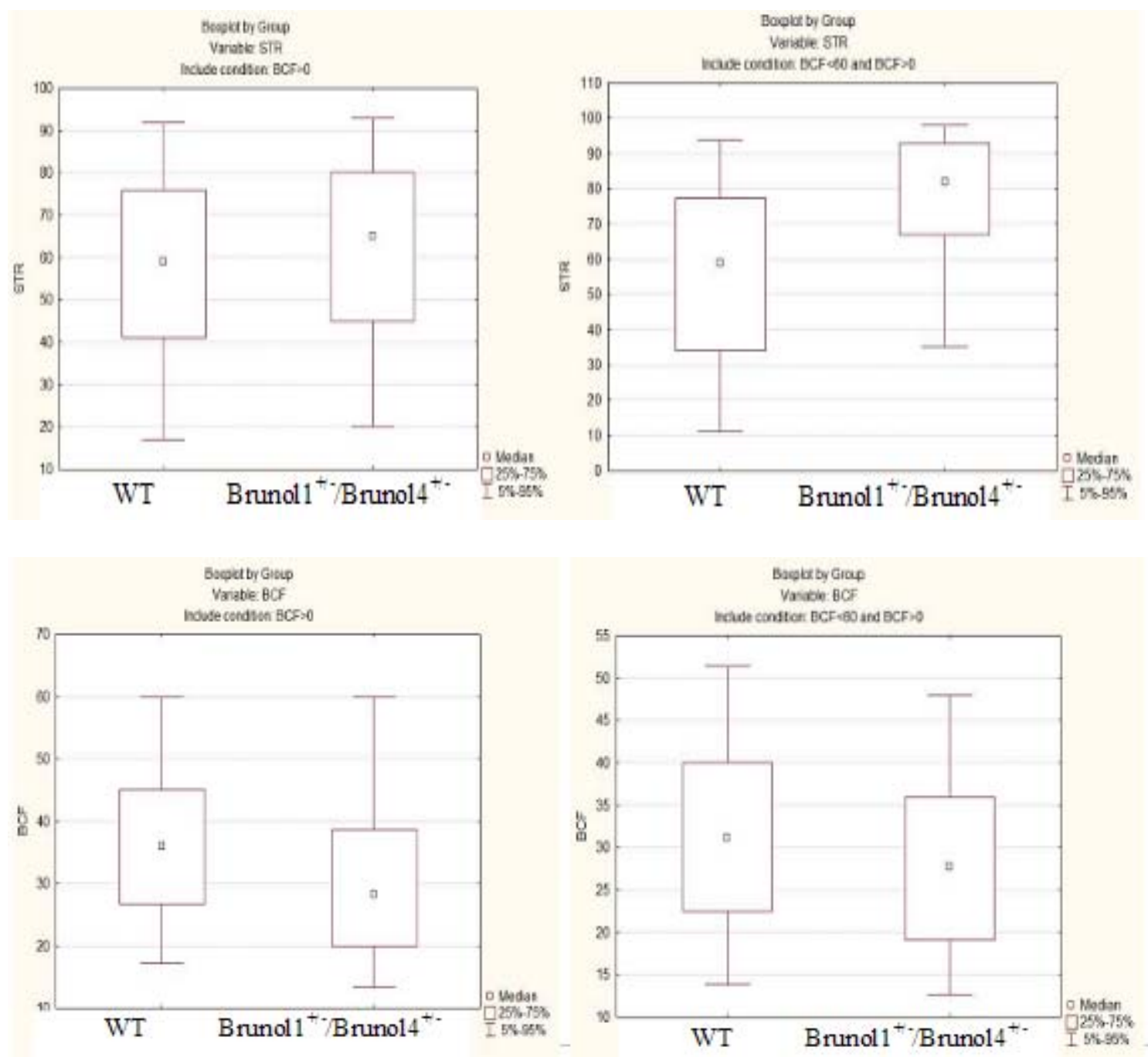

Abb. 3.25: Auswertung der Untersuchung zur Spermienmotilität

Einige Parameter der Spermienmotilität der doppelt heterozygoten Maus und der Wildtyp-Kontrolle wurden genauer untersucht. Dazu gehören die Weggeschwindigkeit (average path velocity, VAP), die progressive Geschwindigkeit (straight line velocity, VSL), Bahngeschwindigkeit (curvilinear velocity, VCL), die Breite des Kopfausschlages des Spermiums (lateral amplitude of the head, ALH), Schlagfrequenz des Spermiumschwanzes (beat cross frequency, BCF) und Geradlinigkeit (straightness, STR). 


\section{Diskussion}

\subsection{Zusammenfassung der Ergebnisse}

Die vorliegende Arbeit beschäftigt sich mit der Analyse von Knockout-Mäusen für das Brunol4-Gen sowie mit Doppel-Knockout-Mäusen für Brunol1 und Brunol4.

Auch in Brunol4 ${ }^{-/-}$-Mäusen ließen sich Brunol4-Transkripte nachweisen. Im Gegensatz zu den Wildtyp-Transkripten fehlte diesen jedoch das Exon 1.

Es ergaben sich keine Hinweise auf eine erhöhte intrauterine Letalität von heterozygoten Brunol4 ${ }^{+/-}$- oder homozygoten Brunol4 ${ }^{-/-}$-Mäusen. Die Anzahl der Nachkommen des 129Sv-Hintergrunds war jedoch reduziert. Brunol4 ${ }^{-/-}$-Mäuse starben zu 50\% vor dem elften Lebenstag (129/Sv) bzw. vor dem 20. Lebenstag (C57Bl/6J x 129/Sv). Sie zeigten außerdem eine Wachstumsretardierung. Analysen des Körpergewichts haben ergeben, dass Brunol4 ${ }^{-/-}$-Mäuse des Hybridhintergrunds signifikant leichter waren als ihre Geschwister.

Brunol4 $^{-/}$-Mäuse zeigten zudem vermehrtes Zittern, krampfartige Schwanzbewegungen und fünf von sechs Tieren, die länger als drei Monate lebten, bekamen Krampfanfälle $\mathrm{ab}$ einem Alter von drei bis vier Monaten. Die Gehirnmorphologie, die Morphologie hippokampaler Nervenzellen sowie die Verteilung von Munc-18 und beta-III-Tubulin in diesen Zellen waren in Brunol4 ${ }^{-/-}$-Mäusen jedoch unauffällig.

Die Verteilung der weiblichen Nachkommen von doppelt heterozygoten Mäusen für Brunol1 und Brunol4 (Brunol1 ${ }^{+/} /$Brunol4 $^{+-}$) war signifikant zu Gunsten der WildtypTiere verschoben. Bei den männlichen Nachkommen zeigte sich diese Auffälligkeit nicht. 100\% der Brunol1 ${ }^{+/} /$Brunol4 $^{-/-}$-Mäuse starben innerhalb der ersten Woche nach der Geburt und 100\% der Brunol1 $1^{-/} /$Brunol $^{-/-}$-Mäuse starben innerhalb der ersten zwei Lebenstage. Ein infertil verpaartes Brunol1 $^{+/} /$Brunol4 $^{+/-}$-Männchen zeigte eine verringerte Spermienzahl, herabgesetzte Spermienmotilität sowie eine auffällige TestisHistologie.

\subsection{Zur Struktur der Brunol-Genfamilie}


Die Brunol-Genfamilie enthält sechs Mitglieder, welche sowohl ähnliche Sequenzen aufweisen als auch strukturell verwandt sind.
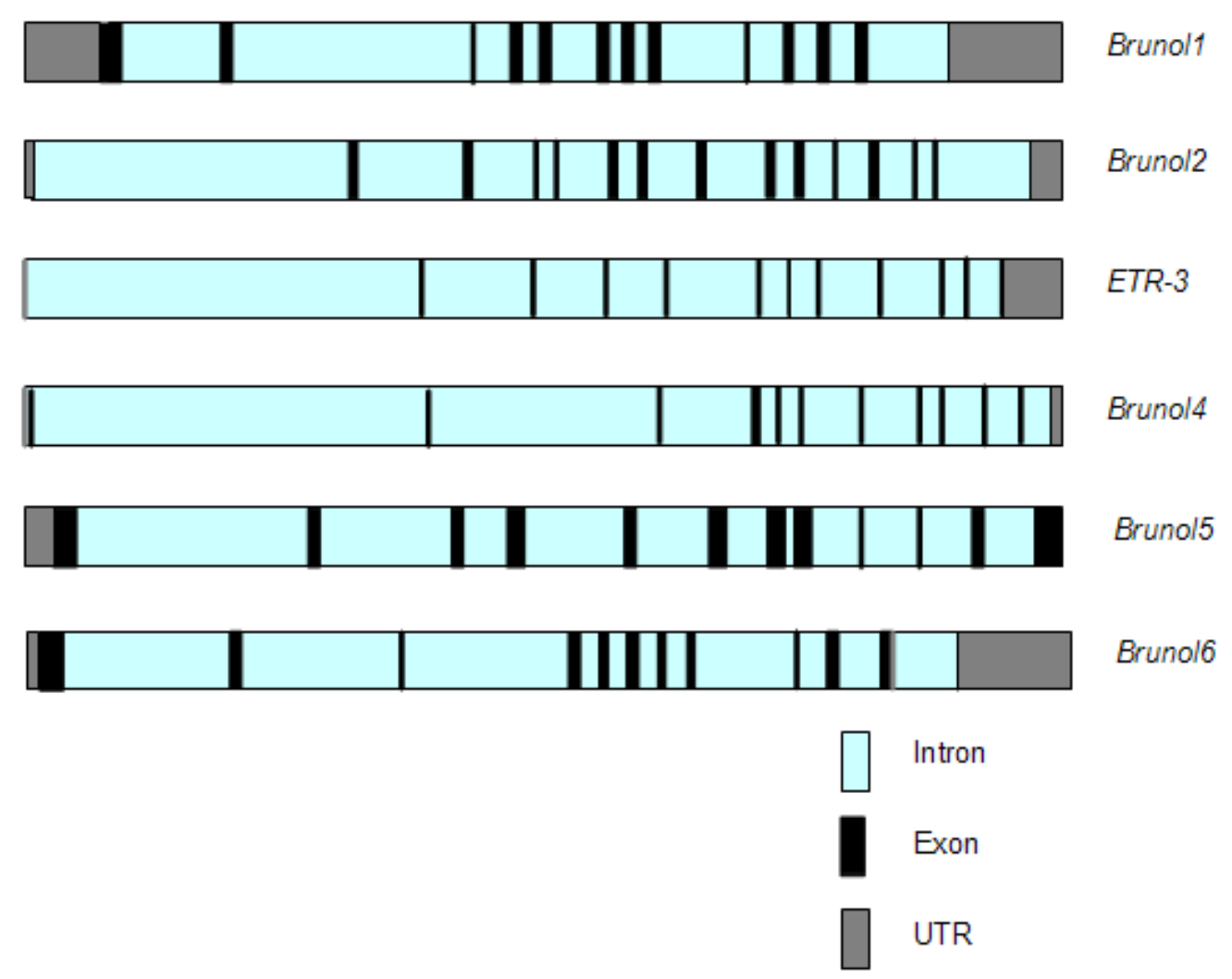

Abb. 4.1: Schematische Darstellung der Genstruktur der Mitglieder der Brunol-Familie

Dargestellt sind die Gene der sechs Mitglieder der Brunol-Familie. Schematisch sind die Lokalisation der Exons sowie der UTRs (untranslated regions, vgl. NCBI) markiert.

Aufgrund der Ähnlichkeit in der Sequenz mit dem Drosophila-melanogaster-Protein Bruno (Kim-Ha et al. 1995) wird die Familie Brunol-Familie (bruno like) genannt (Good et al. 2000). In Abbildung 4.1 sind die Exon-Intron-Strukturen der verschiedenen Mitglieder der Familie schematisch dargestellt. Vertreter der Brunol-Genfamilie finden sich in vielen Spezies, nicht nur in Homo sapiens und Mus musculus, sondern u.a. in Xenopus (Silurana) tropicalis, Xenopus laevis, Gallus gallus, Danio rerio und Rattus norvegicus. Die meisten Proteine der Familie haben drei RNA recognition motifs (RRMs, siehe 1.1). Dabei handelt es sich um Bereiche, die bestimmte RNA-Abschnitte erkennen und an diese binden, so dass das jeweilige Protein seiner RNA-modulierenden Funktion (siehe 4.3) nachgehen kann. 


\subsection{Zur Funktion der Brunol-Gene}

Bei den Proteinen der Brunol-Familie handelt es sich um an RNA bindende Proteine (RBPs). In Wirbeltieren existieren viele verschiedene RBPs, die jeweils eine und häufig mehrere RNA-bindende Domänen (RBDs) besitzen. Diese können gewöhnlich sequenzoder strukturspezifisch an ihrem RNA-Substrat binden. Brunol-Proteine sind an der posttranskriptionellen Prozessierung, wie etwa am Alternativen Spleißen (Barreau et al. 2006), an der Translation, der Deadenylierung und an der mRNA-Degradation beteiligt (Siomi und Dreyfuss 1997) und haben zum Teil überlappende Funktionen. BrunolProteine verschiedener Spezies binden innerhalb der mRNA vor allem an GU-reiche Sequenzen (GU-rich elements, GREs) (Takahashi et al. 2000; Delaunay et al. 2004; Faustino und Cooper 2005; Marquis et al. 2006; Vlasova und Bohjanen 2008; Graindorge et al. 2008). Diese GRE-vermittelte posttranskriptionelle Regulation der Genexpression ist in verschiedenen Spezies hoch konserviert (Vlasova und Bohjanen 2008). Die detailliertesten Untersuchungen zur Funktion der Brunol-Proteine existieren zu Brunol2 oder ETR-3 (s. 4.3.2 und 4.3.3).

\subsubsection{Zur Funktion von Brunol1}

Die meisten Untersuchungen zu Brunoll wurden bei Xenopus laevis durchgeführt. In Xenopus konnten bisher fünf Brunol-Mitglieder identifiziert werden. Brunoll/Etr-1 (Knecht et al. 1995), Brunol2/EDEN-BP (Paillard et al. 1998) sowie Brunol3, Brunol4 und Brunol5 (Wu et al. 2010). Brunoll wird in Xenopus während der Entwicklung vor allem im ventralen Neuralrohr und in der Retina exprimiert (Knecht et al. 1995; Knecht und Harland 1997; Amato et al. 2005). Zudem wurde eine Expression im Gastrointestinaltrakt und eine Anreicherung im dorsalen Pankreas beobachtet (Jarikji et al. 2009; Horb und Horb 2010). Brunoll spielt in Xenopus eine Rolle bei der Entwicklung des Endoderms, indem es die Proliferation von endodermalen Zellen durch Aktivierung der Translation der Cyclin A2-mRNA mittels Bindung an 3'-UTR-Brunoresponse-elements (BREs) reguliert. Die entscheidende Domäne für diese Wirkung stellt die Linker-Region bzw. divergent region dar. Ein Knockdown des Gens hemmt 
die Proliferation und damit die Differenzierung des gesamten Endoderms (Horb und Horb 2010).

Brunol1, welches auch Celf3 oder TNRC4 genannt wird, wird in der Maus bereits an E9,5 exprimiert. In adulten Tieren beschränkt sich die Expression auf die Testes und das Gehirn (Dev et al. 2007). Brunoll-Knockout-Mäuse haben einen milden Phänotyp. So weisen sie zwar eine verminderte Beweglichkeit der Spermien auf, die Fertilität ist jedoch nicht beeinträchtigt (Dev et al. 2007).

Es ist bekannt, dass Brunoll das Spleißen von Exon 10 der prä-mRNA des humanen Tau/MAPT (microtubule-associated protein tau) reguliert, indem es die Inklusion fördert (Wang J et al. 2004). Auch in Testes von Brunol1 ${ }^{-/}$-Mäusen kommt es zu einer Verminderung von Tau mit Exon 10 im Verhältnis zum Trankskript ohne Exon 10 (Chapple et al. 2007). Bei Tau handelt es sich um ein Protein, das an Mikrotubuli bindet und deren Zusammenbau steuert (Goedert et al. 1989a; 1989b). Trotzdem zeigen die Testes von Brunol1-defizienten Mäusen keine morphologischen Veränderungen (Dev et al. 2007). Mutationen im Tau sind u.a. mit verschiedenen Demenzerkrankungen wie Frontotemporaler Demenz mit parkinsonähnlichen Symptomen, Progressiver supranukleärer Paralyse und Cortikobasaler Degeneration assoziiert (Hutton et al. 1998; Poorkaj et al. 1998; Spillantini et al. 1998; Bugiani et al. 1999; Delisle et al. 1999; Stanford et al. 2000; Pastor et al. 2001; Poorkaj et al. 2002).

\subsubsection{Zur Funktion von Brunol2}

Die verschiedenen Isoformen von Brunol2, auch CUG-BP, CUG-BP1 oder Celf1 genannt, werden während der Myogenese in der Maus unterschiedlich exprimiert. Wie die anderen Mitglieder der Brunol-Familie spielt Brunol2 eine Rolle beim Alternativen Spleißen (Phillips et al. 1998; Savkur et al. 2001; Charlet et al. 2002b), bei der Regulation der Translation (Timchenko et al. 1999; Iakova et al. 2004) und bei der Deadenylierung von mRNA (Paillard et al. 2003; Moraes et al. 2006).

Brunol2 ist damit u.a. an der Regulation der Entwicklung und an der Fertilität beteiligt, wie Untersuchungen mit Brunol2-defizienten Organismen zeigen. So weist eine Brunol2-Knockout-Maus eine erhöhte perinatale Mortalität, eine embryonale Wachstumsretardierung, eine Hypofertilität beider Geschlechter sowie eine Beeinträchtigung der Spermatogenese bei einem Großteil der Männchen auf (Kress et 
al. 2007). Ein Knockout des Brunol2-Homologen Eden-BP in Xenopus führt zu Defekten in der Segmentation der Somiten, was für eine entscheidende Rolle von Brunol2 in der Entwicklung spricht (Gautier-Courteille et al. 2004). Ein Ausschalten von ETR-1, dem Brunol2-Homologen bei Caenorhabdidis elegans führt zu erhöhter Letalität und beeinflusst die Muskelentwicklung (Milne und Hodgkin 1999). Dies unterstützt die Identifikation diverser Brunol2-target-mRNAs, die eine Rolle in der Myogenese spielen. Dazu gehören die mRNA des cdk-Inhibitors p21, einem Inhibitor des Zellzyklus (Timchenko et al. 2001b), sowie die mRNAs des myocyte enhancer factor $2 A$ (Timchenko et al. 2004), des Insulin-Rezeptors (Savkur et al. 2001) und eines Chloridionen-Kanals (Charlet-B et al. 2002b).

Die Rolle von Brunol2 in der Myogenese und auch in der Pathogenese der Myotonen Dystrophie Typ I (DM1) ist Inhalt vieler Untersuchungen. Die Myotone Dystrophie ist beim Menschen die zweithäufigste Ursache von muskulärer Dystrophie und die häufigste Ursache für muskuläre Dystrophie im Erwachsenenalter. Phänotypisch zeigen sich Skelettmuskeldystrophie, Reizleitungsstörungen im Herzen, Myotonie, Katarakt und Insulinresistenz.

Normalerweise herrscht im adulten Skelettmuskel ein erhöhtes Muscleblind-like (MBNL) und eine relativ erniedrigte Expression von Brunol2 vor. Bei der DM1 ist dieses Verhältnis andersherum, was zu einem embryonalen Spleißmuster führt (Cooper et al. 2009). Im Skelettmuskel von DM2-Patienten/innen ist Brunol2 dagegen nicht hochreguliert (Lin et al. 2006). Gezielte Überexpression von Brunol2 in der Maus führt $\mathrm{zu}$ einer Verzögerung in der Entwicklung und Differenzierung des Skelettmuskels sowie zu Muskeldystrophie (Timchenko et al. 2004; Ho et al. 2005) und Myotonie (Charlet-B et al. 2002b) wie bei DM1 (Timchenko et al. 2001a). Die Menge an Brunol2-Protein in murinem Herzgewebe sinkt normalerweise ab dem sechsten bzw. zehnten Tag postnatal. Da aber die Menge an RNA unverändert bleibt, handelt es sich wahrscheinlich um eine posttranskriptionelle Regulation (Kalsotra et al. 2008). Eine herzspezifische Überexpression von Brunol2 im Mausmodell ist ausreichend für die Ausprägung eines kardialen Phänotyps wie bei DM1 (Wang GS et al.; 2007; Koshelev et al. 2010).

Bei DM1-Patienten/innen liegt ein mutiertes DMPK-Gen (Dystrophia Myotonia Protein Kinase) mit verlängerten CTG-repeats vor, dessen mRNA für den Phänotyp maßgeblich verantwortlich ist (Mankodi et al. 2000) und die Funktion von Brunol2 beeinflusst (Timchenko et al. 1996; Philips et al. 1998; Timchenko et al. 2001a; 2001b; 2004). Eine 
Erhöhung der CUG-Wiederholungen in der DMPK-mRNA führt zu einer Aktivierung einer Proteinkinase und darüber zu einer Hyperphosphorylierung und Stabilisierung von Brunol2, wie es in kultivierten DM1-Hautfibroblasten, Herzgewebe und humanen DM1-Zellen der Fall ist (Savkur et al. 2001; Timchenko et al. 2001a; Dansithong et al. 2005; Kuyumcu-Martinez et al. 2007).

Verschiedene mRNAs, die in DM1-Zellen missreguliert werden, konnten als Brunol2targets identifiziert werden.

Es wurde berichtet, dass das erhöhte Brunol2 in Zellen von DM1-Patienten/innen auf den Kern beschränkt ist (Roberts et al. 1997). Während der normalen Muskelentwicklung triggert Brunol2 in humanen Myoblasten die Translation sowohl von $p 21$ als auch von $M E F 2 A$ durch Bindung an GCN-repeats. In DM1-Zellen ist Brunol2 und damit seine Bindungsaktivität im Zytoplasma jedoch verringert, was zu verminderten p21 und MEF2A während der Entwicklung führt (Roberts et al. 1997; Timchenko et al. 2001a; 2004). Ebenso ist das proinflammatorische Zytokin Tumornekrosefaktor (TNF) in DM1-Patienten/innen erhöht (Johansson et al. 2000). Brunol2 interagiert mit der PARN-Deadenylase, welche den Poly(A)-Schwanz verkürzt, und destabilisiert so das TNF-Transkript in HeLa-Zellen (Moraes et al. 2006).

Zudem sind das kardiale Troponin $\mathrm{T}(c T N T / T N N T 2)$ und ein Insulinrezeptor (IR) im DM1-Skelettmuskel verändert gespleißt (Philips et al. 1998; Savkur et al. 2001). Im embryonalen, nicht jedoch im adulten Herzen besteht üblicherweise eine Inklusion des Exons 5 der $c T N T$-mRNA (Cooper und Ordahl 1985). cTNT mit Exon 5 wird auch im embryonalen Skelettmuskel exprimiert, nicht jedoch im reifen Skelettmuskel (Cooper und Ordahl 1984). Brunol2 fördert diese Inklusion in Mäusen (Charlet-B et al. 2002a; Ladd et al. 2005a). Der switch der Spleißvarianten korreliert normalerweise mit einer Herunterregulation von ETR-3 und Brunol2 (Ladd et al. 2005a). Bei erhöhtem Brunol2 in DM1-Zellen liegt somit ein embryonales Spleißmuster des cTNT vor (Savkur et al. 2001).

Brunol2 moduliert auch das Alternative Spleißen des Exons 11 des InsulinrezeptorGens (IR) durch Bindung an Spleiß-Silencer (Sen et al. 2009). Brunol2-Überespression führt in normalen Myoblasten zur Hemmung der Inklusion von Exon 11 des $I R$ wie es auch bei der DM1 vorliegt (Savkur et al. 2001; Paul et al. 2006).

Eine erhöhte Brunol2-Aktivität scheint außerdem eine Fehlregulation des Alternativen Spleißen des humanen ClC-1 (ein Muskel-spezifischer Chlorid-Kanal, auch CLCN-1) zu 
induzieren, woraus ein ClC-1-Verlust im Skelettmuskel resultiert, welcher zu Myotonien im Rahmen der DM1 führt (Charlet-B et al. 2002b).

Ein weiterer Mechanismus, in dem Brunol2 involviert ist, ist in DM1-Patienten/innen verändert. In der normalen Myogenese wird Brunol2 in prämyeloblastischen Vorläuferzellen (C2C12-Zellen) unter anderem über einen Cyclin-D3-cdk4-vermittelten Signalweg phosphoryliert. Das phosphorylierte Brunol2-Protein interagiert verstärkt mit dem eukaryontischen Translationsinitiationsfaktor 2 (eIF2) und bildet einen Translationsinitiationskomplex. Phosphorylierungen an verschiedenen Stellen des Proteins dirigieren Brunol2 jeweils zu unterschiedlichen mRNAs und verstärken auch die Affinität zum CCAAT/enhancer-binding protein beta (C/EBPbeta) und zur p21mRNA (Salisbury et al. 2008). Für eine normale Muskelentwicklung ist daher eine zeitgerechte Erhöhung von Cyclin D3 erforderlich (De Santa et al., 2007). In DM1Patienten/innen findet keine Erhöhung von Cyclin D3 statt. Es entstehen daher weniger Brunol2-eIF2 Komplexe (Salisbury et al. 2008).

Schließlich interagiert Brunol2 mit der 3'-UTR von SBP2 (Bubenik 2009), welches die Expression von Selenoproteinen reguliert (Bubenik und Driscoll 2007; Squires et al. 2007). Selenoproteine sind unter anderem an der Pathogenese einer Myopathie beteiligt (Moghadaszadeh et al. 2001).

Der o.g. Brunol2-eIF2-Komplex spielt auch bei anderen Erkrankungen, wie einigen Malignomen, eine Rolle. So bindet er wie o.g. an die mRNA des C/EBPbeta und triggert dadurch die Translation der Isoform des C/EBPbeta, LIP. Diese Isoform wird in proliferierenden Lebern und auch in Tumorzellen, etwa beim Mammakarzinom, Kolorektalen Karzinom oder Ovarialkarzinom, verstärkt exprimiert (Baldwin et al. 2004; Timchenko et al. 2005; Zahnow et al. 1997; Rask et al. 2000; Sundfeldt et al. 1999). Des Weiteren kontrolliert Brunol2 die CD9-Expression (Le Tonquéze et al. 2010), welches in einigen Krebsarten herunterreguliert ist (Miyake et al. 1995; Higashiyama et al. 1995).

\subsubsection{Zur Funktion von ETR-3}

Die Sequenz des namensgebenden founder-Proteins der Celf-Familie, Etr-3 (embryonic lethal abnormal vision RNA-binding Protein 3) ist zu 76\% identisch mit Brunol2 (Hwang et al. 1994). 
Etr-3 wird während der Embryogenese und in den ersten Wochen postnatal im gesamten Vorderhirn exprimiert (Levers et al 2002). Im Herzgewebe des Embryos wird Etr-3 wie Brunol2 stärker exprimiert als im adulten Herzgewebe (Ladd et al. 2005a). Eine Herunterregulation erfolgt bereits am zehnten postnatalen Tag und wird auch hier wahrscheinlich posttranskriptionell reguliert (Kalsotra et al. 2008). Auch in anderen Organen wird Etr-3 im Laufe der Entwicklung herunterreguliert (Ladd et al. 2005a).

Viele Veröffentlichungen zu Etr-3 (Celf2/CUG-BP2/Napor) beschreiben dessen Bedeutung als Spleißfaktor verschiedener mRNAs. So fördert Etr-3 wie die anderen

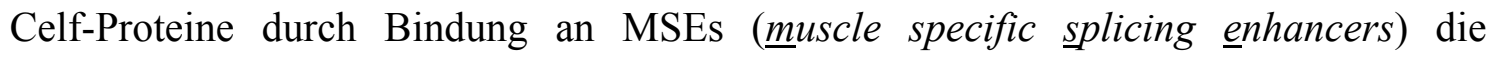
Inklusion des v.a. im erwachsenen Herzen integrierten Exon 5 in der cTNT-mRNA (Ladd et al. 2001; 2004; Charlet-B et al. 2002a). Die Herunterregulation von Etr-3 im adulten Herzen korreliert mit dem switch von der Exon-5-Inklusion zum Exon-5skipping.

Des Weiteren wurde berichtet, dass die Proteinverteilung von Etr-3 in der Ratte mit dem Spleißmuster der NMDAR1-Rezeptor-Transkripte (1N-Methyl-D-Aspartat-receptor-1 Rezeptor) korreliert und Etr-3 das skipping von Exon 5 und die Inklusion des Exons 21 der Rezeptor-mRNA in C2C12-Zellen (murine prämyeloblastische Vorläuferzellen) fördert (Zhang W et al. 2002).

Neben cTNT und dem NMDAR1-Rezeptor wird das Alternative Spleißen der mRNAs weiterer Gene durch Etr-3 reguliert. Dazu gehören Exone der mRNAs des Insulinrezeptors und des Tau (Leroy et al. 2006b) sowie des $\alpha$-Aktinin 3 (Gromak et al. 2003). Daneben ist Etr-3 wie Brunol2 im induzierbaren herzspezifischen DM1Mausmodell erhöht (Wang GS et al. 2007) und gilt zudem als Kandidatengen für die Herzdefekte und Thymushypoplasie/-aplasie im Rahmen der partiellen Monosomie 10p beim Menschen (Lichtner et al. 2002).

Bereits 1999 vermuteten Choi et al., dass Etr-3 eine Rolle in der Apoptose spielt. Untersuchungen zeigten, dass die mRNA von Etr-3 und Cox-2 (syn. PTGS2: Prostaglandin-endoperoxid-Synthase 2, Prostaglandin $G / H$ Synthase und Cyclooxygenase), nicht jedoch das Cox-2-Protein nach $\gamma$-Bestrahlung von HeLa-Zellen und intestinalen Epithelzellen von Mäusen und Ratten hochreguliert ist. Etr-3 lässt sich dann nicht nur im Kern sondern auch im Zytoplasma nachweisen. Etr-3 wird unter der Kontrolle von drei unterschiedlichen Promotoren exprimiert. Je nach Promotor resultieren unterschiedliche Varianten. Diese drei Varianten, insbesondere die Variante 2, werden in der Maus im gesamten Gastrointestinaltrakt exprimiert. Nach Bestrahlung 
mit 12 Gy findet jedoch ein Wechsel auf die Variante 1 statt, welche über Stabilisierung der Cox-2-mRNA und Hemmung ihrer Translation zu einer Apoptose aufgrund von Mitosefehlern (mitotic catastrophe) führt. Die Varianten 2 und 3 haben keinen Einfluss auf die Cox-2-Translation oder die Apoptose (Mukhopadhyay et al. 2003a; Sureban et al. 2007; Ramalingam et al. 2008).

Auch in der bestrahlungsinduzierten Apoptose von Tumorzellen spielt Etr-3 eine Rolle. So resultiert die Überexpression von Etr-3 in HT-29-Kolonkarzinomzellen darin, dass diese in die Apoptose übergehen (Mukhopadhyay et al. 2003a; Murmu et al. 2004).

Prostaglandin E2 (PGE2) schützt Kolonkarzinomzellen (HCT-116-Zellen) zum Teil durch Unterdrückung der Etr-3-Expression vor bestrahlungsinduzierter Apoptose (Natarajan et al. 2008). HCT-116-Zellen, die stabil Etr-3 exprimieren, zeigen daher eine erniedrigte Proliferation und eine erhöhte Apoptoserate im Vergleich zu Kontroll-HCT116-Zellen. Die Etr-3-Überexpression scheint in diesen Zellen durch Bindung von Etr-3 an die mRNA des $\mathrm{Mcl}-1$ (myeloid cell leukemia sequencec 1) und dessen Stabilisierung sowie Hemmung der Translation den Übergang in die Apoptose während der G2-MPhase zu induzieren (Subramaniam et al. 2008).

Etr-3- sowie Cox-2-mRNA sind ebenfalls hochreguliert in bestrahlten MCF-7-Zellen, Mammacarcinomzellen, welche nach der Bestrahlung in die Apoptose gehen (Mukhopadhyay et al. 2003b).

\subsubsection{Zur Funktion von Brunol5}

Über die Funktion von Brunol5/Celf5 ist bisher wenig bekannt. Es fördert in geringem Maße wie die anderen Mitglieder der Brunol-Familie die MSE-abhängige ExonInklusion in cTNT-Minigen-mRNA in Fibroblasten (Ladd et al. 2001). Außerdem beeinflusst Brunol5 das Alternative Spleißen des Exons 6 des Tau-Proteins (Leroy et al. 2006b).

\subsubsection{Zur Funktion von Brunol6}

Brunol6 fördert ebenfalls die Exon-5-Inklusion in kardialem Troponin T über Bindung an MSEs in transfizierten Fibroblasten. Außerdem triggert Brunol6 das Überspringen des Exons 11 der mRNA des Insulin-Rezeptors in transfizierten Fibroblasten (Ladd et 
al. 2004) und beeinflusst wie Brunol5 das Spleißen des Exons 6 der Tau-mRNA (Leroy et al. 2006b).

\subsection{Zur Funktion von Brunol4}

Das murine Brunol4 enthält 13 Exons und ist auf dem Chromosom 18 lokalisiert (Meins et al. 2002). Mütterliche Brunol4-mRNA lässt sich bereits im 2-Zellstadium von MausEmbryonen nachweisen, während das väterliche Allel erst ab dem 4-Zell-Stadium transkribiert wird (Dev 2006). In adulten Mäusen wird Brunol4 im Gehirn sowie in den Augen exprimiert. Besonders hohe Level an Brunol4-RNA lassen sich im Hippocampus und dort v.a. in den Pyramidenzellen der CA2- und CA3-Regionen nachweisen (Meins et al. 2002; Dev 2006; Yang et al. 2007). Während der Embryogenese wird Brunol4 auch im Nervensystem von Hühnern exprimiert. Die Expression beginnt im NeurulaStadium im Kopf und im Neuralrohr des Embryos und ist auch in der späteren Entwicklung auf das Nervensystem beschränkt. Im Gehirn ist die Expression in der äußersten Zellschicht am höchsten (Brimacombe und Ladd 2007). Im Menschen wird Brunol4 in mehreren Geweben exprimiert. Bereits Meins et al. (2002) und Ladd et al. (2001) haben diverse RNA-Varianten bzw. Protein-Isoformen nachgewiesen, wobei Exon 11, welches für einen Teil der dritten RRM kodiert, unterschiedlich gespleißt wird.

Brunol4 spielt wie die anderen Mitglieder der Brunol-Familie eine Rolle im Alternativen Spleißen. So fördert auch Brunol4 über Bindung an MSEs die Inklusion des Exons 5 der mRNA eines cTNT-Minigens in Fibroblasten von Menschen und Hühnern (Ladd et al. 2001). Exon 5 ist vor allem in mRNA des embryonalen Herzens vorhanden, während es in mRNA des adulten Herzens meist fehlt (Cooper und Ordahl 1985). Die Brunol4-Expression im Herzen korreliert jedoch nicht mit dem switch im cTNT (Ladd et al. 2001). Für das MSE-abhängige Spleißen sind in vivo entweder das RRM1 oder das RRM2 ausreichend. Das RRM2 mit zusätzlichen 66 Aminosäuren (AS) der divergent region sind genauso effektiv wie das komplette Protein. Dies impliziert, dass diese 66 AS-Stellen für die volle Aktivität notwendig sind, wie Deletionsanalysen der Proteine gezeigt haben (Singh et al. 2004).

Zudem spielt Brunol4 eine Rolle in der Regulation des Alternativen Spleißen des CLCN1- bzw. ClC-1-Gens. Dieses kodiert für einen Chloridionenkanal im 
Skelettmuskel. Bei der Myotonen Dystrophie liegt eine erhöhte Expression einer mRNA-Variante vor, welche das Exon 7A enthält. Dieses abnorme Spleißen führt zu einer erhöhten Degradation der Transkripte durch nonsense-mediated mRNA decay (NMD) oder zur Produktion von verkürzten Proteinen, die einen dominant-negativen Effekt zeigen. Klinisch zeigen sich Myotonien (Charlet-B et al. 2002b; Mankodi et al. 2002; Berg et al. 2004). Die Inklusion des Exons 7A im murinen ClC-1-Minigen wird durch MBNL-Proteine unterdrückt und durch Brunol4 antagonistisch stimuliert (Kino et al. 2009). Möglicherweise spielt Brunol4 wie auch Brunol2 eine Rolle bei der Myotonen Dystrophie. Bisher ist bekannt, dass Brunol4 im Gehirn von DM1Patienten/innen erniedrigt ist (Leroy et al. 2006b).

Es ist zudem bekannt, wie Experimente mit Co-Expression eines beta-TropomyosinMinigen mit Brunol4 in Myoblasten zeigen, dass Brunol4 die Inklusion des Exons 6B der Beta-Tropomyosin-mRNA während der Myogenese des Herzmuskels fördert. Ein Wechsel von einer mRNA-Variante mit Exon 6A zu einer Variante mit Exon 6B ist in sich entwickelnden Herzmuskelzellen physiologisch (Sureau et al. 2010).

Im Zusammenhang mit onkologischen Erkrankungen wird ein Genkopie-Verlust (copy number loss) des Brunol4 als unabhängiger prognostischer Faktor beim Kolorektalen Karzinom beschrieben (Poulogiannis et al. 2010).

\subsubsection{Neurologische Auffälligkeiten bei Brunol4-defizienten Tieren ohne morphologisches Korrelat im Gehirn}

In dieser Arbeit wurde gezeigt, dass einige Brunol4-defiziente Mäuse einen Tremor, sowie Myotonien in Form von krampfartigem Ausstrecken des Schwanzes zeigten. Ab einem Alter von drei bis vier Monaten traten zusätzlich bei $80 \%$ der Tiere, die dieses Alter erreichten, tonisch-klonische Anfälle auf (s. Kap. 3.4.2).

Im Zusammenhang mit dem Auftreten des Ohtahara Syndroms (frühkindliche epileptische Enzephalopathie) sind missense Mutationen des Proteins Munc-18 (synaptic binding protein 1, syn.: STXBP1) beschrieben worden (Saitsu et al. 2008), welches zum synaptischen Fusionskomplex gehört. Eine erniedrigte Abbaurate von Munc-18, d.h. eine Stabilisierung, könnte mit einer höheren Sekretionsrate an der Synapse einhergehen. Es wurden daher im Rahmen dieser Arbeit mittels Immunofluoreszenzfärbung mit Antikörpern gegen Munc-18 hippokampale Neurone 
von Brunol4 ${ }^{-/}$-Tieren und Wildtypkontrollen verglichen. Es zeigten sich jedoch keine Auffälligkeiten (s.Kap. 3.5.2). Auch die Verteilung von Beta-III-Tubulin unterschied sich nicht von Wildtypkontrollen, obwohl Hoch- bzw. Herunterregulation von betaTubulinen mit dem Auftreten von Epilepsie korreliert (Guo und Kuang 1993; Yang et al. 2007).

Auch histologische Untersuchungen von Gehirnschnitten Brunol4-defizienter Mäuse zeigten keine Auffälligkeiten (s. Kap. 3.5.1), so dass vermutet werden kann, dass es durch Missregulation aufgrund von Brunol4-Defizienz z.B. zu Störungen anderer Neurotransmitter oder Rezeptoren in der Signalbildung oder -weiterleitung an Neuronen kommt.

Wie oben genannt, ist Brunol4 ein gehirnspezifisches RNA-Bindungsprotein. Mehrere gehirnspezifische targets sind für Brunol4 beschrieben worden, deren Fehlregulationen $\mathrm{zu}$ den neurologischen Symptomen des o.g. klinischem Erscheinungsbildes führen könnte. So unterdrückt Brunol4 das Spleißen des Exons 5 des humanen NMDAR1Minigens. Hierfür ist ein Abschnitt der divergent region des Brunol4-Proteins notwendig (Han und Cooper 2005). Bei NMDAR1 (glutamate receptor, ionotropic, $N$ methyl D-aspartate 1, GRIN1) handelt es sich um eine Untereinheit des Glutamatrezeptors. NMDA-Rezeptoren werden in fast allen zentralen Nervenzellen exprimiert (Kutsuwada et al. 1992; Ishii et al. 1993). In der Retina werden während der embryonalen Entwicklung zunächst mRNA-Isoformen des NMDARl exprimiert, denen das Exon 5 fehlt. Später in der Entwicklung treten dann relativ mehr mRNA-Isoformen mit Exon 5 auf (Lee-Rivera et al. 2003). Die Annahme, dass der Glutamatrezeptor für die Pathogenese von Epilepsien bedeutsam ist, wird dadurch unterstützt, dass durch NMDA-Gabe epileptische Anfälle induziert werden können (Faingold et al. 1989). NMDAR1-Polymorphismen werden zudem im Zusammenhang mit dem West-Syndrom, einer epileptischen Enzephalopathie im Kindesalter, beschrieben (Ding et al. 2010). Des Weiteren ist bekannt, dass NMDA-Rezeptoren in Mausmodellen für Chorea Huntington eine gesteigerte Empfindlichkeit aufweisen und möglicherweise die Vulnerabilität striataler Neurone erhöhen (Cepeda et al. 2001), so dass der Rezeptor auch für die typische Symptomatik dieser Erkrankung, d.h. choreatische Hyperkinesen, bedeutsam sein könnte. Mäuse, die lediglich $5 \%$ der üblichen Menge des NMDAR1 exprimieren, überleben bis ins adulte Alter und zeigen abnorme schizophrene Verhaltensweisen wie eine erhöhte motorische Aktivität, Stereotypien und Defizite in sozialen und sexuellen Interaktionen (Mohn et al. 1999). 
Ein Bereich der divergent region von Brunol4 ist daneben notwendig für die Inklusion des Exons 11 der mRNA des Polypyrimidine tract binding protein (PTB/hnRNP 1, Han und Cooper 2005). Brunol4 stimuliert das Spleißen des Exons 11 der PTB-mRNA, welches für ein RNA-Bindungsprotein kodiert, das seinerseits expressionsmodulierend wirkt (Valcárcel und Gebauer 1997; Wollerton et al. 2004). PTB wird unter anderem im Gehirn exprimiert (Patton et al. 1991). Alternatives Überspringen des Exons 11 der PTB-mRNA führte bei Untersuchungen an HeLa-Zellen $\mathrm{zu}$ einer mRNA, die mindestens zu 20\% durch NMD abgebaut wird (Wollerton et al. 2004). So führt eine Brunol4-Defizienz möglicherweise zu einem vermehrten Abbau der PTB-mRNA und damit zu einer Verminderung der Funktion von PTB. PTB selbst reguliert das Spleißen mehrerer mRNAs, die neuronal bedeutsam sind. So scheint PTB unter anderem das Alternative Spleißen des smooth muscle-Exons des $\alpha$-Aktinin zu unterdrücken (Southby et al. 1999). Daneben hemmt PTB unter anderem das Spleißen des N-Exons der GABARezeptor-Untereinheit $\gamma$-2GABA (Ashiya und Grabowski 1997), dessen Ligand GABAinhibitorisch wirkt, sowie des Exons 5 des NMDARl (Zhang L et al. 1999) und des Exons 6 des Tau. Auch Tau scheint an der DM1 beteiligt zu sein, da das Exon 6 des Tau im Gehirn von DM1-Patienten/innen, nicht jedoch in deren Muskel, unterdrückt ist (Wei et al. 2000; Leroy et al. 2006b). Tau kodiert für ein Mikrotubulus-assoziiertes Protein, welches in den Axonen von reifen und aussprossenden Nervenzellen angereichert ist (Kempf et al. 1996). Es wird vermutet, dass die Tau-Isoform mit Exon 6 eine Rolle in der axonalen Migration spielt (Wang J et al. 2007). So könnte es durch abnormes Alternativen Spleißen des Exons 6 aufgrund des fehlenden Regulatorproteins Brunol4 zu einer gestörten Ausbildung von Axonen kommen. Die untersuchten hippokampalen Neurone zeigten mit den untersuchten Färbungen keine Auffälligkeiten. Es ist jedoch möglich, dass Neurone anderer Hirnareale morphologische Abweichungen aufweisen.

Brunol4 unterdrückt zudem wie auch Brunol1, Brunol2, Etr-3 und Brunol5 die Inklusion des Exons 23a der mRNA des Neurofibromatose-Typ-I-Gens (NF1) (Barron et al. 2010). Dieses Gen kodiert für das Protein Neurofibromin, welches weit verbreitet, besonders jedoch im Nervensystem exprimiert wird (Daston et al. 1992). Es handelt sich dabei um ein Tumorsuppressorgen (Xu et al. 1990), dessen Mutation die Grundlage der Neurofibromatose Typ I bildet (Wallace et al. 1990). Diese Erkrankung manifestiert sich neurologisch mit ZNS-Tumoren, mentaler Retardierung, Lernschwierigkeiten und Epilepsie (Riccardi 1987). 7\% einer Population von NF1-Patienten/innen entwickelte 
v.a. fokale epileptische Anfälle. Bei $60 \%$ traten diese Anfälle sekundär infolge von Gehirnläsionen auf (Vivarelli et al. 2003). Vier unterschiedlich exprimierte Transkripte, Typ I-IV, konnten für das NF1-Gen nachgewiesen werden. Die Transkripte werden in zahlreichen Geweben exprimiert, wobei die einzelnen Isoformen unterschiedliche Schwerpunkte zeigen. So wird Typ I vor allem in neuronalem Gewebe und im Testis exprimiert, während Typ III und IV v.a. in der Nebenniere und im Testis exprimiert werden. Exon 23a ist in den Transkriptvarianten Typ II, welches v.a. in Nebenniere, Lunge, Niere und Ovar exprimiert wird, und im Typ III enthalten (Nishi et al. 1991; Mantani et al. 1994). Hier könnte es zu einer Misregulation der Isoform Typ I kommen, indem durch eine fehlende Unterdrückung der Inklusion des Exons 23a dieses integriert wird. Als Folge sind neurologische Fehlregulationen denkbar.

Eine weitere Funktion des Brunol4 ist die Unterdrückung der Inklusion zweier Exons des $\alpha$-Aktinins 1 der Ratte, einer Komponente des Zytoskeletts (Gromak et al. 2003). Hierbei handelt es sich um das sogenannte non-muscle- sowie das smooth-muscle-Exon, welche in einer gehirnspezifischen Isoform zusammen exprimiert sind (Kremerskothen et al. 2002). Durch eine Funktionsstörung des Brunol4 könnte es demzufolge zu einer Hochregulation dieser Isoform und damit zur Ausbildung neurologischer Symptome kommen.

Eine erhöhte Anfallsbereitschaft sowie Krampfanfälle verschiedener Ausprägungen zeigt ebenfalls ein früher beschriebenes Mausmodell der frequent flyer, bei dem das Brunol4-Gen durch gene trap verändert worden ist (Yang et al. 2007). Hier hat eine Transgen-Insertion in Intron 1 von Brunol4 in C57BL/6J-Tieren zu einem veränderten Spleißen des Gens geführt. Liegt die Insertion in beiden Allelen vor, ist das Brunol4Transkript stark herunterreguliert, in heterozygoten Tieren um etwa 45\%. Diese frequent flyer (Ff) zeigen, wenn sie heterozygot für das mutierte Allel sind, ab einem Alter von drei Monaten epileptische Anfälle in unterschiedlicher Ausprägung, wobei die Inzidenz bei Männchen höher ist. Vorher zeigt sich eine Hyperaktivität, eine herabgesetzte elektrokonvulsive Schwelle und ein geringeres Körpergewicht. Im Verlauf tritt dann jedoch im Vergleich zu Wildtypgeschwistern eine Gewichtszunahme ein. Die Lebenszeit ist nicht reduziert. Auch die Lebenszeit unserer Brunol4 ${ }^{+/}$-Mäuse war nicht verkürzt. Jedoch bildeten die heterozygoten Mäuse keine Epilepsien aus. Heterozygote Weibchen waren zeitweise signifikant leichter als Wildtypgeschwister. Dieser Gewichtsunterschied zeigte sich nicht bei Männchen. Einige Ff-Homozygote, die mit Hybrid-genetischem Hintergrund gezüchtet worden waren, lebten länger als sechs 
Monate und zeigten ab einem Alter von acht Monaten limbische und tonisch-klonische Anfälle und auch Absencen mit spike-wave-Komplexen im EEG, ähnlich zu unseren Brunol4 $^{-/}$-Tieren, die ab einem Alter von drei bis vier Monaten zu 80\% tonischklonische Anfälle präsentierten. Homozygote $F f$-Tiere mit reinem C57B1/6JHintergrund fielen zu Lebzeiten nicht mit Krampfanfällen auf. Die Gehirnmorphologie heterozygoter sowie homozygoter Ff-Tiere war, wie die der Brunol4 ${ }^{-/-}$-Mäuse, unauffällig und obwohl Brunol4 mit $\alpha$-Aktinin eine Komponente des Zytoskeletts als target hat und andere Brunol-Proteine direkt und Brunol4 indirekt das Alternative Spleißen von Tau regulieren, welches möglicherweise eine Rolle in der Ausbildung von Axonen hat (Gromak et al. 2003; Leroy et al. 2006a und 2006b; Wang J et al. 2007) unterschieden sich die Axone hippokampaler Neurone in ihrer Länge nicht von denen gleichaltriger Wildtypkontrollen (Vgl. 3.5.2).

Untersuchungen zeigten, dass in den Hippocampi von heterozygoten adulten frequentflyer-Mäusen Transkripte von vier Genen um ca. 30-39\% herunterreguliert waren, die zum Phänotyp der Epilepsie beigetragen haben könnten. Knockout-Mäuse des herunterregulierten Serotonin Rezeptor 2c (Htr2c) zeigen spontane epileptische Anfälle, sowie Hyperaktivität und ein später einsetzendes Übergewicht (Tecott et al. 1995). Bei einem weiteren herunterregulierten Protein handelte es sich um Synapsin II (Syn2), dessen Knockout zu provozierbaren Anfällen führt (Rosahl et al. 1995). Der NEthylmaleimide-sensitive Faktor (Nsf), ein weiteres erniedrigtes Protein in heterozygoten adulten frequent-flyer-Mäusen, reguliert die Exozytose an Synapsen und das AMPA-Rezeptor-trafficing (Schiavo et al. 1995; Shi et al. 2001). Ebenfalls reduziert zeigte sich das Neuronen-spezifische präsynaptische Protein Alpha-Synuclein (Snca) (Iwai et al. 1995).

Die meisten der bisher identifizierten und für Epilepsie mitverantwortlichen Gene kodieren für Ionenkanäle oder dazugehörende Untereinheiten. Jedoch existieren einige Ausnahmen wie LGI1 (leucine-rich, glioma inactivated 1, Kalachikov et al. 2002), EFHC1 (EF-hand domain (C-terminal) containing 1, Suzuki et al. 2004) im Menschen und JRK/JH8 ( jerky bzw. jerky homolog Toth et al. 1995; Moore et al. 2001) sowohl in der Maus als auch im Menschen. Dieses macht deutlich, dass nicht nur die primäre Modifikation der Erregungsleitung als Ursache in Frage kommt, sondern auch die Änderung der Expression von Genen, die etwa für Ionenkanäle, Neurotransmiter Rezeptoren und synaptische Proteine kodieren, bedeutsam ist. 


\subsubsection{Verkürzte Lebenserwartung von Brunol4-defizienten Tieren}

Wie die Brunol4 ${ }^{--}$-Mäuse wurden auch homozygote $F f$-Tiere lebend geboren, starben jedoch meist am ersten Tag postnatal. Hierbei zeigte sich eine Abhängigkeit vom genetischen Hintergrund. So machten homozygote $F f$-Tiere mit C57Bl/6J-Hintergrund im Alter von vier Wochen noch 1,1\% statt der nach MENDELschen Regeln erwarteten 25\% der Nachkommen aus. Diese Zahl betrug jedoch bei einem Hybridhintergrund mit C57B1/6J x 129S1 8,2\%. Auch in unseren Untersuchungen liegt das mediane Überleben des Hybridhintergrunds bei Brunol4 ${ }^{-/-}$-Mäusen mit 20 Tagen über dem einer Inzuchtlinie. Von beobachteten homozygoten Nachkomen der Linie 129/Sv lebten bereits nach 11 Tagen nur noch 50\%. 40\% starben bereits in den ersten vier Lebenstagen. Jedoch lebten mehr als $10 \%$ bis zu 40 Tage lang, während bei homozygoten Nachkommen des hybriden Hintergrunds bereits bis zum 25. Tag postnatal mehr als 90\% verstorben waren. Die reduzierte Nachkommenzahl in der 129Sv-Linie ließ sich durch die Ergebnisse der Embryonenuntersuchungen nicht auf eine erhöhte intrauterine Letalität der Brunol4 ${ }^{-/-}$-Mäuse zurückführen. Möglicherweise werden die Nachkommen der heterozygoten 129Sv-Verpaarungen vermehrt postnatal vernachlässigt oder gefressen, etwa aufgrund einer erhöhten Anfälligkeit für Störungen während des Geburtsvorgangs. Soziale Auffälligkeiten in Form von schizophrenen Verhaltensweisen wurden im Zusammenhang mit stark verminderter Expression von NMRARl berichtet, einer Untereinheit des Glutamatrezeptors, dessen Spleißen durch Brunol4 moduliert wird (Mohn et al. 1999; Han und Cooper 2005). Homozygotie für einen genetischen Hintergrund könnte den Phänotyp also verstärken, wie es auch für andere Mutationen in Mäusen bekannt ist (z.B. Kent et al. 1997; Buchner et al. 2003). Ungeklärt ist die Ursache der erhöhten Letalität der Brunol4 ${ }^{-/-}$-Mäuse. Morphologische Auffälligkeiten konnten weder in der histologischen Untersuchung des Gehirns noch in kultivierten Hippocampus-Neuronen homozygoter Tiere nachgewiesen werden. NMDAR1-Knockout-Mäuse sterben innerhalb von Stunden nach der Geburt an respiratorischer Insuffizienz (Forrest et al. 1994; Li Y et al. 1994) und Punktmutationen im NMDARl-Gen führen zu einer erhöhten neonatalen Letalität (Kew et al. 2000). Auch frühe letale Krampfanfälle könnten eine mögliche Ursache der verkürzten Lebenserwartung von Brunol4 $4^{-/}$-Tieren sein. 


\subsubsection{Signifikante Wachstumsretardierung bei Brunol4- defizienten Tieren}

Brunol4 $^{-/}$-Mäuse beider Linien waren fast immer signifikant leichter als Heterozygote oder Wildtypgeschwister. Auch homozygote Ff-Tiere mit Hybridhintergrund waren kleiner als Kontrollen. Als Spleißregulator spielt Brunol4 eine Rolle im Spleißen von mRNAs von für die Entwicklung wichtigen Proteinen wie NMDAR1 oder alphaAktinin sowie möglicherweise indirekt oder direkt auch Tau. Fehlspleißen oder Fehlen eines entwicklungsbedingten Wechsels des Spleißens bestimmter Exons könnte zu derartiger Retardierung im Wachstum führen. Punktmutationen im NMDARl-Gen, dessen Alternatives Spleißen durch Brunol4 reguliert wird, führen unter anderem zu einem verminderten Geburtsgewicht (Kew et al. 2000).

\subsubsection{Mögliche Infertilität der Brunol4\%--Männchen}

Da Brunol4 ${ }^{+/}$-Mäuse des Hybridhintergrunds keine Reduktion der Nachkommenzahl aufwiesen, war es interessant zu sehen, ob Brunol4 ${ }^{-/-}$-Mäuse desselben Hintergrunds ebenfalls fertil verpaart werden können. Die Verpaarung eines Brunol4 ${ }^{-/}$-Weibchens mit einem Wildtyp-Männchen ergab mehrere Würfe. Die Nachkommen wurden jedoch jedesmal direkt nach der Geburt aufgefressen. Sowohl aus einer Verpaarung eines Brunol4 $^{-/-}$-Männchens mit einem Wildtyp-Weibchen als auch aus einer Verpaarung des fertilen Brunol4 ${ }^{-/-}$-Weibchens aus der erstgenannten Verpaarung mit einem Brunol $^{-/-}$Männchen entstanden auch nach über zwei Monaten keine Nachkommen. Dieses könnte ein Hinweis auf eine Infertilität oder ein gestörtes Sexualverhalten des Männchens sein. Allerdings sind deutlich mehr Verpaarungen und Untersuchungen notwendig, um die Fertilität von Brunol4 ${ }^{-/-}$-Männchen genauer zu beurteilen. Nur wenige Tiere haben jedoch aufgrund der erhöhten Letalität das geschlechtsreife Alter erreicht.

Brunol4 wird in der Maus ausschließlich im Gehirn exprimiert, so dass als mögliche Ursachen u.a. Infertilität durch Hypophyseninsuffizienz oder eine Verhaltensstörung in Frage kommen. So führt z.B. die stark verminderte Expression von $N M D A R 1$, dessen Alternatives Spleißen von Brunol4 reguliert wird, bei Mäusen zu abnormen 
schizophrenen Verhaltensweisen wie Defiziten in sozialen und sexuellen Interaktionen (Mohn et al. 1999).

Effekte von Brunol-Proteinen auf GnRH (gonadotropin releasing hormone 1) oder LHB (luteinizing hormone beta) bzw. FSHB (follicle stimulating hormone beta) oder deren Rezeptoren sind bisher nicht beschrieben.

\subsection{Zur Expression der Bruno-like-Gene bei der Maus}

Bisher konnten in der Maus und beim Menschen von einigen Mitgliedern der BrunolFamilie mehrere Isoformen als Folge von Alternativem Spleißen identifiziert werden (Vgl. Tab. 4.1), und es kann davon ausgegangen werden, dass auch die anderen Gene der Brunol-Familie für verschiedene Isoformen kodieren. Die Mitglieder der BrunolFamilie haben zum Teil überlappende, jedoch auch unterschiedliche Expressionsmuster (Vgl. Tab. 4.1). Brunoll und Brunol6 werden in der Maus ausschließlich in Gehirn und Testis exprimiert (Dev 2006; Dev et al. 2007), die Expression von Brunol4 wird in der Literatur unterschiedlich beschrieben. Von Ladd et al. (2001) wird eine Expression in vielen murinen Geweben gezeigt, während u.a. Meins et al. (2002) und Dev (2006) eine Beschränkung der Expression auf das Gehirn und allenfalls sehr schwache Signale (Meins et al. 2002) in anderen Geweben gefunden haben, wobei unspezifische Bindungen nicht sicher ausgeschlossen wurden. Brunol2 und ETR-3 wurden durch Western Blot in vielen Geweben nachgewiesen (Ladd et al. 2001). Beim Menschen ist die Expression von Brunol1 sowie Brunol5 auf das Gehirn beschränkt (Ladd et al. 2001; 2004). Brunol2, Brunol3 und Brunol4 werden in vielen humanen Geweben exprimiert, Brunol3 v.a. in Herz, Gehirn und Skelettmuskel (Good et al. 2000; Ladd et al. 2004). Transkripte von menschlichem Brunol6 konnten v.a. in Niere und Gehirn, in weiteren Untersuchungen aber auch im Testis und mit schwächeren Signalen in anderen Geweben nachgewiesen werden (Ladd et al. 2004). Für Xenopus laevis ist die Expression zudem während der Entwicklung untersucht worden. So werden Brunoll, Brunol4 und Brunol5 v.a. im Nervensystem, Brunol2 und Brunol3 in den Somiten, aus denen sich u.a. die Skelettmuskulatur entwickelt, sowie ebenfalls im Nervensystem exprimiert. Brunol2 zeigt zudem eine starke Expression in der Linse (Wu et al. 2010). 
Diskussion

\begin{tabular}{|c|c|c|c|c|}
\hline \multicolumn{5}{|c|}{ Mus musculus } \\
\hline & Gene ID & Chr. & Proteinisoformen & Expression \\
\hline Brunol1 & 13046 & 3 & $N P 766022.1$ & $\begin{array}{l}\text { Gehirn und Testis (Dev et al. } \\
\text { 2007) }\end{array}$ \\
\hline Brunol2 & 78784 & 2 & $\begin{array}{l}N P \quad 059064.2 \\
N P \quad 941955.1 \\
\end{array}$ & Viele Gewebe (Ladd et al. 2001) \\
\hline Etr-3 & 14007 & 2 & 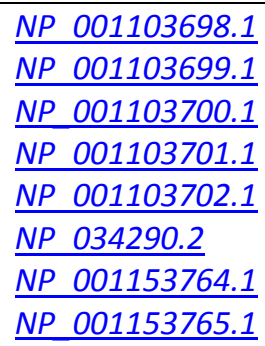 & Viele Gewebe (Ladd et al. 2001) \\
\hline Brunol4 & 108013 & 18 & $\begin{array}{ll}N P & 001139764.1 \\
N P & 001139765.1 \\
N P & 001139766.1 \\
N P & 573458.2 \\
N P & 001139767.1 \\
N P & 001167545.1 \\
\end{array}$ & $\begin{array}{l}\text { Gehirn (Meins et al. 2002; Dev } \\
\text { 2006)) }\end{array}$ \\
\hline Brunol5 & 319586 & 10 & NP 795928 & \\
\hline Brunol6 & 76183 & 9 & NP 780444 & Gehirn und Testis (Dev 2006) \\
\hline \multicolumn{5}{|c|}{ Homo sapiens } \\
\hline & Gene ID & Chr. & Proteinisoformen & Expression \\
\hline Brunol1 & 11189 & $1 q 21$ & $\begin{array}{l}N P \quad 009116.3 \\
N P \quad 001166119.1 \\
N P \quad 001166120.1\end{array}$ & Gehirn (Ladd et al. 2004) \\
\hline Brunol2 & 10658 & 11p11 & 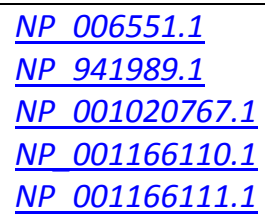 & $\begin{array}{l}\text { Viele Gewebe (Herz, Gehirn, } \\
\text { Plazente, Lunge, Leber, } \\
\text { Skelettmuskel, Niere, Pankreas, } \\
\text { jeweils } 3 \text { mRNAs (Good et al. } \\
\text { 2000) }\end{array}$ \\
\hline Brunol3 & 10659 & $10 p 13$ & $\begin{array}{ll}\text { NP } & 001020247.1 \\
N P & 006552.3 \\
N P & 001020248.1 \\
N P & 001077060.1 \\
\end{array}$ & $\begin{array}{l}\text { V.a. Herz, Gehirn und } \\
\text { Skelettmuskel, auch in Plazenta, } \\
\text { Pankreas und Lunge (Good et al. } \\
\text { 2000) }\end{array}$ \\
\hline Brunol4 & 56853 & $18 q 12$ & $\begin{array}{ll}P P & 064565.1 \\
N P & 001020258.1 \\
N P & 001020259.1 \\
N P & 001020260.1 \\
\end{array}$ & Viele Gewebe (Ladd et al. 2004) \\
\hline Brunol5 & 60680 & $19 p 13$ & $\begin{array}{l}\text { NP } 068757.2 \\
N P \quad 001166144.1 \\
\end{array}$ & Gehirn (Ladd et al. 2001;2004) \\
\hline Brunol6 & 60677 & $15 q 24$ & 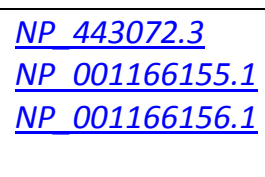 & $\begin{array}{l}\text { V.a. Niere, Gehirn und Testis, } \\
\text { auch schwache Signale in } \\
\text { anderen Geweben (Ladd et al. } \\
\text { 2004) }\end{array}$ \\
\hline
\end{tabular}




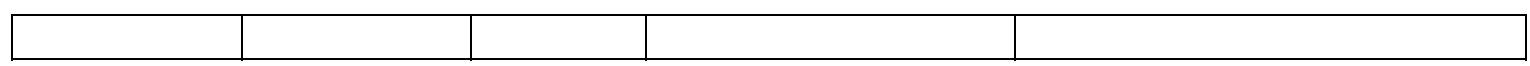

Tab. 4.1: Merkmale der sechs Brunol-Mitglieder von Maus und Mensch

Aufgeführt sind für Maus und Mensch jeweils die Gene ID, die chromosomale Lokalisation (Chr.), die Anzahl der Proteinisoformen und deren Kennnummern, sowie die Gewebe, in denen die Expression nachgewiesen wurde.

\subsubsection{Weitere Spleißvariante der Brunol4 -mRNA}

Untersuchungen mit Northern Blot haben gezeigt, dass neben den etwa 4 kb langen Transkripten in Wildtyp-Tieren zudem ein 2,8 kb langes Transkript vorliegt, welches durch eine 3'-Sonde erkannt wird. Diese 3'-Sonde bindet an Exon 12 und Exon 13. Diesem Transkript fehlen das komplette oder Teile des Exons 1, da es von einer Sonde, die Exon 1 bindet, nicht erkannt wird. Das Exon 1 enthält die Startcodons und die zur Inaktivierung des Gens inserierte GFP/Neo-Kassette. Alle bisher beschriebenen Transkriptvarianten enthalten entweder das Exon 1 oder sind kürzer (ENSMUST00000115815, $1670 \mathrm{~kb}$ ), so dass es sich bei dem vorliegenden Transkript möglicherweise um bisher noch nicht beschriebenes zur Funktion von Brunol4 beitragendes oder aber funktionsloses, nicht translatiertes Produkt handeln könnte.

Untersuchungen mit Northern Blot und RT-PCR in dieser Arbeit haben gezeigt, dass auch in Brunol4 ${ }^{-/}$-Tieren sowohl in einem Alter von 10 Tagen als auch bei adulten Tieren Transkripte (ca. 3,9 kb und ca. 2,8 kb) vorliegen. Diesen Transkripten fehlt ebenfalls ein Teil oder das komplette Exon 1 (E1--Transkripte), so dass es sich bei der 2,8 kb großen Variante um die oben beschriebene handeln könnte. Das längere Transkript ist mit ca. 3,9 kb etwas kürzer als das Wildtyp-Trannskript, so dass möglicherweise die ca. 4 kb großen Wildtyp-Varianten ohne das Exon 1 transkribiert wurden und somit nicht translatiert werden. Möglich wäre auch, dass das 3,9 kb große Transkript zu einem Protein führt, was abnorm wirkt und so zum Phänotyp der Brunol4defizienten Mäuse beiträgt. Dagegen spricht, dass heterozygote Tiere sich in ihrem Phänotyp kaum vom Wildtyp unterscheiden und insbesondere keine neurologischen Auffälligkeiten präsentieren. 


\subsection{Hohe Letalität bei Brunol1\%/Brunol4\%--Doppelt-Knockout- Mäusen}

Viele Untersuchungen $\mathrm{zu}$ den Brunol-Proteinen haben ergeben, dass verschiedene Vertreter der Proteinfamilie sowohl Ähnlichkeiten in ihrer Sequenz aufweisen als auch an den gleichen targets wirken. So regulieren z.B. sowohl Brunol5 als auch Brunol6 das Alternative Spleißen des Exons 6 des Tau-Proteins (Leroy et al. 2006a). Alle sechs Brunol-Proteine wirken zudem auf das Spleißen des Exons 5 von cTNT (Ladd et al. 2001; 2004). Brunol2, ETR-3 und Brunol6 modulieren alle das Spleißen des InsulinRezeptors (Savkur et al. 2001; Ladd et al. 2004; Han und Cooper 2005) und das Spleißen von Exon 5 des NMDAR1 wird von Brunol2, Etr-3 und Brunol4 reguliert (Zhang W et al. 2002; Han und Cooper 2005). Der Phänotyp der Brunoll-KnockoutMaus (Dev et al. 2007) ist sehr milde. Möglich ist, dass andere Mitglieder der BrunolFamilie die Funktionen des defizienten Brunol-Proteins im Sinne einer funktionellen Redundanz übernehmen können.

Eine derartige Redundanz ist u.a. für such-1 und gfi-3, zwei APC5-Paraloge (Anaphase Promoting Complex/Cyclosome) in Caenorhabditis elegans beschrieben. So zeigen einfach defiziente Tiere für das jeweilige Gen keinen nennenswerten Phänotyp, während bei doppelt defizienten Tieren ein meiotischer Arrest vorliegt (Stein et al. 2010). Ebenso kann $\mathrm{C} / \mathrm{EBP} \beta$ Funktionen des $\mathrm{C} / \mathrm{EBP} \alpha$ übernehmen, indem es bei $\mathrm{C} / \mathrm{EBP} \alpha$-Defizienz die Hämatopoese und die Leberfunktion normalisiert (Jones et al. 2002; Chen et al. 2000). Auch der Phänotyp der Brunol4 ${ }^{-/}$-Maus könnte durch redundante Hochregulation anderer Brunol-Proteine abgemildert sein.

Um zu Überprüfen, ob Brunol1 und Brunol4 funktionelle Redundanz zeigen, wurde im Rahmen dieser Arbeit eine für Brunol1 und Brunol4 doppelt defiziente Maus gezüchtet. Doppelt heterozygote Tiere waren fertil verpaart.

Die Verteilung der weiblichen Nachkommen von doppelt heterozygoten Mäusen für Brunol1 und Brunol4 (Brunol1 ${ }^{+/} /$Brunol4 $^{+-}$) war signifikant zu Gunsten der WildtypTiere verschoben. $100 \%$ der Brunol1 ${ }^{+/} /$Brunol4 $^{-/-}$-Mäuse starben innerhalb der ersten Woche nach Geburt und 100\% der Brunol1 ${ }^{-/} /$Brunol4 $^{-/-}$-Mäuse starben innerhalb der ersten zwei Lebenstage.

Die gesteigerte Letalität der doppelt defizienten Mäuse im Vergleich zu Brunol4 ${ }^{-/}$Mäusen kann darauf hinweisen, dass Brunol1, welches wie Brunol4 im Gehirn 
exprimiert wird, in Brunol4 ${ }^{-/-}$-Tieren Funktionen von Brunol4 übernommen hat, zumal Brunoll $^{-/}$-Mäuse keine erhöhte Letalität zeigen (Dev et al. 2007). Folglich sollte untersucht werden, ob Brunol1 in Brunol4 ${ }^{-/}$-Mäusen verstärkt exprimiert wird. Es wäre zudem sinnvoll, Brunol1 ${ }^{+/}$- und Brunol4 ${ }^{+-}$-Tiere mit Knockout-Mäusen für Brunol2 oder anderen Brunol-Genen zu verpaaren und deren Phänotypen zu untersuchen.

Ein infertil verpaartes Brunol1 $1^{+/} /$Brunol4 $^{+/}$-Männchen zeigte eine verringerte Spermienzahl, herabgesetzte Spermienmotilität sowie eine auffällige Testis-Histologie. Zehn andere untersuchte doppelt heterozygote Tiere wiesen jedoch unauffällige Testes auf, so dass es sich hierbei möglicherweise um einen Einzelfall gehandelt hat.

Weitere Tiere sollten untersucht werden, um zu überprüfen, ob es sich um eine Folge der Inaktivierung der beiden Gene handelt.

Auch andere Punkte dieser Arbeit sollten tiefergehend untersucht werden, wie etwa die Sequenz der E1'-Transkripte sowie Western Blot-Analysen, um zu überprüfen, ob ein Brunol4-Protein in Brunol1 ${ }^{-/}$-Mäusen vorliegt. Auch die Todesursachen der Brunol4defizienten als auch der Brunol1/Brunol4-Doppelt-Knockout-Mäuse sollten durch Obduktionen untersucht werden. Heterozygote und homozygote junge und adulte Mäuse sollten mittels Testung der elektrokonvulsiven Schwellen auf herabgesetzte Krampfanfälligkeit hin untersucht werden. Interessant wäre zudem die Identifikation von abnorm regulierten Spleißvarianten anderer mRNAs in den Knockout-Mäusen. Eine größere Anzahl an Brunol4-Knockout-Mäusen als auch an Doppelt-KnockoutTieren für Brunoll und Brunol4 ist nötig, um die Ergebnisse $\mathrm{zu}$ verifizieren und gegebenenfalls weitere Untersuchungen durchführen $\mathrm{zu}$ können. 


\section{Zusammenfassung}

Die Familie der Brunol-Proteine ist eine in Wirbeltieren verbreitet exprimierte Gruppe von RNA-Bindungsproteinen, die durch Expressionsmodulation eine wichtige Rolle in der Entwicklung und der Aufrechterhaltung der Organismen spielen.

Die vorliegende Arbeit hat sich mit der Analyse von Knockout-Mäusen für das Brunol4-Gen sowie mit Mäusen, die sowohl für Brunoll als auch für Brunol4 defizient sind, beschäftigt.

Brunol4 $^{-/}$-Mäuse zeigen bei regelrechter Gehirnmorphlogie postnatal eine erhöhte Letalität, sind wachstumsretardiert und zeigen neurologische Auffälligkeiten, wie epileptische Anfälle ab einem Alter von drei bis vier Monaten. Zudem kann für Brunol4-defiziente Männchen entweder eine Infertilität oder ein gestörtes Sexualverhalten angenommen werden. Diese Symptome sind vermutlich Ausdruck der gestörten Regulation mehrerer target-mRNAs, deren Expression von Brunol4 direkt oder indirekt reguliert wird, wie etwa NMDAR1, Tau, PTB, NF1 oder $\alpha$-Aktinin.

Der Phänotyp des Syndroms unserer Brunol4-defizienten Tiere ist ähnlich dem der frequent-flyer-Mäuse, deren Brunol4-Gen durch gene trap unterbrochen wurde (Yang et al. 2007).

Das kombinierte Ausschalten von Brunoll und Brunol4 führt zu einem verstärkten Phänotyp mit einer im Vergleich zur isolierten Brunol4-Defizienz sehr kurzen Lebenszeit bei Brunol1 $1^{-/} /$Brunol4 $4^{-/}$-und auch Brunol1 $1^{+/} /$Brunol4 $^{-/-}$-Tieren.

Doppelt heterozygote Mäuse waren meist fertil verpaart. Ein infertil verpaartes Männchen zeigte neben einer verminderten Zahl und Beweglichkeit der Spermien morphologisch auffällige Hoden mit Sklerosierungen und Zystenbildung. Es kann vermutet werden, dass durch das kombinierte Ausschalten der Brunol-Proteine eine zuvor bestehende Redundanz aufgehoben wird, so dass es zu einem stärker ausgeprägten Phänotyp kommt.

Des Weiteren wurde gezeigt, dass zusätzlich $\mathrm{zu}$ den bekannten $4 \mathrm{~kb}$ großen Transkriptvarianten von Brunol4 in Wildtyptieren ein 2,8 kb großes Produkt exprimiert wird. 
Anhang

\section{Anhang}

\subsection{Abbildungsverzeichnis}

Abb. 1.1: Proteinstruktur der Mitglieder der Bruno-like/Celf- Familie ....................................................... 2 Abb. 1.2: Schematische Darstellung der Insertion der gene-trap-Kassette in Brunol4 (Yang et al, 2007) ...5 Abb. 3.1: Graphische Darstellung der 6 Transkriptvarianten nach NCBI............................................. 41 Abb. 3.2: Konstrukt für die zielgerichtete Inaktivierung des Brunol4-Gens (nach Dev 2006, S. 71) ...........42

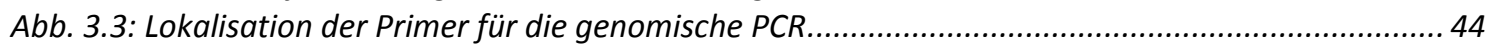
Abb. 3.4: Southern-Blot- und PCR-Analyse zur Untersuchung der ES-Zellen ...........................................44 Abb. 3.5: Genotypisierung der Nachkommen in der F1- und F2-Generation ..........................................46 Abb. 3.6: A: Graphische Darstellung der CDNA und der Northern-Blot-Sonden mit Lokalisation der

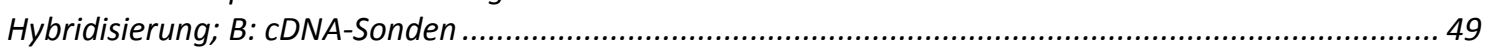

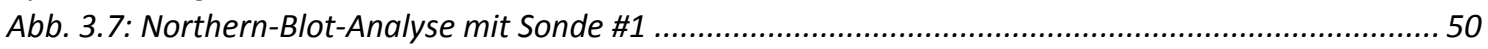

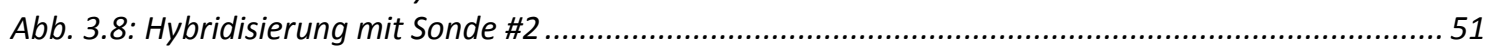

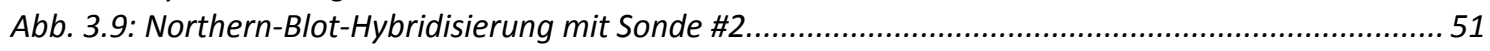

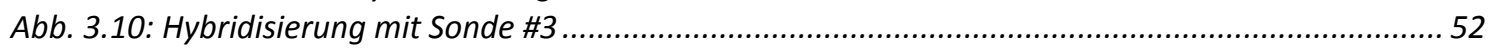

Abb. 3.11: Darstellung der Primerbindungsstellen für die RT- PCR ..................................................5 53

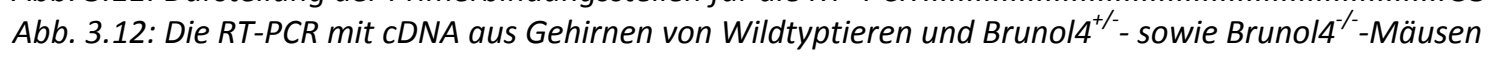

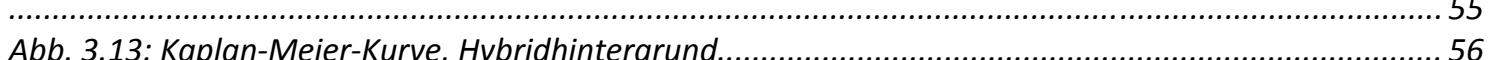

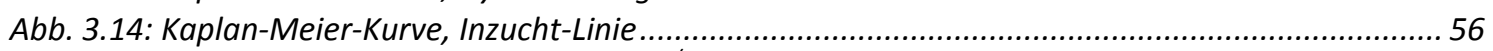

Abb. 3.15: Unterschiedliche Größe von Brunol4 ${ }^{-/}$-Mäusen und WT-Geschwistern....................................5 57

Abb. 3.16: Gewichte, Hybridhintergrund, Weibchen ......................................................................... 58

Abb. 3.17: Gewichte, Hybridhintergrund, Männchen .................................................................. 59

Abb. 3.18: Histologischer Vergleich der Hippocampus-Region von Wildtyp und Brunol4-defizienter Maus

Abb. 3.19: Histologischer Vergleich der Kleinhirnrinde und der Frontalhirnrinde von Wildtyp und Brunol4-

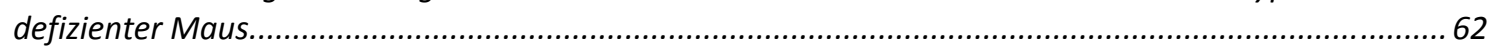
Abb. 3.20: Histologischer Vergleich der Großhirnrinde und der Pyramidenzellen von Wildtyp und Brunol4defizienter Maus............................................................................................................... 63 Abb. 3.21: Immunfluoreszenzfärbung von hippokampalen Neuronen von Wildtyp und Brunol4-defizienter

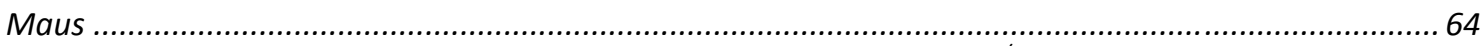
Abb. 3.22: Auftragung der Verteilung der Fortsatzlängen einer Brunol4 ${ }^{-1-}$-Maus und einer Wildtyp-

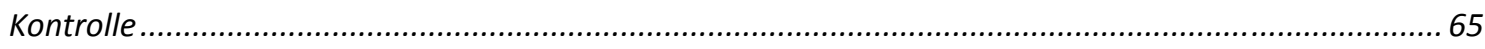

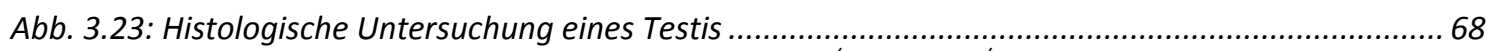
Abb. 3.24: Spermienköpfe einer 8,5 Monate alten Brunol $1^{+/-} /$Brunol4 ${ }^{+/-}$-Maus $(A)$ und einer gleichaltrigen

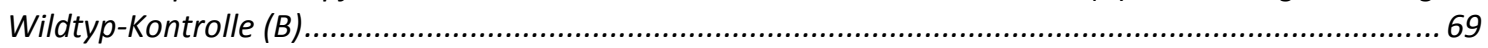

Abb. 3.25: Auswertung der Untersuchung zur Spermienmotilität ............................................................. 72

Abb. 4.1: Schematische Darstellung der Genstruktur der Mitglieder der Brunol-Familie ......................... 74

\subsection{Tabellenverzeichnis}

Tab. 1.1: Nomenklatur, Lokalisation und Homologien zwischen den Mitgliedern der Brunol/Celf-Familie bei Maus und Mensch ...................................................................................................................... 1

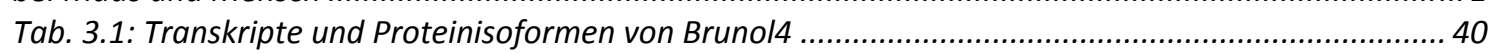
Tab. 3.2: Quantitative Verteilung von Wildtyp-, heterozygoten und homozygoten Mäusen in der F2Generation auf dem 129/Sv x C57BI/6J-Hybridhintergrund (2-3 d) 
Anhang

Tab. 3.3: Quantitative Verteilung von Wildtyp-, heterozygoten und homozygoten Mäusen in der F2Generation mit 129/Sv x C57BI/6J-Hybridhintergrund (drei Wochen) 47 Tab. 3.4: Quantitative Verteilung von Wildtyp-, heterozygoten und homozygoten Mäusen in der F2Generation mit 129/Sv-Inzuchthintergrund (2-3 d).

Tab. 3.5: Quantitative Verteilung von Wildtyp-, heterozygoten und homozygoten Mäusen in der F2Generation mit 129/Sv-Inzuchthintergrund (drei Wochen).

Tab. 3.6: Zuordnung der Nummern zu den jeweiligen Namen der Primer ............................................5 53

Tab. 3.7: Quantitative Verteilung verschiedener Genotypen von Mäusen der F2-Generation mit 129/Sv-

Inzuchthintergrund (2-3 d alt)....

Tab. 4.1: Merkmale der sechs Brunol-Mitglieder von Maus und Mensch. 


\title{
7. Literaturverzeichnis
}

\author{
Amato MA, Boy S, Arnault E, Girard M, Della Puppa A, Sharif A, Perron M (2005): \\ Comparison of the expression patterns of five neural RNA binding proteins in the Xenopus \\ retina. J Comp Neurol 481, 331-339
}

Antic D, Keene JD (1997): Embryonic lethal abnormal visual RNA-binding proteins involved in growth, differentiation, and posttranscriptional gene expression. Am J Hum Genet 61, 273278

Ashiya M, Grabowski PJ (1997): A neuron-specific splicing switch mediated by an array of pre-mRNA repressor sites: evidence of a regulatory role for the polypyrimidine tract binding protein and a brain-specific PTB counterpart. RNA $\underline{3}$, 996-1015

Ausubel FM, Brent R, Kingston RE, Moore DD, Seidman JG, Smith JA and Struhl K: Current protocols in molecular biology. John Wiley \& Sons Inc.,Malden/USA 1994

Baldwin BR, Timchenko NA, Zahnow CA (2004): Epidermal growth factor receptor stimulation activates the RNA binding protein CUG-BP1 and increases expression of C/EBPbeta-LIP in mammary epithelial cells. Mol Cell Biol 24, 3682-3691

Barreau C, Paillard L, Méreau A, Osborne HB (2006): Mammalian CELF/Bruno-like RNAbinding proteins: molecular characteristics and biological functions.

Biochimie $\underline{88}, 515-525$

Barron VA, Zhu H, Hinman MN, Ladd AN, Lou H (2010): The neurofibromatosis type I pre-mRNA is a novel target of CELF protein-mediated splicing regulation. Nucleic Acids Res $\underline{38}, 253-264$

Berg J, Jiang H, Thornton CA, Cannon SC (2004): Truncated ClC-1 mRNA in myotonic dystrophy exerts a dominant-negative effect on the $\mathrm{Cl}$ current. Neurology $\underline{63}, 2371-2375$

Brimacombe KR, Ladd AN (2007): Cloning and embryonic expression patterns of the chicken CELF family. Dev Dyn 236, 2216-2224

Bubenik JL, Driscoll DM (2007): Altered RNA binding activity underlies abnormal thyroid hormone metabolism linked to a mutation in selenocysteine insertion sequence-binding protein 2. J Biol Chem $\underline{282}$, 34653-34662

Bubenik JL, Ladd AN, Gerber CA, Budiman ME, Driscoll DM (2009): Known turnover and translation regulatory RNA-binding proteins interact with the 3' UTR of SECIS-binding protein 2. RNA Biol $\underline{6}, 73-83$

Buchner DA, Trudeau M, Meisler MH (2003): SCNM1, a putative RNA splicing factor that modifies disease severity in mice. Science 301, 967-969 
Bugiani O, Murrell JR, Giaccone G, Hasegawa M, Ghigo G, Tabaton M, Morbin M, Primavera A, Carella F, Solaro C et al (1999): Frontotemporal dementia and corticobasal degeneration in a family with a P301S mutation in tau. J Neuropathol Exp Neurol 58, 667-677

Burd CG, Dreyfuss G. (1994): Conserved structures and diversity of functions of RNAbinding proteins. Science 265, 615-621

Cepeda C, Ariano MA, Calvert CR, Flores-Hernández J, Chandler SH, Leavitt BR, Hayden MR, Levine MS (2001): NMDA receptor function in mouse models of Huntington disease. J Neurosci Res $\underline{66}$, 525-539

Chapple JP, Anthony K, Martin TR, Dev A, Cooper TA, Gallo JM (2007): Expression, localization and tau exon 10 splicing activity of the brain RNA-binding protein TNRC4. Hum Mol Genet 16, 2760-2769

Charlet-B N, Logan P, Singh G, Cooper TA (2002a): Dynamic antagonism between ETR-3 and PTB regulates cell type-specific alternative splicing. Mol Cell $\underline{9}, 649-658$

Charlet-B N, Savkur RS, Singh G, Philips AV, Grice EA, Cooper TA (2002b): Loss of the muscle-specific chloride channel in type 1 myotonic dystrophy due to misregulated alternative splicing. Mol Cell $\underline{10}, 45-53$

Chen SS, Chen JF, Johnson PF, Muppala V, Lee YH (2000): C/EBPbeta, when expressed from the C/ebpalpha gene locus, can functionally replace C/EBPalpha in liver but not in adipose tissue. Mol Cell Biol 20, 7292-7299

Chien A, Edgar DB, Trela JM (1976): Deoxyribonucleic acid polymerase from the extreme thermophile Thermus aquaticus. J Bacteriol 127, 1550-1557

Choi DK, Ito T, Mitsui Y, Sakaki Y (1998): Fluorescent differential display analysis of gene expression in apoptotic neuroblastoma cells. Gene $\underline{223}, 21-31$

Choi DK, Ito T, Tsukahara F, Hirai M, Sakaki Y (1999): Developmentally-regulated expression of mNapor encoding an apoptosis-induced ELAV-type RNA binding protein. Gene $\underline{237}, 135-142$

Clark JM (1988): Novel non-templated nucleotide addition reactions catalyzed by procaryotic and eucaryotic DNA polymerases. Nucleic Acid Res 16, 9677-9686

Cooper TA, Ordahl CP (1984): A single troponin T gene regulated by different programs in cardiac and skeletal muscle development. Science 226, 979-982

Cooper TA, Ordahl CP (1985): A single cardiac troponin T gene generates embryonic and adult isoforms via developmentally regulated alternate splicing. J Biol Chem $\underline{260}, 11140-11148$

Cooper TA, Wan L, Dreyfuss G (2009): RNA and disease. Cell $\underline{136}, 777-793$

Dansithong W, Paul S, Comai L, Reddy S (2005): MBNL1 is the primary determinant of focus formation and aberrant insulin receptor splicing in DM1. J Biol Chem $\underline{280}$, 5773-5780 
Daston MM, Scrable H, Nordlund M, Sturbaum AK, Nissen LM, Ratner N (1992): The protein product of the neurofibromatosis type 1 gene is expressed at highest abundance in neurons, Schwann cells, and oligodendrocytes. Neuron $\underline{8}, 415-428$

De Santa F, Albini S, Mezzaroma E, Baron L, Felsani A, Caruso M (2007): pRb-dependent cyclin D3 protein stabilization is required for myogenic differentiation. Mol Cell Biol 27, 7248-7265

Delaunay J, Le Mée G, Ezzeddine N, Labesse G, Terzian C, Capri M, Aït-Ahmed O (2004): The Drosophila Bruno paralogue Bru-3 specifically binds the EDEN translational repression element. Nucleic Acids Res 32, 3070-3082

Delisle MB, Murrell JR, Richardson R, Trofatter JA, Rascol O, Soulages X, Mohr M, Calvas P, Ghetti B (1999): A mutation at codon 279 (N279K) in exon 10 of the Tau gene causes a tauopathy with dementia and supranuclear palsy. Acta Neuropathol $\underline{98}, 62-77$

Denhardt DT (1966): A membrane-filter technique for the detection of complementary DNA. Biochem Biophys Res Commun 23, 641-646

Dev A: Expression and functional analysis of murine Brunoll und bruno 14, members of elavbruno family. Biol. Diss. Göttingen, 2006

Dev A, Nayernia K, Meins M, Adham I, Lacone F, Engel W (2007): Mice deficient for RNA-binding protein brunoll show reduction of spermatogenesis but are fertile. Mol Reprod Dev $\underline{74}, 1456-1464$

Ding YX, Zhang Y, He B, Yue WH, Zhang D, Zou LP (2010): A possible association of responsiveness to adrenocorticotropic hormone with specific GRIN1 haplotypes in infantile spasms. Dev Med Child Neurol, $\underline{52}$, 1028-1032

Faingold CL, Millan MH, Boersma Anderson CA, Meldrum BS (1989): Induction of audiogenic seizures in normal and genetically epilepsy-prone rats following focal microinjection of an excitant amino acid into reticular formation and auditory nuclei. Epilepsy Res $\underline{3}, 199-205$

Faustino NA, Cooper TA (2005): Identification of putative new splicing targets for ETR-3 using sequences identified by systematic evolution of ligands by exponential enrichment. Mol Cell Biol 25, 879-887

Feinberg AP and Vogelstein B (1989): A technique for radiolabeling DNA restriction endonuclease fragments to high specific activity. Anal Biochem $\underline{123}$, 6-13

Forrest D, Yuzaki M, Soares HD, Ng L, Luk DC, Sheng M, Stewart CL, Morgan JI, Connor JA, Curran T (1994): Targeted disruption of NMDA receptor 1 gene abolishes NMDA response and results in neonatal death. Neuron. 13, 325-338

\section{Gautier-Courteille C, Le Clainche C, Barreau C, Audic Y, Graindorge A, Maniey} D, Osborne HB, Paillard L (2004): EDEN-BP-dependent post-transcriptional regulation of gene expression in Xenopus somitic segmentation. Development 131, 6107-6117 
Goedert M, Spillantini MG, Jakes R, Rutherford D, Crowther RA (1989a): Multiple isoforms of human microtubule-associated protein tau: sequences and localization in neurofibrillary tangles of Alzheimer's disease. Neuron $\underline{3}, 519-526$

Goedert M, Spillantini MG, Potier MC, Ulrich J, Crowther RA (1989b): Cloning and sequencing of the cDNA encoding an isoform of microtubule-associated protein tau containing four tandem repeats: differential expression of tau protein mRNAs in human brain. EMBO J $\underline{8}, 393-399$

Good PJ, Chen Q, Warner SJ, Herring DC (2000): A family of human RNA-binding proteins related to the Drosophila Bruno translational regulator. J Biol Chem 275, 28583-28592

Graindorge A, Le Tonquèze $O$, Thuret R, Pollet N, Osborne HB, Audic Y (2008): Identification of CUG-BP1/EDEN-BP target mRNAs in Xenopus tropicalis. Nucleic Acids Res $\underline{36}, 1861-1870$

Gromak N, Matlin AJ, Cooper TA, Smith CW (2003): Antagonistic regulation of alpha-actinin alternative splicing by CELF proteins and polypyrimidine tract binding protein. RNA $\underline{9}, 443-456$

Guo Q, Kuang P (1993): Effect of qingyangshen on hippocampal alpha- and beta-tubulin gene expression during kainic acid induced epileptogenesis. J Tradit Chin Med 13, 281-286

Han J, Cooper TA (2005): Identification of CELF splicing activation and repression domains in vivo. Nucleic Acids Res $\underline{33}, 2769-2780$

Hanahan D (1983): Studies on transformation of Escherichia coli with plasmids. JMol Biol $\underline{166}, 557-580$

Higashiyama M, Taki T, Ieki Y, Adachi M, Huang CL, Koh T, Kodama K, Doi O, Miyake M (1995): Reduced motility related protein-1 (MRP-1/CD9) gene expression as a factor of poor prognosis in non-small cell lung cancer. Cancer Res 55, 6040-6044

Ho TH, Bundman D, Armstrong DL, Cooper TA (2005): Transgenic mice expressing CUGBP1 reproduce splicing mis-regulation observed in myotonic dystrophy. Hum Mol Genet $\underline{14}$, $1539-1547$

Hodge R (1994):Preparation of RNA gel blots. Methods Mol Biol $\underline{28}, 49-54$

Horb LD, Horb ME (2010): BrunoL1 regulates endoderm proliferation through translational enhancement of cyclin A2 mRNA. Dev Biol 345, 156-169

Hu G (1993): DNA polymerase-catalyzed addition of nontemplated extra nucleotides to the 3' end of a DNA fragment. DNA Cell Biol 12, 763-770

Hutton M, Lendon CL, Rizzu P, Baker M, Froelich S, Houlden H, Pickering-Brown S, Chakraverty S, Isaacs A, Grover A et al (1998): Association of missense and 5'-splice-site mutations in tau with the inherited dementia FTDP-17. Nature $\underline{393}$, 702-705 
Hwang DM, Hwang WS, Liew CC (1994): Single pass sequencing of a unidirectional human fetal heart cDNA library to discover novel genes of the cardiovascular system. J Mol Cell Cardiol 26, 1329-1333

Iakova P, Wang GL, Timchenko L, Michalak M, Pereira-Smith OM, Smith JR, Timchenko NA (2004): Competition of CUGBP1 and calreticulin for the regulation of p21 translation determines cell fate. EMBO J $\underline{23}, 406-417$

Ishii T, Moriyoshi K, Sugihara H, Sakurada K, Kadotani H, Yokoi M, Akazawa C, Shigemoto R, Mizuno N, Masu M, Nakanishi S (1993): Molecular characterization of the family of the N-methyl-D-aspartate receptor subunits. J Biol Chem 268, 2836-2843

Iwai A, Masliah E, Yoshimoto M, Ge N, Flanagan L, de Silva HA, Kittel A, Saitoh T (1995): The precursor protein of non-A beta component of Alzheimer's disease amyloid is a presynaptic protein of the central nervous system. Neuron $\underline{14}, 467-475$

Jarikji Z, Horb LD, Shariff F, Mandato CA, Cho KW, Horb ME (2009): The tetraspanin $\mathrm{Tm} 4 \mathrm{sf} 3$ is localized to the ventral pancreas and regulates fusion of the dorsal and ventral pancreatic buds. Development 136, 1791-1800

Johansson A, Carlström K, Ahrén B, Cederquist K, Krylborg E, Forsberg H, Olsson T (2000): Abnormal cytokine and adrenocortical hormone regulation in myotonic dystrophy. J Clin Endocrinol Metab 도, 3169-3176

Jones LC, Lin ML, Chen SS, Krug U, Hofmann WK, Lee S, Lee YH, Koeffler HP (2002): Expression of C/EBPbeta from the C/ebpalpha gene locus is sufficient for normal hematopoiesis in vivo. Blood $\underline{99}$, 2032-2036

Kalachikov S, Evgrafov O, Ross B, Winawer M, Barker-Cummings C, Martinelli Boneschi F, Choi C, Morozov P, Das K, Teplitskaya E et al (2002): Mutations in LGI1 cause autosomal-dominant partial epilepsy with auditory features. Nat Genet $\underline{30}, 335-341$

Kalsotra A, Xiao X, Ward AJ, Castle JC, Johnson JM, Burge CB, Cooper TA (2008): A postnatal switch of CELF and MBNL proteins reprograms alternative splicing in the developing heart. Proc Natl Acad Sci U S A $\underline{105}$, 20333-20338

Kempf M, Clement A, Faissner A, Lee G, Brandt R (1996): Tau binds to the distal axon early in development of polarity in a microtubule- and microfilament-dependent manner. J Neurosci $\underline{16}, 5583-5592$

Kent G, Iles R, Bear CE, Huan LJ, Griesenbach U, McKerlie C, Frndova H, Ackerley C, Gosselin D, Radzioch D et al (1997): Lung disease in mice with cystic fibrosis. J Clin Invest 100, 3060-3069

Kew JN, Koester A, Moreau JL, Jenck F, Ouagazzal AM, Mutel V, Richards JG, Trube G, Fischer G, Montkowski A et al (2000): Bluethmann H. Functional consequences of reduction in NMDA receptor glycine affinity in mice carrying targeted point mutations in the glycine binding site. J Neurosci 20, 4037-4049 
Kim-Ha J, Kerr K, Macdonald PM (1995):Translational regulation of oskar mRNA by bruno, an ovarian RNA-binding protein, is essential. Cell $\underline{81}, 403-412$

Kino Y, Washizu C, Oma Y, Onishi H, Nezu Y, Sasagawa N, Nukina N, Ishiura S (2009): MBNL and CELF proteins regulate alternative splicing of the skeletal muscle chloride channel CLCN1. Nucleic Acids Res $\underline{37}$, 6477-6490

Knecht AK, Harland RM (1997): Mechanisms of dorsal-ventral patterning in noggin-induced neural tissue. Development $\underline{124}$, 2477-2488

Knecht AK, Good PJ, Dawid IB, Harland RM (1995): Dorsal-ventral patterning and differentiation of noggin-induced neural tissue in the absence of mesoderm. Development 121 , 1927-1935

Koshelev M, Sarma S, Price RE, Wehrens XH, Cooper TA (2010): Heart-specific overexpression of CUGBP1 reproduces functional and molecular abnormalities of myotonic dystrophy type 1 . Hum Mol Genet $\underline{19}$, 1066-1075

Kremerskothen J, Teber I, Wendholt D, Liedtke T, Böckers TM, Barnekow A (2002): Brain-specific splicing of alpha-actinin 1 (ACTN1) mRNA. Biochem Biophys Res Commun $\underline{295}, 678-681$

Kress C, Gautier-Courteille C, Osborne HB, Babinet C, Paillard L (2007): Inactivation of CUG-BP1/CELF1 causes growth, viability, and spermatogenesis defects in mice. Mol Cell Biol $\underline{27}, 1146-1157$

Kutsuwada T, Kashiwabuchi N, Mori H, Sakimura K, Kushiya E, Araki K, Meguro H, Masaki H, Kumanishi T, Arakawa M et al (1992): Molecular diversity of the NMDA receptor channel. Nature $\underline{358}, 36-41$

Kuyumcu-Martinez NM, Wang GS, Cooper TA (2007): Increased steady-state levels of CUGBP1 in myotonic dystrophy 1 are due to PKC-mediated hyperphosphorylation. Mol Cell $\underline{28}, 68-78$

Ladd AN, Charlet N, Cooper TA (2001): The CELF family of RNA binding proteins is implicated in cell-specific and developmentally regulated alternative splicing. Mol Cell Biol $\underline{21}, 1285-1296$

Ladd AN, Nguyen NH, Malhotra K, Cooper TA (2004): CELF6, a member of the CELF family of RNA-binding proteins, regulates muscle-specific splicing enhancer-dependent alternative splicing. J Biol Chem $\underline{279}$, 17756-17764

Ladd AN, Stenberg MG, Swanson MS, Cooper TA (2005a): Dynamic balance between activation and repression regulates pre-mRNA alternative splicing during heart development. Dev Dyn 233, 783-793

Ladd AN, Taffet G, Hartley C, Kearney DL, Cooper TA (2005b): Cardiac tissue-specific repression of CELF activity disrupts alternative splicing and causes cardiomyopathy. Mol Cell Biol 25, 6267-6278 
Laird PW, Zijderveld A, Linders K, Rudnicki MA, Jaenisch R and Berns A (1991):

Simplified mammalian DNA isolation procedure. Nucleic Acids Res $\underline{19}, 4293$

Lee-Rivera I, Zarain-Herzberg A, López-Colomé AM (2003): Developmental expression of $\mathrm{N}$-methyl-D-aspartate glutamate receptor 1 splice variants in the chick retina. J Neurosci Res $\underline{73}, 369-383$

Le Tonquèze O, Gschloessl B, Namanda-Vanderbeken A, Legagneux V, Paillard L, Audic Y (2010): Chromosome wide analysis of CUGBP1 binding sites identifies the tetraspanin CD9 mRNA as a target for CUGBP1-mediated down-regulation. Biochem Biophys Res Commun $\underline{394}, 884-889$

Leroy O, Dhaenens CM, Schraen-Maschke S, Belarbi K, Delacourte A, Andreadis A, Sablonnière B, Buée L, Sergeant N, Caillet-Boudin ML (2006a): ETR-3 represses Tau exons $2 / 3$ inclusion, a splicing event abnormally enhanced in myotonic dystrophy type I. J Neurosci Res $\underline{84}, 852-859$

Leroy O, Wang J, Maurage CA, Parent M, Cooper T, Buée L, Sergeant N, Andreadis A, Caillet-Boudin ML (2006b): Brain-specific change in alternative splicing of Tau exon 6 in myotonic dystrophy type 1. Biochim Biophys Acta 1762, 460-467

Levers TE, Tait S, Birling MC, Brophy PJ, Price DJ (2002): Etr-r3/mNapor, encoding an ELAV-type RNA binding protein, is expressed in differentiating cells in the developing rodent forebrain. Mech Dev 112, 191-193

Li D, Bachinski LL, Roberts R (2001): Genomic organization and isoform-specific tissue expression of human NAPOR (CUGBP2) as a candidate gene for familial arrhythmogenic right ventricular dysplasia. Genomics $\underline{74}, 396-401$

Li Y, Erzurumlu RS, Chen C, Jhaveri S, Tonegawa S (1994): Whisker-related neuronal patterns fail to develop in the trigeminal brainstem nuclei of NMDAR1 knockout mice. Cell $\underline{76}$, $427-437$

Lichtner P, Attié-Bitach T, Schuffenhauer S, Henwood J, Bouvagnet P, Scambler PJ, Meitinger T, Vekemans M (2002): Expression and mutation analysis of BRUNOL3, a candidate gene for heart and thymus developmental defects associated with partial monosomy 10p. J Mol Med $\underline{80}, 431-442$

Lin X, Miller JW, Mankodi A, Kanadia RN, Yuan Y, Moxley RT, Swanson MS, Thornton CA (2006): Failure of MBNL1-dependent post-natal splicing transitions in myotonic dystrophy. Hum Mol Genet $\underline{15}$, 2087-2097

Mankodi A, Logigian E, Callahan L, McClain C, White R, Henderson D, Krym M, Thornton CA (2000): Myotonic dystrophy in transgenic mice expressing an expanded CUG repeat. Science $\underline{289}, 1769-1773$

Mankodi A, Takahashi MP, Jiang H, Beck CL, Bowers WJ, Moxley RT, Cannon SC, Thornton CA (2002): Expanded CUG repeats trigger aberrant splicing of ClC-1 chloride channel pre-mRNA and hyperexcitability of skeletal muscle in myotonic dystrophy. Mol Cell $\underline{10}, 35-44$ 
Mantani A, Wakasugi S, Yokota Y, Abe K, Ushio Y, Yamamura K (1994): A novel isoform of the neurofibromatosis type-1 mRNA and a switch of isoforms during murine cell differentiation and proliferation. Gene $\underline{148}, 245-251$

Marquis J, Paillard L, Audic Y, Cosson B, Danos O, Le Bec C, Osborne HB (2006): CUGBP1/CELF1 requires UGU-rich sequences for high-affinity binding. Biochem J $\underline{400}, 291-301$

Meins M, Schlickum S, Wilhelm C, Missbach J, Yadav S, Gläser B, Grzmil M, Burfeind P, Laccone F (2002): Identification and characterization of murine Brunol4, a new member of the elav/bruno family. Cytogenet Genome Res 97, 254-260

Milne CA, Hodgkin J (1999): ETR-1, a homologue of a protein linked to myotonic dystrophy, is essential for muscle development in Caenorhabditis elegans. Curr Biol 9, 12431246

Miyake M, Nakano K, Ieki Y, Adachi M, Huang CL, Itoi S, Koh T, Taki T (1995): Motility related protein 1 (MRP-1/CD9) expression: inverse correlation with metastases in breast cancer. Cancer Res $\underline{55}, 4127-4131$

Moghadaszadeh B, Petit N, Jaillard C, Brockington M, Roy SQ, Merlini L, Romero N, Estournet B, Desguerre I, Chaigne D et al (2001): Mutations in SEPN1 cause congenital muscular dystrophy with spinal rigidity and restrictive respiratory syndrome. Nat Genet $\underline{29}, 17-$ 18

Mohn AR, Gainetdinov RR, Caron MG, Koller BH (1999): Mice with reduced NMDA receptor expression display behaviors related to schizophrenia. Cell $\underline{98}, 427-436$

Moore T, Hecquet S, McLellann A, Ville D, Grid D, Picard F, Moulard B, Asherson P, Makoff AJ, McCormick D et al (2001): Polymorphism analysis of JRK/JH8, the human homologue of mouse jerky, and description of a rare mutation in a case of CAE evolving to JME. Epilepsy Res $\underline{46}, 157-167$

Moraes KC, Wilusz CJ, Wilusz J (2006): CUG-BP binds to RNA substrates and recruits PARN deadenylase. RNA 12, 1084-1091

Mukhopadhyay D, Houchen CW, Kennedy S, Dieckgraefe BK, Anant S (2003a): Coupled mRNA stabilization and translational silencing of cyclooxygenase-2 by a novel RNA binding protein, CUGBP2. Mol Cell 11, 113-126

Mukhopadhyay D, Jung J, Murmu N, Houchen CW, Dieckgraefe BK, Anant S (2003b): CUGBP2 plays a critical role in apoptosis of breast cancer cells in response to genotoxic injury. Ann N Y Acad Sci 1010, 504-509

Murmu N, Jung J, Mukhopadhyay D, Houchen CW, Riehl TE, Stenson WF, Morrison AR, Arumugam T, Dieckgraefe BK, Anant S (2004): Dynamic antagonism between RNAbinding protein CUGBP2 and cyclooxygenase-2-mediated prostaglandin E2 in radiation damage. Proc Natl Acad Sci U S A 101, 13873-13878

Nagy A, Rossant J, Nagy R, Abramow-Newerly W, Roder JC (1993): Derivation of 
completely cell culture-derived mice from early-passage embryonic stem cells. Proc Natl Acad Sci U S A $\underline{90}, 8424-8428$

Natarajan G, Ramalingam S, Ramachandran I, May R, Queimado L, Houchen CW, Anant S (2008): CUGBP2 downregulation by prostaglandin E2 protects colon cancer cells from radiation-induced mitotic catastrophe. Am J Physiol Gastrointest Liver Physiol 294, G1235-1244

Nishi T, Lee PS, Oka K, Levin VA, Tanase S, Morino Y, Saya H (1991): Differential expression of two types of the neurofibromatosis type 1 (NF1) gene transcripts related to neuronal differentiation. Oncogene $\underline{6}, 1555-1559$

Paillard L, Omilli F, Legagneux V, Bassez T, Maniey D, Osborne HB (1998): EDEN and EDEN-BP, a cis element and an associated factor that mediate sequence-specific mRNA deadenylation in Xenopus embryos. EMBO J $\underline{17}, 278-287$

Paillard L, Legagneux V, Beverley Osborne H (2003): A functional deadenylation assay

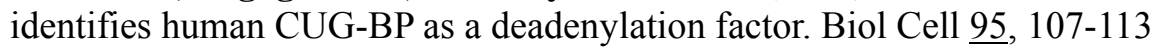

Pastor P, Pastor E, Carnero C, Vela R, García T, Amer G, Tolosa E, Oliva R (2001): Familial atypical progressive supranuclear palsy associated with homozigosity for the delN296 mutation in the tau gene. Ann Neurol $\underline{49}, 263-267$

Patton JG, Mayer SA, Tempst P, Nadal-Ginard B (1991): Characterization and molecular cloning of polypyrimidine tract-binding protein: a component of a complex necessary for pre-mRNA splicing. Genes Dev $\underline{5}, 1237-1251$

Paul S, Dansithong W, Kim D, Rossi J, Webster NJ, Comai L, Reddy S (2006): Interaction of muscleblind, CUG-BP1 and hnRNP H proteins in DM1-associated aberrant IR splicing. EMBO J 25, 4271-4283

Philips AV, Timchenko LT, Cooper TA (1998): Disruption of splicing regulated by a CUGbinding protein in myotonic dystrophy. Science 280, 737-741

Poorkaj P, Bird TD, Wijsman E, Nemens E, Garruto RM, Anderson L, Andreadis A, Wiederholt WC, Raskind M, Schellenberg GD (1998): Tau is a candidate gene for chromosome 17 frontotemporal dementia. Ann Neurol 43, 815-825

Poorkaj P, Muma NA, Zhukareva V, Cochran EJ, Shannon KM, Hurtig H, Koller WC, Bird TD, Trojanowski JQ, Lee VM et al (2002): An R5L tau mutation in a subject with a progressive supranuclear palsy phenotype. Ann Neurol $\underline{52}, 511-516$

Poulogiannis G, Ichimura K, Hamoudi RA, Luo F, Leung SY, Yuen ST, Harrison DJ, Wyllie AH, Arends MJ (2010): Prognostic relevance of DNA copy number changes in colorectal cancer. J Pathol 220, 338-347

Ramalingam S, Natarajan G, Schafer C, Subramaniam D, May R, Ramachandran I, Queimado L, Houchen CW, Anant S (2008): Novel intestinal splice variants of RNA-binding protein CUGBP2: isoform-specific effects on mitotic catastrophe. Am J Physiol Gastrointest 
Liver Physiol 294, G971-981

Rask K, Thörn M, Pontén F, Kraaz W, Sundfeldt K, Hedin L, Enerbäck S (2000): Increased expression of the transcription factors CCAAT-enhancer binding protein- beta (C/EBBeta) and C/EBzeta (CHOP) correlate with invasiveness of human colorectal cancer. Int J Cancer $\underline{86}, 337-343$

Riccardi VM (1987): Neurofibromatosis. Neurol Clin $\underline{5}$, 337-349

Roberts R, Timchenko NA, Miller JW, Reddy S, Caskey CT, Swanson MS, Timchenko LT (1997): Altered phosphorylation and intracellular distribution of a (CUG)n triplet repeat RNAbinding protein in patients with myotonic dystrophy and in myotonin protein kinase knockout mice. Proc Natl Acad Sci U S A 94, 13221-13226

Rosahl TW, Spillane D, Missler M, Herz J, Selig DK, Wolff JR, Hammer RE, Malenka RC, Südhof TC (1995): Essential functions of synapsins I and II in synaptic vesicle regulation. Nature $\underline{375}, 488-493$

Saiki RK, Gelfand DH, Stoffel S, Scharf SJ, Higuchi R, Horn GT, Mullis KB and Erlich HA (1988): Primer directed enzymatic amplification of DNA with a thermostable DNA polymerase. Science $\underline{239}, 487-491$

Saitsu H, Kato M, Mizuguchi T, Hamada K, Osaka H, Tohyama J, Uruno K, Kumada S, Nishiyama K, Nishimura A et al (2008): De novo mutations in the gene encoding STXBP1 (MUNC18-1) cause early infantile epileptic encephalopathy. Nat Genet $\underline{40}, 782-788$

Salisbury E, Sakai K, Schoser B, Huichalaf C, Schneider-Gold C, Nguyen H, Wang GL, Albrecht JH, Timchenko LT (2008): Ectopic expression of cyclin D3 corrects differentiation of DM1 myoblasts through activation of RNA CUG-binding protein, CUGBP1. Exp Cell Res $\underline{314}, 2266-2278$

Sambrook J, Fritsch EF and Maniatis T: Molecular cloning: a laboratory manual (2nd edition). Cold Spring Harbor, New York, USA 1989

Sanger F, Nicklen S and Coulson AR (1977): DNA sequencing with the chain terminating inhibitors. Proc Natl Acad Sci U S A $\underline{74}$, 5463-5467

Savkur RS, Philips AV, Cooper TA (2001): Aberrant regulation of insulin receptor alternative splicing is associated with insulin resistance in myotonic dystrophy. Nat Genet $\underline{29}, 40-47$

Schiavo G, Gmachl MJ, Stenbeck G, Söllner TH, Rothman JE (1995): A possible docking and fusion particle for synaptic transmission. Nature $\underline{378}, 733-736$

Sen S, Talukdar I, Webster NJ (2009): SRp20 and CUG-BP1 modulate insulin receptor exon 11 alternative splicing. Mol Cell Biol 29, 871-880

Sergeant N, Sablonnière B, Schraen-Maschke S, Ghestem A, Maurage CA, Wattez A, Vermersch P, Delacourte A (2001): Dysregulation of human brain microtubule-associated tau mRNA maturation in myotonic dystrophy type 1 . Hum Mol Genet $\underline{10}$, 2143-2155 
Shi S, Hayashi Y, Esteban JA, Malinow R (2001): Subunit-specific rules governing AMPA receptor trafficking to synapses in hippocampal pyramidal neurons. Cell $\underline{105}, 331-343$

Singh G, Charlet-B N, Han J, Cooper TA (2004): ETR-3 and CELF4 protein domains required for RNA binding and splicing activity in vivo. Nucleic Acids Res 32, 1232-1241

Siomi H, Dreyfuss G (1997): RNA-binding proteins as regulators of gene expression. Curr Opin Genet Dev $\underline{7}, 345-353$

Southby J, Gooding C, Smith CW (1999): Polypyrimidine tract binding protein functions as a repressor to regulate alternative splicing of alpha-actinin mutally exclusive exons. Mol Cell Biol 19, 2699-2711

Southern EM (1975): Detection of specific sequences among DNA fragments separated by gel electrophoresis. J Mol Biol $\underline{98}, 503-517$

Spillantini MG, Murrell JR, Goedert M, Farlow MR, Klug A, Ghetti B (1998): Mutation in the tau gene in familial multiple system tauopathy with presenile dementia. Proc Natl Acad Sci U S A $\underline{95}, 7737-7741$

Squires JE, Stoytchev I, Forry EP, Berry MJ (2007): SBP2 binding affinity is a major determinant in differential selenoprotein mRNA translation and sensitivity to nonsense-mediated decay. Mol Cell Biol 27, 7848-7855

Stanford PM, Halliday GM, Brooks WS, Kwok JB, Storey CE, Creasey H, Morris JG, Fulham MJ, Schofield PR (2000): Progressive supranuclear palsy pathology caused by a novel silent mutation in exon 10 of the tau gene: expansion of the disease phenotype caused by tau gene mutations. Brain $\underline{123}, 880-893$

Stein KK, Nesmith JE, Ross BD, Golden A (2010): Functional Redundancy of Paralogs of an APC/C Subunit in Caenorhabditis elegans Meiosis. Genetics 186, 1285-1289

Subramaniam D, Natarajan G, Ramalingam S, Ramachandran I, May R, Queimado L,Houchen CW, Anant S (2008): Translation inhibition during cell cycle arrest and apoptosis: Mcl-1 is a novel target for RNA binding protein CUGBP2. Am J Physiol Gastrointest Liver Physiol 294, G1025-1032

Sundfeldt K, Ivarsson K, Carlsson M, Enerbäck S, Janson PO, Brännström M, Hedin L (1999): The expression of CCAAT/enhancer binding protein (C/EBP) in the human ovary in vivo: specific increase in C/EBPbeta during epithelial tumour progression. Br J Cancer $\underline{79}, 1240-1248$

Sureau A, Saulière J, Expert-Bezançon A, Marie J (2010): CELF and PTB proteins modulate the inclusion of the $\beta$-tropomyosin exon $6 \mathrm{~B}$ during myogenic differentiation. Exp Cell Res $\underline{317}$, 94-106

Sureban SM, Murmu N, Rodriguez P, May R, Maheshwari R, Dieckgraefe BK, Houchen CW, Anant S (2007): Functional antagonism between RNA binding proteins HuR and CUGBP2 determines the fate of COX-2 mRNA translation. Gastroenterology $\underline{132}, 1055-1065$ 
Suzuki T, Delgado-Escueta AV, Aguan K, Alonso ME, Shi J, Hara Y, Nishida M, Numata T, Medina MT, Takeuchi T et al (2004): Mutations in EFHC1 cause juvenile myoclonic epilepsy. Nat Genet $\underline{36}, 842-849$

Takahashi N, Sasagawa N, Suzuki K, Ishiura S (2000): The CUG-binding protein binds specifically to UG dinucleotide repeats in a yeast three-hybrid system. Biochem Biophys Res Commun 277, 518-523

Tecott LH, Sun LM, Akana SF, Strack AM, Lowenstein DH, Dallman MF, Julius D (1995): Eating disorder and epilepsy in mice lacking 5-HT2c serotonin receptors. Nature $\underline{374}$, $542-546$

Terenzi F, Brimacombe KR, Penn MS, Ladd AN (2009): CELF-mediated alternative splicing is required for cardiac function during early, but not later, postnatal life. J Mol Cell Cardiol 46, $395-404$

Timchenko LT, Timchenko NA, Caskey CT, Roberts R (1996): Novel proteins with binding specificity for DNA CTG repeats and RNA CUG repeats: implications for myotonic dystrophy. Hum Mol Genet $\underline{5}, 115-121$

Timchenko NA, Welm AL, Lu X, Timchenko LT (1999): CUG repeat binding protein (CUGBP1) interacts with the 5 'region of C/EBPbeta mRNA and regulates translation of C/EBPbeta isoforms. Nucleic Acids Res 27, 4517-4525

Timchenko NA, Cai ZJ, Welm AL, Reddy S, Ashizawa T, Timchenko LT (2001a): RNA CUG repeats sequester CUGBP1 and alter protein levels and activity of CUGBP1. J Biol Chem $\underline{276}, 7820-7826$

Timchenko NA, Iakova P, Cai ZJ, Smith JR, Timchenko LT (2001b): Molecular basis for impaired muscle differentiation in myotonic dystrophy. Mol Cell Biol 21, 6927-3698

Timchenko NA, Patel R, Iakova P, Cai ZJ, Quan L, Timchenko LT (2004): Overexpression of CUG triplet repeat-binding protein, CUGBP1, in mice inhibits myogenesis. J Biol Chem $\underline{279}, 13129-13139$

Timchenko NA, Wang GL, Timchenko LT (2005): RNA CUG-binding protein 1 increases translation of $20-\mathrm{kDa}$ isoform of CCAAT/enhancer-binding protein beta by interacting with the alpha and beta subunits of eukaryotic initiation translation factor 2. J Biol Chem $\underline{280}, 20549-20557$

Toth M, Grimsby J, Buzsaki G, Donovan GP (1995): Epileptic seizures caused by inactivation of a novel gene, jerky, related to centromere binding protein-B in transgenic mice. Nat Genet $\underline{11}, 71-75$

Valcárcel J, Gebauer F (1997): Post-transcriptional regulation: the dawn of PTB. Curr Biol $\underline{7}$, R705-708 
Vlasova IA, Bohjanen PR (2008): Posttranscriptional regulation of gene networks by GU-rich elements and CELF proteins. RNA Biol $\underline{5}$, 201-207

Wallace MR, Marchuk DA, Andersen LB, Letcher R, Odeh HM, Saulino AM, Fountain JW, Brereton A, Nicholson J, Mitchell AL, et al. (1990): Type 1 neurofibromatosis gene: identification of a large transcript disrupted in three NF1 patients. Science 249, 181-186

Wang GS, Kearney DL, De Biasi M, Taffet G, Cooper TA (2007): Elevation of RNAbinding protein CUGBP1 is an early event in an inducible heart-specific mouse model of myotonic dystrophy. J Clin Invest 117, 2802-2811

Wang J, Gao QS, Wang Y, Lafyatis R, Stamm S, Andreadis A (2004): Tau exon 10, whose missplicing causes frontotemporaldementia, is regulated by an intricate interplay of cis elements and trans factors. J Neurochem $\underline{88}, 1078-1090$

Wang J, Tse SW, Andreadis A (2007): Tau exon 6 is regulated by an intricate interplay of trans factors and cis elements, including multiple branch points. J Neurochem $\underline{100}$, 437-445

Wei ML, Memmott J, Screaton G, Andreadis A (2000): The splicing determinants of a regulated exon in the axonal MAP tau reside within the exon and in its upstream intron. Brain Res Mol Brain Res $\underline{80}$, 207-218

Wollerton MC, Gooding C, Wagner EJ, Garcia-Blanco MA, Smith CW (2004): Autoregulation of polypyrimidine tract binding protein by alternative splicing leading to nonsense-mediated decay. Mol Cell $\underline{13}, 91-100$

Wu J, Li C, Zhao S, Mao B (2010): Differential expression of the Brunol/CELF family genes during Xenopus laevis early development. Int J Dev Biol 54, 209-214

Xu GF, O'Connell P, Viskochil D, Cawthon R, Robertson M, Culver M, Dunn D, Stevens J, Gesteland R, White R, et al. (1990): The neurofibromatosis type 1 gene encodes a protein related to GAP. Cell $\underline{62}, 599-608$

Yang Y, Mahaffey CL, Bérubé N, Maddatu TP, Cox GA, Frankel WN (2007): Complex seizure disorder caused by Brunol4 deficiency in mice. PLoS Genet $\underline{3}$, e124

Zahnow CA, Younes P, Laucirica R, Rosen JM (1997): Overexpression of C/EBPbeta-LIP, a naturally occurring, dominant-negative transcription factor, in human breast cancer. J Natl Cancer Inst $\underline{89}, 1887-1891$

Zhang L, Liu W, Grabowski PJ (1999): Coordinate repression of a trio of neuron-specific splicing events by the splicing regulator PTB. RNA $\underline{5}, 117-130$

Zhang W, Liu H, Han K, Grabowski PJ (2002): Region-specific alternative splicing in the nervous system: implications for regulation by the RNA-binding protein NAPOR. RNA $\underline{8}, 671-$ 685 


\section{Danksagung}

Mein herzlicher Dank gilt Herrn Prof. Dr. med. Dr. h.c. Engel für die Überlassung dieses Themas und die exzellente Begleitung meiner Arbeit durch die Bereitschaft, jederzeit für wissenschaftliche Unterstützung durch vielfältige Anregungen und Diskussionen zur Verfügung zu stehen. Des Weiteren danke ich für das stets gründliche Korrekturlesen meines Manuskripts.

Ich danke meiner Betreuerin Dr. Katayoon Shirneshan für die hervorragende und stets geduldige fachliche Unterstützung sowie für die Aufmunterungen in schwierigen Abschnitten dieser Arbeit. Besonders hilfreich waren die ständige Ansprechbarkeit bei Problemen, sowie die gute und freundschaftliche Atmosphäre, die wesentlich zum Gelingen meiner Arbeit beigetragen hat.

Des Weiteren danke ich Prof. Dr. Adham für die exzellente Unterstützung und die vielen hilfreichen Ideen und Anregungen, sowie für das gründliche Korrekturlesen meines Manusktripts.

Prof. Dr. A. Meinhardt danke ich herzlich für die histologische Untersuchung der Testes und seine Hilfestellung bei der Beurteilung.

Mein weiterer Dank gilt PD. Dr. Rickmann, Dr. Pawel Grzmil, Dr. Krishna Pantakani, Dr. Nadja Drusenheimer, Sandra Lührig und Janine Ulrich für ihre Erklärungen und technische Unterstützung.

Einen großen Dank möchte ich ebenfalls den Mitarbeiter/innen aus dem Tierstall aussprechen. Insbesondere danke ich Axel für seine Geduld und all seine Hilfe mit den Mäusen.

Für das zusätzliche Korrekturlesen meiner Arbeit danke ich zudem Laura und Diana.

Schließlich möchte ich allen Mitarbeiter/innen des Instituts für die wunderbare und kollegiale Atmosphäre danken, die das Arbeiten sehr angenehm gemacht und wesentlich erleichtert hat. 